
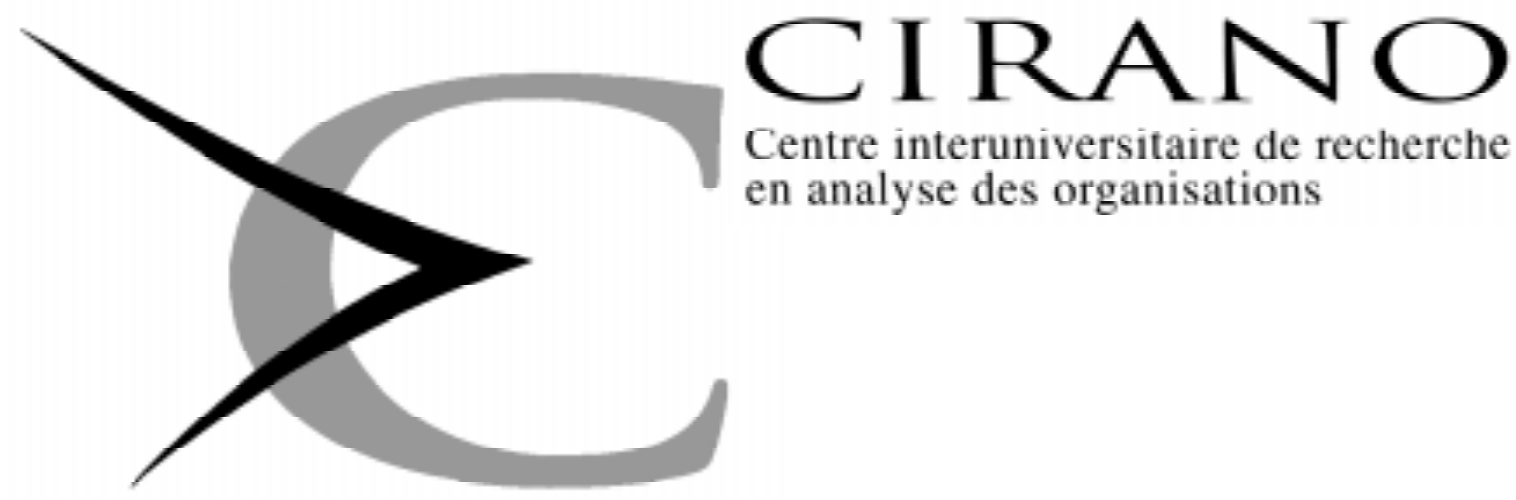

Centre interuniversitaire de recherche en analyse des organisations

Série Scientifique

Scientific Series

$95 s-47$

\title{
Asset and Commodity Prices with Multiattribute Durable Goods
}

Jérôme B. Detemple, Christos I. Giannikos

Montréal

novembre 1995 


\section{CIRANO}

Le CIRANO est une corporation privée à but non lucratif constituée en vertu de la Loi des compagnies du Québec. Le financement de son infrastructure et de ses activités de recherche provient des cotisations de ses organisations-membres, d'une subvention d'infrastructure du ministère de l'Industrie, du Commerce, de la Science et de la Technologie, de même que des subventions et mandats obtenus par ses équipes de recherche. La Série Scientifique est la réalisation d'une des missions que s'est données le CIRANO, soit de développer l'analyse scientifique des organisations et des comportements stratégiques.

CIRANO is a private non-profit organization incorporated under the Québec Companies Act. Its infrastructure and research activities are funded through fees paid by member organizations, an infrastructure grant from the Ministère de l'Industrie, du Commerce, de la Science et de la Technologie, and grants and research mandates obtained by its research teams. The Scientific Series fulfils one of the missions of CIRANO: to develop the scientific analysis of organizations and strategic behaviour.

\section{Les organisations-partenaires / The Partner Organizations}

-Ministère de l'Industrie, du Commerce, de la Science et de la Technologie.

-École des Hautes Études Commerciales.

-École Polytechnique.

-Université de Montréal.

-Université Laval.

-McGill University.

-Université du Québec à Montréal.

-Bell Québec.

-La Caisse de dépôt et de placement du Québec.

-Hydro-Québec.

-Fédération des caisses populaires de Montréal et de l'Ouest-du-Québec.

-Téléglobe Canada.

-Société d'électrolyse et de chimie Alcan Ltée.

-Avenor.

-Service de développement économique de la ville de Montréal.

-Raymond, Chabot, Martin, Paré

Ce document est publié dans l'intention de rendre accessibles les résultats préliminaires de la recherche effectuée au CIRANO, afin de susciter des échanges et des suggestions. Les idées et les opinions émises sont sous l'unique responsabilité des auteurs, et ne représentent pas nécessairement les positions du CIRANO ou de ses partenaires.

This paper presents preliminary research carried out at CIRANO and aims to encourage discussion and comment. The observations and viewpoints expressed are the sole responsibility of the authors. They do not necessarily represent positions of CIRANO or its partners.

\section{ISSN 1198-8177}




\title{
Asset and Commodity Prices with Multiattribute Durable Goods*
}

\author{
Jérôme B. Detemple ${ }^{\dagger}$ Christos I. Giannikos
}

Résumé / Abstract

\begin{abstract}
Nous considérons une économie de pur échange à agent représentatif avec biens périssables et durables dans laquelle le bien durable procure du statut ainsi que des services. Nous examinons les effets de ces deux attributs du bien durable sur les demandes et les prix d'équilibre. Lorsque les attributs sont des substituts parfaits l'irréversibilité des achats du durable peut créer des excès temporaires de services courants par rapport à leur niveau désiré. L'inflexibilité de l'ajustement est asymmétrique puisqu'une augmentation du niveau de statut désiré est réalisée par des achats immédiats. Nous démontrons que le taux d'intérêt d'équilibre dépend, en particulier, des taux de croissance des attributs du bien durable et que les primes de risque vérifient un MÉDAF de consommation à deux bétas. Nous examinons les conditions sous lesquelles la durabilité augmente les primes de risque des actifs financiers.
\end{abstract}

We consider a pure exchange representative agent economy with perishable and durable commodities in which the durable good provides status as well as services. We examine the effects of the durable's attributes on demands and equilibrium prices. When the attributes are perfect substitutes irreversibility of the durable's purchases may cause temporary excesses of actual services over their desired level. Stickiness in adjustment is asymmetric since increases in desired status level are met by immediate purchases. We show that the equilibrium interest rate depends, in particular, on the growth rates of the durable's attributes and that asset risk premia satisfy a two-beta consumption CAPM. Conditions under which durability increases asset risk premia are provided.

Mots Clefs: Biens durables, statut, services, prix des actifs et des biens, taux d'intérêt.

Keywords: Durables, status attribute, services, asset and commodity prices, interest rate.

JEL Classification: C60, D52, D91, G12.

\footnotetext{
${ }^{\star}$ Part of this work was completed while the first author was visiting the Sloan School of Management, MIT,Cambridge. We have benefitted from the comments of John Donaldson, Bernard Dumas, Suresh Sundaresan and seminar participants at Baruch College, ESSEC and Stony Brook. Corresponding author : Jérôme B. Detemple, Faculty of Management, McGill University, 1001 Sherbrook Street West, Montréal, PQ, Canada, H3A 1G5. Tel.: (514) 398-4059, Fax: (514) 398-3876,email: Detemple@Management.McGill.CA.

${ }^{\dagger}$ McGill University \& CIRANO

${ }^{\ddagger}$ Baruch College, CUNY
} 


\section{Introduction.}

In this paper we consider an economy with perishable and durable commodities in which the durable commodity functions as a symbol of status in addition to providing services. We analyze the effects of these two attributes of durable goods on the demand functions and equilibrium prices in a pure exchange representative agent economy. When the attributes of durables are perfect substitutes irreversibility of durable purchases may cause temporary excesses of actual services over their desired level. Stickiness in adjustment is asymmetric since increases in desired status level are met by instantaneous purchases. The possibility of future excesses affects both the current demands for durables and perishables. Closed form solutions for the price of the durable commodity, the interest rate and asset risk premia are derived. In equilibrium the interest rate depends on the moments of the rate of growth in the consumption of the perishable good as well as on the rates of growth in the attributes (status and services) of durables; asset risk premia satisfy a two-beta consumption CAPM. We provide conditions under which the multiattribute nature of durable goods simultaneously increases asset risk premia and lowers the interest rate.

In the traditional intertemporal asset pricing model commodities provide immediate gratification through consumption. Indeed, in the standard setting, the instantaneous utility function depends on contemporaneous consumption rates only. It is clear though that this choice of structure fails to capture the diversity of functions played by a large fraction of commodities in modern economies. A wide array of commodities manufactured and sold in markets, indeed, fulfil multiple needs. Durable goods, such as automobiles, furniture or clothing typically play two roles. On the one hand, they provide services and therefore utility over extended periods of time, i.e. they have a usage function. On the other hand they also play an important role of "status" creation, i.e. they have a symbolic function. This symbolic function is revealed in feelings of proudness, worthiness or status which are often associated with ownership of durable goods. It is perhaps the dominant function of items such as luxury cars, fashionable clothes or jewelry. 
The role of status creation has been amply documented in sociological studies (Baudrillard (1981)) and used as a motivation for the study of models involving "Catching Up with the Joneses" or habit formation (Ryder and Heal (1973), Abel (1990)). The dual role of durables also been recognized in consumer theory (Lancaster (1991)). In their role of status creation durables provide immediate utility as well as, possibly, future utility which reflect the symbolic value attached to the ownership of the commodity. ${ }^{1}$ Hence, a durable commodity is best described as a multiattribute commodity with two main attributes: status and services. Each of these attributes is valued by agents who purchase the commodity to fulfil their needs for status and for services.

Expenditures on durables represent about $12.5 \%$ of consumer expenditures on goods and services. Durables expenditures, also, constitute the most volatile component of consumer expenditures: the standard deviation of the growth rate in durables is about six times that of non-durables and services (Mankiw (1985)). Since the durability aspect of these goods and, more specifically, the multiattribute structure of durables does not fit in the classic model, we propose a modification of the standard preference structure to incorporate these considerations. Additionally, implications of a theory incorporating this dichotomy between goods (durables versus perishables) can be tested since National Income Accounts provide a breakdown of consumption between durables and nondurables.

It is well known that the standard asset pricing model with a single perishable consumption good (Merton (1973), Breeden (1979), Cox, Ingersoll and Ross (1985)) fails to explain a number of observed regularities. ${ }^{2}$ Attempts to reconciliate theoretical

1 Lancaster (1991) discusses the 'fashion' or 'style' attributes as a relevant characteristic of durable commodities. He also argues that "...In the decision to buy a new automobile, for example, the characteristic related to 'fashion' or 'style' may be present in relative strength in the first season, relatively less in later seasons, although the characteristics related to 'transportation' (use) may remain with constant coefficients over several seasons."

2 Some of the shortcomings of the standard model based on time additive von Neumann-Morgenstern preferences are described in Grossman and Shiller (1981) and 
implications with observed empirical regularities have mainly focussed on the structure of preferences. To this end recursive preferences (Epstein and Zin (1989), Duffie and Epstein (1992)), preferences embodying substitutability of consumptions at different dates (Hindy and Huang $(1992,1993)$ ) and habit forming preferences (Abel (1989), Sundaresan (1989), Constantinides (1990), Detemple and Zapatero (1991, 1992) and Heaton (1993)) have been investigated. ${ }^{3}$ Models based on habit forming preferences, for instance, may produce low volatility of consumption since habits increase the cost of current consumption; they may also increase the magnitude of asset risk premia as a result of "increased risk aversion".

One feature absent from the standard model is the dichotomy between durable and nondurable commodities. While the importance of this dichotomy has already been demonstrated in the context of the term structure of interest rates ${ }^{4}$ (Dunn and Singleton (1986)) current research has mostly centered on single good models with durability in which the durable good has a single attribute. Recent findings suggest that nondurable consumptions at nearby points in time are substitutes and that services from durable and nondurable goods may not be perfect substitutes (Eichenbaum and Hansen (1990)). In economies in which a single durable good, such as housing, provides instantaneous services which are valued by households but is costly to adjust, equilibrium asset prices satisfy the traditional CAPM while the consumption CAPM fails (Grossman and Laroque (1990)). Also, durability and habit formation exert conflicting effects on asset risk premia: evaluation of a model incorporating both aspects reveals an improvement in the fit of the model but also suggests that habit persistence dominates durability (Ferson and Constantinides (1991)). Durable goods, additionally, can be valued as contingent claims: the price of a durable good with single (service) attribute is the current market value of its future service flows (Eichenbaum, Hansen and Richard (1987)). Finally Hindy and Huang

Mehra and Prescott (1985).

${ }^{3}$ See also Farmer (1990) and Weil (1990).

${ }^{4}$ Durability may help to explain the varied shapes of the yield curve. 
(1993) study a model in which a single durable good produces services from past purchases. They find that the agent consumes periodically and invests more in the risky asset than the corresponding agent with standard time additive utility.

Hence, the current literature clearly underscores the need for further analysis of general models which involve multiattribute durable goods. In this paper we formulate a model of asset pricing in a class of stochastic exchange economies with two types of commodities, durable and nondurable (or perishable) goods. In our model the durable commodity has two attributes. It provides services from past purchases and it creates status, immediately, at the time of purchase. The agent's preferences are defined over the perishable consumption good, status and services. In a first step we assume (i) perfect substitutability between status and services, (ii) linearity of the production function for status with respect to the contemporaneous quantity of the durable commodity purchased and (iii) linearity and history dependence in the technology for production of services which is a weighted average of past durable purchases. This basic model is later extended to more general preferences defined over attributes.

\subsection{Summary of results.}

In the presence of multiattribute durability consumption choices are driven by the following considerations. The choice of consumption of the perishable commodity involves the usual comparison between the current marginal utility of consumption and the marginal (monetary) cost. By way of contrast an increase in current purchases of the durable good produces an immediate increase in status as well as an increase in future services produced, i.e., it raises contemporaneous utility as well as future utilities. The optimal policy balances the marginal utility of status plus the marginal utility attached to future services and the marginal cost of the durable's purchases. When the instantaneous utility function is not additively separable across goods the demands for the durable and the perishable interact and depend both on the stock of services provided by past purchases and on the status level achieved. 
Durability implies an effect of past purchases on current utility and choices. If past acquisitions of the durable are irreversible and if status and services are perfect substitutes nonnegativity consumption constraints may become binding even if the marginal utility at zero is infinite. Indeed, since past purchases provide current services the economy may reach states in which a reduction in services is desired. By precluding an instantaneous reduction in services below these provided by past durable's purchases irreversibility may force temporary excesses of current services over their desired level. Stickiness in adjustment, furthermore, is asymmetric: increases in desired status level are met by instantaneous purchases. The possibility of future excesses affects both the current demands for the durable and the perishable. When the endogenous constraint is currently active an excess or deficient demand for the perishable good is recorded depending on whether the cross partial derivative of the utility function is positive or negative.

In equilibrium, Arrow-Debreu prices are proportional to the marginal utility of perishable consumption evaluated at the aggregate consumption of the perishable, the status level achieved and the aggregate flow of services produced from past durable's purchases. The (relative) price of the durable reflects the intertemporal nonseparabilities inherent in durability: it depends on current marginal utility of status as well as on the marginal utility of future services. By way of contrast, the interest rate and asset risk premia are not directly influenced by intertemporal nonseparabilities induced by the service attribute of the durable good.

The equilibrium interest rate is related to the moments of the growth rates in perishable consumption, status and services produced from the durable. In particular, a negative relation to the expected growth in the services from the durable emerges if and only if the cross partial of the instantaneous utility function is positive $\left(u_{12}>0\right)$. Under appropriate conditions a negative relation to the quadratic variation of the growth rate in status and to the covariation between the growth rates in status and in the perishable's consumption is recorded.

The presence of a multiattribute durable good also changes the structural form of asset risk premia (relative to a single attribute durable model): a two beta 
consumption CAPM holds where the factors are aggregate consumption of the perishable good and aggregate status level associated with the durable respectively. Durability also changes the weights of the respective factors. If the (atemporal) conditional relative risk aversion of the instantaneous utility function $\left(-\mathrm{u}_{11} / \mathrm{u}_{1}\right)$ is increasing with respect to the attributes of the durable the effect of the first factor is magnified. Under appropriate conditions durability also boosts the effect of the second factor. Hence, comparison of equilibria across economies reveals that asset risk premia may be higher while the interest rate may be lower when one of the two commodities is a multiattribute durable. The source of this effect is the nonseparability across the perishable and the attributes of the durable and the presence of the status attribute. Thus, explicit modelling of multiattribute durability in a two-good economy may help to resolve the equity premium puzzle.

Section 2 presents the structure of the economy and the assumptions. Demands for consumptions of the durable and nondurable are derived in section 3; equilibrium allocations and prices are solved for in section 4 . Section 5 focuses on the behavior and properties of the interest rate and of asset risk premia and specializes the results to a Cobb-Douglas economy. An extension to a more general model of preferences over attributes is presented in section 6. All proofs are collected in Appendix A; Appendix B derives the equilibrium volatilities of the values of the firms producing the two goods; Appendix $\mathrm{C}$ contains an analysis of the demand functions for the model of section 6; Appendix D provides a solution method for linear backward equations.

\section{The economy.}

We consider a pure exchange economy with a representative agent (Lucas (1978)) and two types of commodities: durable and perishable. The durable commodity has two characteristics: it provides services and status.

The uncertainty is represented by a complete probability space $(\Omega, \Im, P)$ where $\Omega$ is the set of states of nature, $\Im$ is a $\sigma$-algebra representing the collection of observable events and $\mathrm{P}$ is a probability measure defined on $(\Omega, \Im)$. On $(\Omega, \Im, \mathrm{P})$ 
define a Brownian Motion process $\mathrm{W}$ with values in $\Re^{\mathrm{d}}$. The economy has finite time $[0, \mathrm{~T}]$. Let $\Im_{(\rightarrow)} \equiv\left\{\Im_{\mathrm{t}} ; \mathrm{t} \in[0, \mathrm{~T}]\right\}$ denote the augmented filtration generated by $\mathrm{W}$ and set

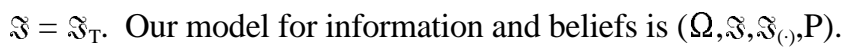

There are two commodities in the economy. The first commodity is a standard perishable good which is physically destroyed in the process of consumption. The consumption good has a unique attribute which can be interpreted as the health benefits that it provides. In the remainder of the paper we assimilate the consumption of the perishable commodity with its unique characteristic: both are denoted by c. The second commodity is a durable good which has two distinct functions or attributes. On the one hand the durable provides services, $\mathrm{z}$, which are valued by the agent. On the other hand it functions as a symbol of value and provides status to its owner, $\mathrm{s}$. The durable commodity represents a common input in the production of these two characteristics. The structure of these production functions will be specified below. Preferences are defined over (the triplet of) characteristics. The consumption space is the positive cone of the space of square-integrable and $\Im_{(\cdot)}$-progressively measurable processes. $^{5}$

Assumption 1: Preferences have the von Neumann-Morgenstern representation,

$$
\mathrm{U}(\mathrm{c}, \mathrm{s}, \mathrm{z}) \equiv \mathrm{E}\left[\int_{0}^{\mathrm{T}}\left(\rho_{\mathrm{t}}\right)^{-1} \mathrm{u}\left(\mathrm{c}_{\mathrm{t}}, \mathrm{s}_{\mathrm{t}}+\mathrm{z}_{\mathrm{t}}\right) \mathrm{dt}\right]
$$

where $\rho_{\mathrm{t}} \equiv \exp \left[\int_{0}^{\mathrm{t}} \beta_{\mathrm{v}} \mathrm{dv}\right], \beta$ is a bounded, $\mathfrak{\Im}_{(\cdot)}$-progressively measurable process representing the subjective discount rate, $\mathrm{u}(\cdot, \cdot)$ is the instantaneous utility function, $\mathrm{c}_{\mathrm{t}}$ represents the consumption of the perishable commodity at date $t, \mathrm{~s}_{\mathrm{t}}$ is the consumption of the status attribute and $\mathrm{z}_{\mathrm{t}}$ the consumption of services. The utility function, $\mathrm{u}(\cdot, \cdot):[0, \infty) \mathrm{x}[0, \infty) \rightarrow(-\infty, \infty)$, is twice continuously differentiable, strictly increasing, strictly concave with respect to each argument and concave in $(\mathrm{c}, \mathrm{s}+\mathrm{z})$.

${ }^{5}$ A stochastic process $X$ is square-integrable $\left(X \in \mathscr{L}^{2}[0, T]\right)$ if $E\left[\int_{0}^{\mathrm{T}}\left(X_{t}\right)^{2} d t\right]<\infty$. A stochastic process $\mathrm{X}$ is $\Im_{(-)}$-progressively measurable (with respect to the filtration $\left.\Im_{(\cdot)}\right)$ if, for each $t \geq 0$ and each $A \in \boldsymbol{3}(\Re)$ the set $\left\{(\mathrm{v}, \omega): \mathrm{v} \in[0, \mathrm{t}], \omega \in \Omega, \mathrm{x}_{\mathrm{v}}(\omega) \in \mathrm{A}\right\}$ belongs to the product $\boldsymbol{\sigma}$-field $\mathbf{3}([0, \mathrm{t}]) \mathrm{x}_{\Im_{\mathrm{t}}}$. 
Let $\mathrm{u}_{1}(\cdot, \cdot)$ and $\mathrm{u}_{2}(\cdot, \cdot)$ denote the derivatives of $\mathrm{u}(\cdot, \cdot)$ with respect to the first and the second argument respectively. We assume that $\lim _{\mathrm{c}\lrcorner 0} \mathrm{u}_{1}(\mathrm{c}, \mathrm{s}+\mathrm{z})=\infty, \forall \mathrm{s}+\mathrm{z} \in \Re^{+}$. Also define the functions $\mathrm{I}(\mathrm{y}, \mathrm{s}+\mathrm{z})$ and $\mathrm{H}(\mathrm{y}, \gamma)$ representing the inverse of $\mathrm{u}_{1}(\mathrm{c}, \mathrm{s}+\mathrm{z})$ with respect to $\mathrm{c}$ for $\mathrm{s}+\mathrm{z}$ given and the inverse of $\mathrm{u}_{2}(\mathrm{I}(\mathrm{y}, \mathrm{s}+\mathrm{z}), \mathrm{s}+\mathrm{z})$ with respect to $\mathrm{s}+\mathrm{z}$ for $\mathrm{y}$ fixed, i.e.,

$$
\begin{gathered}
\mathrm{u}_{1}(\mathrm{I}(\mathrm{y}, \mathrm{s}+\mathrm{z}), \mathrm{s}+\mathrm{z})=\mathrm{y} \\
\mathrm{u}_{2}(\mathrm{I}(\mathrm{y}, \mathrm{H}(\mathrm{y}, \gamma)), \mathrm{H}(\mathrm{y}, \gamma))=\gamma
\end{gathered}
$$

We assume that the functions $\mathrm{I}(\cdot, \cdot)$ and $\mathrm{H}(\cdot, \cdot)$ exist, are continuously differentiable and have the limiting values:

(i) $\mathrm{I}\left(0^{+}, \mathrm{s}+\mathrm{z}\right)=\lim _{\mathrm{y} \downarrow 0} \mathrm{I}(\mathrm{y}, \mathrm{s}+\mathrm{z})=+\infty, \forall \mathrm{s}+\mathrm{z} \in \mathfrak{\Re}^{+}$.

(ii) $\mathrm{H}(+\infty,+\infty)=\lim _{\mathrm{y} 1 \infty, \gamma 1 \infty} \mathrm{H}(\mathrm{y}, \gamma)=0$.

(iii) $\mathrm{H}\left(0^{+}, 0^{+}\right)=\lim _{\mathrm{y} \downarrow 0, \gamma\lrcorner 0} \mathrm{H}(\mathrm{y}, \gamma)=\kappa ; 0 \leq \kappa<\infty$.

(iv) $\mathrm{I}(\infty, \mathrm{H}(\infty, \infty))=\lim _{\mathrm{y} 1 \infty, \gamma \uparrow \infty} \mathrm{I}(\mathrm{y}, \mathrm{H}(\mathrm{y}, \gamma))=0$.

The utility specification (1) embodies an assumption of perfect substitutability between status and services. We focus on this simple case first to provide elementary insights about the effects of durable goods with multiple attributes. Many structural results are independent of this particular assumption. An extension to a general preference structure allowing for imperfect substitution between the attributes of durability is studied in section 7 .

The assumptions on the utility function are standard. Increases in status or in services increase utility, but at a decreasing rate. These assumptions are satisfied by the Cobb-Douglas utility function which is studied in section 6 .

To complete the description of the model we specify the relationship between the attributes of the durable good and the amounts of the commodity bought. We suppose that services are derived from past purchases of the durable commodity only. This is consistent with previous continuous time models of durability such as Hindy and Huang (1993). Status, on the other hand, is related to contemporaneous purchases 
since it is associated with ownership of the commodity. Status also appears to be a more transitory property of durable commodities since the mere use of the commodity makes it more common, thereby reducing its symbolic value for the owner (see footnote 1). Without loss of generality we suppose that status depreciates infinitely fast so that only current purchases produce status. ${ }^{7}$

Assumption 2: The technology for production of services is,

$$
\mathrm{z}_{\mathrm{t}}=\mathrm{z}_{0} \mathrm{e}^{-\alpha \mathrm{t}}+\alpha \int_{0}^{\mathrm{t}} \mathrm{e}^{-\alpha(\mathrm{t}-\mathrm{s})} 1_{\mathrm{s}} \mathrm{ds}, \mathrm{z}_{0} \geq 0 ; \mathrm{t} \in[0, \mathrm{~T}]
$$

where $\alpha$ and $\mathrm{z}_{0}$ are nonnegative constants and $\mathrm{l}_{\mathrm{s}} \geq 0$, represents purchases of the durable commodity at time $\mathrm{s}, \mathrm{s} \in[0, \mathrm{t})$. Initial services, $\mathrm{z}_{0}$, are produced from a stock of durables inherited by the agent. The coefficient $\alpha$ determines the relative weight of past purchases in the production of current services.

Assumption 3: Status is related to contemporaneous durable purchases by,

$$
\mathrm{s}_{\mathrm{t}}=\mathrm{l}_{\mathrm{t}} \text {. }
$$

The technology (4) for production of services is additive and linear with respect to past purchases of the durable. While more general, nonlinear or nonadditive technologies may be of interest as well, the linear technology (4) is easier to handle and leads to closed form solutions for demand functions when appropriate conditions are satisfied. It can therefore be used as a benchmark model for evaluating further extensions to more general production technologies for services.

${ }^{6}$ It can be argued that the status effect even precedes ownership or purchase of a commodity since it may be attached to the intent of purchase. When planning future acquisitions of certain luxury items consumers often experience a sense of achievement associated with their anticipative identification to a higher social class.

7 It is straightforward to model persistence in the "symbolic" function played by durables by adding another index $x$ depending on historical purchases of durables with a depreciation rate $\delta$ (see section 7). 
Similarly, the relationship (5) between the status attribute and the amount purchased is assumed to be linear. Section 6 discusses an extension to intertemporal dependencies and decreasing returns to scale in status creation.

Finally we note that the model with two perishable commodities can be retrieved as a subcase of (1), (4) and (5) by setting $\alpha=0$ and $z_{0}=0$. This economy with two perishable commodities, constitutes the benchmark economy against which the effects of durability can be evaluated.

Endowments of the perishable and durable commodity are respectively e and $\mathrm{f},(\mathrm{e}, \mathrm{f}) \in \mathscr{Q}^{2+}[0, \mathrm{~T}] \times \mathscr{Q}^{2+}[0, \mathrm{~T}]$. Associated with the endowment process of durables $\mathrm{f}$, is the flow of services produced $z_{t}(f) \equiv z_{0} e^{-\alpha t}+\alpha \int_{0}^{t} e^{-\alpha(t-s)} f_{s} d s, z_{0} \geq 0$. In the remainder of the paper we will use both notations $\mathrm{z}_{\mathrm{t}}$ or $\mathrm{z}_{\mathrm{t}}(\mathrm{f})$ when the context requires identification of the arguments of the production function for services. The endowment processes satisfy,

Assumption 4: Aggregate endowments follow Ito processes,

and

$$
\begin{aligned}
d e_{t} & =e_{t}\left[\mu_{e}(t) d t+\sigma_{e}(t) d W_{t}\right], e_{0}>0 \\
d f_{t} & =f_{t}\left[\mu_{f}(t) d t+\sigma_{f}(t) d W_{t}\right], f_{0}>0,
\end{aligned}
$$

where the unidimensional drift coefficients $\mu_{\mathrm{e}}$ and $\mu_{\mathrm{f}}$ and the components of the 1xd vectors of volatility coefficients $\sigma_{\mathrm{e}}$ and $\sigma_{\mathrm{f}}$ are bounded, $\Im_{(\cdot)}$-progressively measurable processes. We assume that the implied process,

$$
\lambda_{t} \equiv-u_{1}\left(e_{t}, f_{t}+z_{t}(f)\right)^{-1}\left[u_{11}\left(e_{t}, f_{t}+z_{t}(f)\right) e_{t} \sigma_{e}{ }^{\prime}+u_{12}\left(e_{t}, f_{t}+z_{t}(f)\right) f_{t} \sigma_{f}{ }^{\prime}\right]
$$

satisfies the (Novikov) condition, $\operatorname{Eexp}\left[(1 / 2) \int_{0}^{\mathrm{T}}\left\|\lambda_{\mathrm{t}}\right\|^{2} \mathrm{dt}\right]<\infty$.

Assumption 4 is standard: it ensures that the equivalent martingale measure evaluated at equilibrium allocations is well defined. 
Two types of investment opportunities are available: a (locally) riskless asset and a set of $\mathrm{d}$ risky securities. ${ }^{8}$ The riskless asset pays an interest rate $\mathrm{r}$ which is a square-integrable and $\Im_{(\cdot)}$-progressively measurable process. The risky assets are contingent claims with exogenously specified payoffs. The vector of asset prices $\mathrm{S}=$ $\left\{\mathrm{S}_{\mathrm{t}} ; \mathrm{t} \in[0, \mathrm{~T}]\right\}$ satisfies,

$$
\mathrm{dS}_{\mathrm{t}}=\mathrm{I}_{\mathrm{S}}\left[\mu_{\mathrm{t}} \mathrm{dt}+\sigma_{\mathrm{t}} \mathrm{dW}_{\mathrm{t}}\right], \mathrm{S}_{0} \text { given; } \mathrm{t} \in[0, \mathrm{~T}]
$$

where $I_{S}$ is a dxd diagonal matrix with the vector of prices on its diagonal. The ddimensional process $\mu$ represents the vector of expected returns and $\sigma$ is a dxd-matrix of volatility coefficients. Components of $\mu$ and $\sigma$ are $\Im_{(\cdot)}$-progressively measurable processes; $\boldsymbol{\sigma}$ is invertible and the vector of unit risk premia, $\theta_{t} \equiv\left(\sigma_{t}\right)^{-1}\left(\mu_{t}-r_{t} \mathbf{1}\right)$ satisfies the condition, $\operatorname{Eexp}\left[(1 / 2) \int_{0}^{\mathrm{T}}\left\|\boldsymbol{\theta}_{\mathrm{t}}\right\|^{2} \mathrm{dt}\right]<\infty$.

A portfolio process $\pi$ is $\Im_{(\cdot)}$-progressively measurable, $\Re^{\mathrm{d}}$-valued and square-integrable $\left(E \int_{0}^{\mathrm{T}}\left\|\pi_{\mathrm{t}}\right\|^{2} \mathrm{dt}<\infty\right)$. Here $\pi$ represents the vector of dollar amounts invested in the risky assets; if $\mathrm{X}$ denotes the wealth process, $\mathrm{X}-\pi \mathbf{1}$ is the investment in the riskless asset.

We also recall that a process of consumption of the perishable good $\mathrm{c}$ is an $\Im_{(-)}$-progressively measurable and square-integrable process with values in $[0, \infty)$. A process of durable good purchases 1 is an $\Im_{(\cdot)}$-progressively measurable, squareintegrable process with values in $[0, \infty)$. A process of relative price of the durable good p is a square-integrable, $\Im_{(\cdot)}$-progressively measurable process.

A triplet $(\pi, \mathrm{c}, \mathrm{l})$ of investment, consumption of perishable and purchases of durables is admissible if and only if the wealth process $\mathrm{X}$ satisfies the no-bankruptcy condition $X_{t} \geq 0, t \in[0, T]$ (P-a.s.) where $X$ solves the stochastic differential equation,

$$
d X_{t}=\left(r_{t} X_{t}+e_{t}+p_{t} f_{t}-c_{t}-p_{t} l_{t}\right) d t+\pi_{t}\left[\left(\mu_{t}-r_{t} \mathbf{1}\right) d t+\sigma_{t} d W_{t}\right] ; X_{0}=0
$$

8 The equilibrium implications of the model are not affected by the number of contingent claims available since markets are effectively complete in single agent economies. Completeness of the asset market, however, is instrumental for our existence results relating to the demand functions (section 3). 
An admissible policy $(\pi, \mathrm{c}, \mathrm{l})$ is optimal for the agent if it cannot be dominated by another admissible policy, i.e. if there is no other admissible $\left(\pi^{\circ}, c^{o}, l^{\circ}\right)$ such that $\mathrm{U}\left(\mathrm{c}^{\mathrm{o}}, \mathrm{s}\left(\mathrm{1}^{\mathrm{o}}\right), \mathrm{z}\left(\mathrm{1}^{\circ}\right)\right)>\mathrm{U}(\mathrm{c}, \mathrm{s}(\mathrm{l}), \mathrm{z}(\mathrm{l}))$.

An equilibrium is a collection of processes $\left(\left(\mathrm{S}^{*}, \mathrm{r}^{*}, \mathrm{p}^{*}\right),\left(\pi^{*}, \mathrm{c}^{*}, 1^{*}\right)\right)$ such that the strategy $\left(\pi^{*}, c^{*}, 1^{*}\right)$ is optimal for the representative agent and markets clear: $c^{*}-e^{*}=0$, $1^{*}-\mathrm{f}^{*}=0$ and $\pi^{*}=0$.

\section{Optimal demands.}

Consider the progressively measurable process $\theta=\left\{\theta_{t} ; t \in[0, T]\right\}, \theta_{t} \equiv\left(\sigma_{t}\right)^{-}$ ${ }^{1}\left(\mu_{\mathrm{t}}-\mathrm{r}_{\mathrm{t}} \mathbf{1}\right)$, which represents the vector of market prices of risk and define the associated exponential martingale $\eta=\left\{\eta_{\mathrm{t}} ; \mathrm{t} \in[0, \mathrm{~T}]\right\}$,

$$
\eta_{\mathrm{t}}=\exp \left[-\int_{0}^{\mathrm{t}} \theta_{\mathrm{s}} \mathrm{dW} \mathrm{W}_{\mathrm{s}}-1 / 2 \int_{0}^{\mathrm{t}}\left\|\boldsymbol{\theta}_{\mathrm{s}}\right\|^{2} \mathrm{ds}\right]
$$

The equivalent martingale measure is $\mathrm{Q}(\mathrm{A})=\mathrm{E}\left[\eta_{\mathrm{T}} 1_{\mathrm{A}}\right] ; \mathrm{A} \in \Im_{\mathrm{T}}$. Under this measure asset prices discounted at the riskfree rate are martingales. The measure is equivalent to $\mathrm{P}$ since $\theta$ is bounded. It is also unique by completeness of the asset market. Also, the process $W W_{t}+\int_{0}^{t} \theta_{s} d s, t \in[0, T]$, is a standard, d-dimensional Brownian Motion relative to $\mathrm{Q}$.

Let us define the discount factor, $\mathrm{b}_{\mathrm{t}} \equiv \exp \left[-\int_{0}^{\mathrm{t}} \mathrm{r}_{\mathrm{v}} \mathrm{dv}\right]$ and the ratio $\mathrm{b}_{\mathrm{t}, \mathrm{s}} \equiv \mathrm{b}_{\mathrm{s}} / \mathrm{b}_{\mathrm{t}}$. The static optimization problem associated with the dynamic optimization problem of the agent is (Cox and Huang (1989, 1991), Karatzas, Lehoczky and Shreve (1987)),

$$
\max _{(c, l)} U(c, s, z) \text { s.t. } E^{*}\left[\int_{0}^{T} b_{t}\left(c_{t}+l_{t} p_{t}\right) d t\right] \leq E^{*}\left[\int_{0}^{T} b_{t}\left(e_{t}+f_{t} p_{t}\right) d t\right]
$$

where $\mathrm{E}^{*}$ represents the expectation under the equivalent martingale measure Q. ${ }^{9}$ Let $\left(c^{*}, 1^{*}\right)$ denote the solution to $(9)$. Then $\left(c^{*}, 1^{*}\right)$ is optimal for the dynamic problem and is supported by a unique portfolio strategy $\pi^{*}$. Specifically $\pi_{t}^{*}=\left(b_{t}\right)^{-1}\left(\sigma_{t}^{\prime}\right)^{-1} \phi_{t}$ where

\footnotetext{
${ }^{9}$ The controls $\mathrm{c}$ and $\mathrm{l}$ in (9) represent respectively consumption of the perishable good and purchase of the durable good. By definition these processes are $\Im_{(\cdot)}$ progressively measurable and square-integrable with values in $[0, \infty)$. Also, note that $\mathrm{pl} \in \mathscr{L}^{+}[0, \mathrm{~T}]$ and $\mathrm{pf} \in \mathscr{L}^{+}[0, \mathrm{~T}]$.
} 
$\phi$ is the unique predictable and square integrable process in the representation of the Q-martingale,

$$
E_{t}^{*}\left[\int_{0}^{T} b_{t}\left(c_{t}^{*}-e_{t}+\left(l_{t}^{*}-f_{t}\right) p_{t}\right) d t\right]-E^{*}\left[\int_{0}^{T} b_{t}\left(c_{t}^{*}-e_{t}+\left(l_{t}^{*}-f_{t}\right) p_{t}\right) d t\right]=\int_{0}^{t} \phi_{v} d \tilde{W}_{v}
$$

where $\tilde{\mathrm{W}} \equiv \mathrm{W}_{\mathrm{t}}+\int_{0}^{\mathrm{t}} \theta_{\mathrm{s}} \mathrm{ds}$ is the Q-Brownian Motion process defined above and $\mathrm{E}_{\mathrm{t}}^{*}[\cdot] \equiv$ $E^{*}\left[\cdot \mid \Im_{t}\right]$ represents the conditional expectation operator.

The static budget constraint in (9) states that the present value at date zero of expenditures $\left(E_{0}^{*} \int_{0}^{T} b_{t}\left(c_{t}+l_{t} p_{t}\right) d t\right)$ cannot exceed the value of resources $\left(E^{*} \int_{0} b_{t}\left(e_{t}+f_{t} p_{t}\right) d t\right)$. Since the asset market is complete any given consumption profile can be attained by an appropriate (and unique) trading strategy. The optimal portfolio is simply proportional to the process $\phi$ which arises in the representation of the value of the net expenditures stream (10).

Let y denote the Lagrange multiplier associated with the static problem and consider the process $\xi$ equal to the discounted value of the martingale density, $\xi_{\mathrm{t}} \equiv \mathrm{b}_{\mathrm{t}} \eta_{\mathrm{t}}$, where the instantaneous discount rate is the riskless rate. The process $\xi$ represents the state price density; Arrow-Debreu prices are given by $\xi_{\mathrm{t}} \mathrm{dP}$. Also define $\rho_{\mathrm{s}, \mathrm{t}}=\rho_{\mathrm{t}} / \rho_{\mathrm{s}}$

The policy (c,l) is optimal if and only if (c,l,y) solves (see Theorem 6 in the Appendix),

$$
\begin{gathered}
\mathrm{u}_{1}\left(\mathrm{c}_{\mathrm{t}}, \mathrm{s}_{\mathrm{t}}+\mathrm{z}_{\mathrm{t}}\right)=\mathrm{y} \rho_{\mathrm{t}} \xi_{\mathrm{t}} \\
\mathrm{u}_{2}\left(\mathrm{c}_{\mathrm{t}}, \mathrm{s}_{\mathrm{t}}+\mathrm{z}_{\mathrm{t}}\right)+\alpha \mathrm{E}_{\mathrm{t}}\left[\int_{\mathrm{t}}^{\mathrm{T}} \rho_{\mathrm{s}, \mathrm{t}} \mathrm{e}^{-\alpha(s-\mathrm{s})} \mathrm{u}_{2}\left(\mathrm{c}_{\mathrm{s}}, \mathrm{s}_{\mathrm{s}}+\mathrm{z}_{\mathrm{s}}\right) \mathrm{ds}\right] \leq \mathrm{y} \rho_{\mathrm{t}} \xi_{\mathrm{t}} \mathrm{p}_{\mathrm{t}} ;=\text { if } \mathrm{l}_{\mathrm{t}}>0 \\
\mathrm{c}_{\mathrm{t}} \geq 0,1_{\mathrm{t}} \geq 0, \mathrm{t} \in[0, \mathrm{~T}] ; \mathrm{y}>0, \\
\mathrm{E}^{*}\left[\int_{0}^{\mathrm{T}} \mathrm{b}_{\mathrm{t}}\left(\mathrm{c}_{\mathrm{t}}+\mathrm{l}_{\mathrm{t}} \mathrm{p}_{\mathrm{t}}\right) \mathrm{dt}\right] \leq \mathrm{E}^{*}\left[\int_{0}^{\mathrm{T}} \mathrm{b}_{\mathrm{t}}\left(\mathrm{e}_{\mathrm{t}}+\mathrm{f}_{\mathrm{t}} \mathrm{p}_{\mathrm{t}}\right) \mathrm{dt}\right] .
\end{gathered}
$$

where $\mathrm{c}$ and $\mathrm{l}$ are progressively measurable and square-integrable processes.

Equation (11) is the standard optimality condition for consumption in a complete market: the marginal utility of consumption in a given state equals the marginal cost of consumption associated with that state. Note that the choice of perishable consumption depends on the choice of status and services if the utility function is not additively separable. Equation (12) characterizing the optimal choice of the durable is more complex due to the multiple attributes of the good and to the 
structure of services involving intertemporal dependencies. The marginal benefit in this case consists of the immediate marginal utility $\left(\mathrm{u}_{2}\left(\mathrm{c}_{\mathrm{t}}, \mathrm{s}_{\mathrm{t}}+\mathrm{z}_{\mathrm{t}}\right)\right)$ associated with status creation as well as of the utility benefits associated with future services provided by a current incremental purchase $\left(\alpha \mathrm{E}_{\mathrm{t}}\left[\int_{\mathrm{t}}^{\mathrm{T}} \rho_{\mathrm{s}, \mathrm{t}} \mathrm{e}^{-\alpha(\mathrm{s}-\mathrm{t})} \mathrm{u}_{2}\left(\mathrm{c}_{\mathrm{s}}, \mathrm{s}_{\mathrm{s}}+\mathrm{z}_{\mathrm{s}}\right) \mathrm{ds}\right]\right){ }^{10}$ In this second component the increase in the flow of services at date s following an incremental purchase at date $t$ is given by $\alpha \mathrm{e}^{-\alpha(s-t)}$. The marginal cost is the Arrow-Debreu price multiplied by the (relative) price of the durable commodity. The equation holds as an equality when purchases of the durable are positive. Perfect substitutability between status and services and the history dependent structure of services imply the possibility of a binding nonnegativity constraint on purchases. At such a corner the marginal cost exceeds the marginal benefit. Lastly equation (14) is the static budget constraint.

To understand the structure of the demand functions it is useful to perform a transformation of (11)-(12). First recall the definitions of the functions $\mathrm{I}(\mathrm{y}, \mathrm{s}+\mathrm{z})$ and $\mathrm{H}(\mathrm{y}, \gamma)$ representing, respectively the inverse of $\mathrm{u}_{1}(\mathrm{c}, \mathrm{s}+\mathrm{z})$ with respect to $\mathrm{c}$ for $\mathrm{s}+\mathrm{z}$ given and the inverse of $\mathrm{u}_{2}(\mathrm{I}(\mathrm{y}, \mathrm{s}+\mathrm{z}), \mathrm{s}+\mathrm{z})$ with respect to $\mathrm{s}+\mathrm{z}$ for $\mathrm{y}$ fixed (equations (2)(3)). Second, introduce the auxiliary process $\gamma$ representing the marginal monetary cost of durable purchases net of the marginal benefits attached to the provision of future services. Let us, in a first step, ignore the nonnegativity constraint on 1 . In this case $\gamma$ satisfies the recursive linear equation,

$$
\mathrm{y} \gamma_{\mathrm{t}}=\mathrm{y} \rho_{\mathrm{t}} \xi_{\mathrm{t}} \mathrm{p}_{\mathrm{t}}-\alpha \mathrm{E}_{\mathrm{t}}\left[\int_{\mathrm{t}}^{\mathrm{T}} \rho_{\mathrm{s}, \mathrm{t}} \mathrm{e}^{-\alpha(s-\mathrm{t})} \mathrm{y} \gamma_{\mathrm{s}} \mathrm{ds}\right], \mathrm{t} \in[0, \mathrm{~T}] .
$$

Since optimal date $t$ policies satisfy $\mathrm{u}_{2}\left(\mathrm{c}_{\mathrm{t}}, \mathrm{s}_{\mathrm{t}}+\mathrm{z}_{\mathrm{t}}\right)=\mathrm{y} \gamma_{\mathrm{t}}$ and $\mathrm{u}_{1}\left(\mathrm{c}_{\mathrm{t}}, \mathrm{s}_{\mathrm{t}}+\mathrm{z}_{\mathrm{t}}\right)=\mathrm{y} \rho_{\mathrm{t}} \xi_{\mathrm{t}}$ they are respectively given by $\mathrm{l}_{\mathrm{t}}=\mathrm{H}\left(\mathrm{y} \rho_{\mathrm{t}} \xi_{\mathrm{t}} \mathrm{y} \gamma_{\mathrm{t}}\right)-\mathrm{z}_{\mathrm{t}}$ and $\mathrm{c}_{\mathrm{t}}=\mathrm{I}\left(\mathrm{y} \rho_{\mathrm{t}} \xi_{\mathrm{t}}, \mathrm{s}_{\mathrm{t}}+\mathrm{z}_{\mathrm{t}}\right)$ where $\mathrm{H}\left(\mathrm{y} \rho_{\mathrm{t}} \xi_{\mathrm{t}}, \mathrm{y} \gamma_{\mathrm{t}}\right)-\mathrm{z}_{\mathrm{t}}$ may take a negative value, but $\mathrm{I}\left(\mathrm{y} \rho_{\mathrm{t}} \xi_{\mathrm{t}}, \mathrm{s}_{\mathrm{t}}+\mathrm{z}_{\mathrm{t}}\right)$ is always nonnegative due to our assumptions on the utility function. The negative value for current purchases of the durable arises when past purchases provide services in excess of the currently desired level of status and services.

${ }^{10}$ When status involves persistence we obtain a second recursive component on the left hand side of (12) which captures the effect of current purchases on the future status of the owner of the commodity. 
Since purchases are irreversible the nonnegativity constraint $1 \geq 0$ may become binding. It follows that purchases of the durable good at date $t$ are the positive part of the unconstrained policy: $\mathrm{l}_{\mathrm{t}}=\left[\mathrm{H}\left(\mathrm{y} \rho_{\mathrm{t}} \xi_{\mathrm{t}}, \mathrm{y} \gamma_{\mathrm{t}}\right)-\mathrm{z}_{\mathrm{t}}\right]^{+}$. Along the optimal trajectory the marginal cost net of future benefits, $\gamma$, takes into account the possibility of binding constraints at future times. The process $\gamma$ then satisfies the nonlinear recursive equation,

$$
\begin{gathered}
\mathrm{y} \gamma_{\mathrm{t}}=\mathrm{y} \rho_{\mathrm{t}} \xi_{\mathrm{t}} \mathrm{p}_{\mathrm{t}}-\alpha \mathrm{E}_{\mathrm{t}}\left[\int _ { \mathrm { t } } ^ { \mathrm { T } } \rho _ { \mathrm { s } , \mathrm { t } } \mathrm { e } ^ { - \alpha ( s - \mathrm { s } ) } \mathrm { u } _ { 2 } \left(\mathrm{I}\left(\mathrm{y} \rho_{\mathrm{s}} \xi_{\mathrm{s}},\left[\mathrm{H}\left(\mathrm{y} \rho_{\mathrm{s}} \xi_{\mathrm{s}} \mathrm{y} \gamma_{\mathrm{s}}\right)-\mathrm{z}_{\mathrm{s}}\right]^{+}+\mathrm{z}_{\mathrm{s}}\right),\right.\right. \\
\left.\left.\left[\mathrm{H}\left(\mathrm{y} \rho_{\mathrm{s}} \xi_{\mathrm{s}} \mathrm{y} \gamma_{\mathrm{s}}\right)-\mathrm{z}_{\mathrm{s}}\right]^{+}+\mathrm{z}_{\mathrm{s}}\right) \mathrm{ds}\right] .
\end{gathered}
$$

for all $\mathrm{t} \in[0, \mathrm{~T}]$.

Our next Theorems characterize the demand functions satisfying conditions (11)-(14). Before stating the results we introduce the cost function $\chi(y)$ associated with a specific family of policies. Specifically, consider the policies,

$$
\begin{gathered}
c_{t}(y)=I\left(y \rho_{t} \xi_{t},\left[H\left(y \rho_{t} \xi_{t}, y \gamma_{t}\right)-z_{t}\right]^{+}+z_{t}\right) \\
l_{t}(y)=\left[H\left(y \rho_{t} \xi_{t}, y \gamma_{t}\right)-z_{t}\right]^{+}
\end{gathered}
$$

parametrized by the constant $\mathrm{y} \in[0,+\infty)$ and where $\mathrm{z}_{\mathrm{t}}$ solves,

$$
\mathrm{dz}=\alpha\left\{\left[\mathrm{H}\left(\mathrm{y} \rho_{\mathrm{t}} \xi_{\mathrm{t}}, \mathrm{y} \gamma_{\mathrm{t}}\right)-\mathrm{z}_{\mathrm{t}}\right]^{+}-\mathrm{z}_{\mathrm{t}}\right\} \mathrm{dt}
$$

The associated cost function is given by,

$$
\chi(y) \equiv E^{*} \int_{0}^{T} b_{t}\left\{I\left(y \rho_{t} \xi_{t},\left[H\left(y \rho_{t} \xi_{t}, y \gamma_{t}\right)-z_{t}\right]^{+}+z_{t}\right)+p_{t}\left[H\left(y \rho_{t} \xi_{t}, y \gamma_{t}\right)-z_{t}\right]^{+}\right\} d t .
$$

In particular for the cases in which $\mathrm{H}\left(\mathrm{y} \rho_{\mathrm{t}} \xi_{\mathrm{t}} \mathrm{y} \gamma_{\mathrm{t}}\right) \geq \mathrm{z}_{\mathrm{t}}$ at all times we have,

$$
\mathrm{l}_{\mathrm{t}}(\mathrm{y})=\mathrm{H}\left(\mathrm{y} \rho_{\mathrm{t}} \xi_{\mathrm{t}}, \mathrm{y} \gamma_{\mathrm{t}}\right)-\mathrm{z}_{0} \mathrm{e}^{-2 \alpha \mathrm{t}}-\alpha \int_{0}^{\mathrm{t}} \mathrm{e}^{-2 \alpha(\mathrm{t}-\mathrm{s})} \mathrm{H}\left(\mathrm{y} \rho_{\mathrm{s}} \xi_{s}, \mathrm{y} \gamma_{\mathrm{s}}\right) \mathrm{ds}
$$

and the cost function takes the simpler form,

$$
\begin{gathered}
\chi(\mathrm{y}) \equiv \mathrm{E}^{*} \int_{0}^{\mathrm{T}} \mathrm{b}_{\mathrm{t}}\left[\mathrm{I}\left(\mathrm{y} \rho_{\mathrm{t}} \xi_{\mathrm{t}}, \mathrm{H}\left(\mathrm{y} \rho_{\mathrm{t}} \xi_{\mathrm{t}} \mathrm{y} \gamma_{\mathrm{t}}\right)\right)+\mathrm{p}_{\mathrm{t}} \mathrm{H}\left(\mathrm{y} \rho_{\mathrm{t}} \xi_{\mathrm{t}}, \mathrm{y} \gamma_{\mathrm{t}}\right)-\mathrm{p}_{\mathrm{t}} \mathrm{z}_{0} \mathrm{e}^{-2 \alpha \mathrm{t}}\right. \\
\left.-\alpha \mathrm{p}_{\mathrm{t}} \int_{0}^{\mathrm{t}} \mathrm{e}^{-2 \alpha(\mathrm{t}-\mathrm{s})} \mathrm{H}\left(\mathrm{y} \rho_{\mathrm{s}} \xi_{\mathrm{s}}, \mathrm{y} \gamma_{\mathrm{s}}\right) \mathrm{ds}\right] \mathrm{dt} .
\end{gathered}
$$

With this notation we have, 
Theorem 1: Consider the economy of section 2 and suppose that assumptions 1 and 2 hold. Suppose that equation (16) admits a solution, $\gamma_{\mathrm{t}}(\mathrm{y})>0, \mathrm{t} \in[0, \mathrm{~T}]$ and consider the map $\chi(\mathrm{y})$ defined in (19) evaluated at $\gamma(\mathrm{y})$. Suppose also that the equation $\chi(\mathrm{y})$ $=\mathrm{E}^{*}\left[\int_{0}^{\mathrm{T}} \mathrm{b}_{\mathrm{t}}\left(\mathrm{e}_{\mathrm{t}}+\mathrm{f}_{\mathrm{t}} \mathrm{p}_{\mathrm{t}}\right) \mathrm{dt}\right]$ has a solution $\mathrm{y}^{*}>0$. Then optimal policies $\left(\mathrm{c}^{*}, 1^{*}, \pi^{*}\right)$ are,

$$
\begin{gathered}
c_{t}^{*}=c_{t}\left(y^{*}\right)=I\left(y^{*} \rho_{t} \xi_{t},\left[H\left(y^{*} \rho_{t} \xi_{t} y^{*} \gamma_{t}\left(y^{*}\right)\right)-z_{t}\right]^{+}+z_{t}\right) \\
1_{t}^{*}=l_{t}\left(y^{*}\right)=\left[H\left(y^{*} \rho_{t} \xi_{t} y^{*} \gamma_{t}\left(y^{*}\right)\right)-z_{t}\right]^{+} \\
\pi_{t}^{*}=\left(b_{t}\right)^{-1}\left(\sigma_{t}^{\prime}\right)^{-1} \phi_{t},
\end{gathered}
$$

where $\phi=\left\{\phi_{t} ; t \in[0, T]\right\}$ is the d-dimensional, square integrable, progressively measurable process that uniquely represents the martingale, $\mathrm{E}^{*}\left[\int_{0}^{\mathrm{T}} \mathrm{b}_{\mathrm{t}}\left(\mathrm{c}_{\mathrm{t}}^{*}-\mathrm{e}_{\mathrm{t}}+\mathrm{p}_{\mathrm{t}}\left(\mathrm{l}_{\mathrm{t}}^{*}-\right.\right.\right.$ $\left.\left.\mathrm{f}_{\mathrm{f}}\right) \mathrm{dt} \mid \Im_{\mathrm{t}}\right]-\mathrm{E}^{*}\left[\int_{0}^{\mathrm{T}} \mathrm{b}_{\mathrm{t}}\left(\mathrm{c}_{\mathrm{t}}^{*}-\mathrm{e}_{\mathrm{t}}+\mathrm{p}_{\mathrm{t}}\left(\mathrm{l}_{\mathrm{t}}^{*}-\mathrm{f}_{\mathrm{t}}\right)\right) \mathrm{dt}\right]$. The production of services from durables $\mathrm{z}\left(\mathrm{l}^{*}\right)$ solves,

$$
\mathrm{z}_{\mathrm{t}}\left(\mathrm{l}^{*}\right)=\mathrm{z}_{0} \mathrm{e}^{-\alpha \mathrm{t}}+\alpha \int_{0}^{\mathrm{t}} \mathrm{e}^{-\alpha(\mathrm{t}-\mathrm{s})}\left[\mathrm{H}\left(\mathrm{y}^{*} \rho_{\mathrm{s}} \xi_{\mathrm{s}}, \mathrm{y}^{*} \gamma_{\mathrm{s}}\left(\mathrm{y}^{*}\right)\right)-\mathrm{z}_{\mathrm{s}}\left(\mathrm{l}^{*}\right)\right]^{+} \mathrm{ds} .
$$

Optimal wealth is $\mathrm{X}_{\mathrm{t}}^{*}=\left(\mathrm{b}_{\mathrm{t}}\right)^{-1}\left[\int_{0}^{t} \mathrm{~b}_{\mathrm{s}}\left(\mathrm{e}_{\mathrm{s}}^{*}+\mathrm{p}_{\mathrm{s}} \mathrm{f}_{\mathrm{s}}^{*}\right) \mathrm{ds}-\int_{0}^{t} \mathrm{~b}_{\mathrm{s}}\left(\mathrm{c}_{\mathrm{s}}^{*}+\mathrm{p}_{\mathrm{s}} \mathrm{l}_{\mathrm{s}}^{*}\right) \mathrm{ds}+\int_{0}^{t} \phi_{\mathrm{s}} \mathrm{d} \tilde{\mathrm{W}}_{\mathrm{s}}\right]$.

Services produced from durables imply an effect of past purchases on current utility and choices. If, in addition, past acquisitions of durables are irreversible nonnegativity consumption constraints may become binding since marginal utility is locally bounded above as a result of past decisions. Since past purchases provide current services the economy may reach states in which a reduction in the flow of services is desired. By making instantaneous adjustment infinitely costly irreversibility may force temporary excesses of actual status and service levels $\left((\mathrm{H}-\mathrm{z})^{+}+\mathrm{z}\right)$ over their desired level $(\mathrm{H})$. Stickiness in adjustment, furthermore, is asymmetric: increases in desired status and services levels are met by instantaneous purchases. The possibility of future excesses affects both the current demand for durables and perishables. When the nonnegativity constraint is currently active an excess or deficient demand for the perishable good is recorded depending on whether the cross partial derivative of the utility function is positive or negative (since $\mathrm{I}_{2}=-\mathrm{u}_{12} / \mathrm{u}_{11}$ ).

For economies in which the constraint on durable purchases is not operative we obtain an explicit solution: 
Theorem 2: Consider the economy of section 2 and suppose that assumptions 1 and 2 hold. Define the cost of the status attribute embedded in durables, N, by,

$$
\mathrm{N}_{\mathrm{t}} \equiv \mathrm{p}_{\mathrm{t}}-\alpha \mathrm{E}_{\mathrm{t}}^{*}\left[\int_{\mathrm{t}}^{\mathrm{T}} \mathrm{e}^{-2 \alpha(\mathrm{s}-\mathrm{t})} \mathrm{b}_{\mathrm{t}, \mathrm{s}} \mathrm{p}_{\mathrm{s}} \mathrm{ds}\right]
$$

and suppose that $\mathrm{N}_{\mathrm{t}}>0$ for all $\mathrm{t} \in[0, \mathrm{~T}]$. Also suppose that the parameters of the economy take values such that purchases of the durable are interior at all times. ${ }^{11}$ Then, the marginal cost net of future benefits is given in closed form by,

$$
\gamma_{t}=\rho_{t} \xi_{t} N_{t}
$$

Optimal policies $\left(\mathrm{c}^{*}, 1^{*}, \pi^{*}\right)$ are,

$$
\begin{gathered}
\mathrm{c}_{\mathrm{t}}^{*}=\mathrm{I}\left(\mathrm{y}^{*} \rho_{\mathrm{t}} \xi_{\mathrm{t}}, \mathrm{H}\left(\mathrm{y}^{*} \rho_{\mathrm{t}} \xi_{\mathrm{t}}, \mathrm{y}^{*} \gamma_{\mathrm{t}}\right)\right) \\
\mathrm{l}_{\mathrm{t}}^{*}=\mathrm{H}\left(\mathrm{y}^{*} \rho_{\mathrm{t}} \xi_{\mathrm{t}}, \mathrm{y}^{*} \gamma_{\mathrm{t}}\right)-\mathrm{z}_{0} \mathrm{e}^{-2 \alpha \mathrm{t}}-\alpha \int_{0}^{\mathrm{t}} \mathrm{e}^{-2 \alpha(\mathrm{t}-\mathrm{s})} \mathrm{H}\left(\mathrm{y}^{*} \rho_{\mathrm{s}} \xi_{\mathrm{s}}, \mathrm{y}^{*} \gamma_{\mathrm{s}}\right) \mathrm{ds} \\
\pi_{\mathrm{t}}^{*}=\left(\mathrm{b}_{\mathrm{t}}\right)^{-1}\left(\sigma_{\mathrm{t}}\right)^{-1} \phi_{\mathrm{t}},
\end{gathered}
$$

where $\mathrm{y}^{*}$ is a multiplier that saturates the budget constraint (solution to the equation $\left.\chi(\mathrm{y})=\mathrm{E}^{*}\left[\int_{0}^{\mathrm{T}} \mathrm{b}_{\mathrm{t}}\left(\mathrm{e}_{\mathrm{t}}+\mathrm{f}_{\mathrm{t}} \mathrm{p}_{\mathrm{t}}\right) \mathrm{dt}\right]\right)$ and $\phi=\left\{\phi_{\mathrm{t}} ; \mathrm{t} \in[0, \mathrm{~T}]\right\}$ is the d-dimensional, square integrable, adapted process that uniquely represents the martingale, $\mathrm{E}_{\mathrm{t}}^{*}\left[\int_{0}^{\mathrm{T}} \mathrm{b}_{\mathrm{t}}\left(\mathrm{c}_{\mathrm{t}}^{*}\right.\right.$ $\left.\left.\mathrm{e}_{\mathrm{t}}+\mathrm{p}_{\mathrm{t}}\left(\mathrm{l}_{\mathrm{t}}^{*}-\mathrm{f}_{\mathrm{t}}\right)\right) \mathrm{dt}\right]-\mathrm{E}^{*}\left[\int_{0}^{\mathrm{T}} \mathrm{b}_{\mathrm{t}}\left(\mathrm{c}_{\mathrm{t}}^{*}-\mathrm{e}_{\mathrm{t}}+\mathrm{p}_{\mathrm{t}}\left(\mathrm{l}_{\mathrm{t}}^{*}-\mathrm{f}_{\mathrm{t}}\right)\right) \mathrm{dt}\right]$. Under the additional condition,

$$
\mathrm{u}_{12} \geq 0
$$

the multiplier $\mathrm{y}^{*}$ and the optimal policies $\left(\mathrm{c}^{*}, 1^{*}\right)$ are unique. The associated production of services from durables and wealth $\left(\mathrm{z}\left(\mathrm{I}^{*}\right), \mathrm{X}^{*}\right)$ are respectively given by,

$$
\begin{gathered}
\mathrm{z}_{\mathrm{t}}\left(1^{*}\right)=\mathrm{z}_{0} \mathrm{e}^{-2 \alpha \mathrm{t}}+\alpha \int_{0}^{\mathrm{t}} \mathrm{e}^{-2 \alpha(\mathrm{t}-\mathrm{s})} \mathrm{H}\left(\mathrm{y}^{*} \rho_{\mathrm{s}} \xi_{\mathrm{s}}, \mathrm{y}^{*} \gamma_{\mathrm{s}}\right) \mathrm{ds} \\
\mathrm{X}_{\mathrm{t}}^{*}=\left(\mathrm{b}_{\mathrm{t}}\right)^{-1}\left[\int_{0}^{\mathrm{t}} \mathrm{b}_{\mathrm{s}}\left(\mathrm{e}_{\mathrm{s}}^{*}+\mathrm{p}_{\mathrm{s}} \mathrm{f}_{\mathrm{s}}^{*}\right) \mathrm{ds}-\int_{0}^{\mathrm{t}} \mathrm{b}_{\mathrm{s}}\left(\mathrm{c}_{\mathrm{s}}^{*}+\mathrm{p}_{\mathrm{s}} \mathrm{l}_{\mathrm{s}}^{*}\right) \mathrm{ds}+\int_{0}^{\mathrm{t}} \phi_{\mathrm{s}} \mathrm{d} \tilde{\mathrm{W}}_{\mathrm{s}}\right] .
\end{gathered}
$$

The solution (25) for the process $\gamma$ is computed using the procedure described in Appendix D. The interpretation of $\gamma$ is intuitive. It represents the Arrow-Debreu prices adjusted by the marginal cost of status: $N_{t}=p_{t}-\alpha E_{t}^{*}\left[\int_{t}^{T} e^{-2 \alpha(s-t)}\right.$

11 A necessary and sufficient condition for the purchases of durables to be interior at all times is, $\mathrm{H}\left(\mathrm{y}^{*} \rho_{\mathrm{t}} \xi_{\mathrm{t}}, \mathrm{y}^{*} \gamma_{\mathrm{t}}\right)-\mathrm{z}_{0} \mathrm{e}^{-2 \alpha \mathrm{t}}-\alpha \int_{0}^{\mathrm{t}} \mathrm{e}^{-2 \alpha(\mathrm{t}-\mathrm{s})} \mathrm{H}\left(\mathrm{y}^{*} \rho_{\mathrm{s}} \xi_{\mathrm{s}}, \mathrm{y}^{*} \gamma_{\mathrm{s}}\right) \mathrm{ds}>0$, for all $\mathrm{t} \in[0, \mathrm{~T}]$. 
$\left.b_{t, s} p_{s} d s\right]$. Indeed, purchase of one unit of the durable at date $t$ costs $p_{t}$ but provides future services valued at $\alpha \mathrm{E}_{\mathrm{t}}^{*}\left[\int_{\mathrm{t}}^{\mathrm{T}} \mathrm{e}^{-2 \epsilon(s-\mathrm{s})} \mathrm{b}_{\mathrm{t}, \mathrm{s}} \mathrm{p}_{\mathrm{s}} \mathrm{ds}\right]$. The difference then captures the cost of the symbolic function of durables. The economic interpretation of $\mathrm{N}_{\mathrm{t}}$ also explains the need for the assumption $\mathrm{N}_{\mathrm{t}}>0$ for all $\mathrm{t} \in[0, \mathrm{~T}]$. Indeed, if this cost becomes null purchases of durables (i.e. purchases of status) are effectively subsidized so that demands explode. Hence, this condition ensures well-behaved demand functions. The demand functions (26)-(27) depend on Arrow-Debreu prices $\xi$, the cost of status $\gamma$ and finally the current level of services resulting from past purchases of the durable.

When the nonnegativity constraint is inactive the demand for the perishable good is decreasing in $\mathrm{y} \xi$, decreasing (increasing) in $\mathrm{y} \gamma$ if $\mathrm{u}_{12}>0\left(\mathrm{u}_{12}<0\right)$ and does not depend on the level of services z. The demand for durables, on the other hand is decreasing in $y \gamma$ and decreasing (increasing) in $y \xi$ if $\mathrm{u}_{12}$ is positive (negative). It is also decreasing in the level of services from past purchases $\mathrm{z}$ : a unit increase in $\mathrm{z}$ causes the current demand for the durable to decrease by one unit (Corollary 1 in the Appendix).

By way of contrast when the nonnegativity constraint is active the demand for the perishable is still decreasing in $\mathrm{y} \xi$ (but at a lower rate than in the reversibility case), independent of $y \gamma$ and increasing (decreasing) in $z$ when $u_{12}$ is positive (negative). Of course, the demand for the durable is null when the constraint is active.

To conclude this section we assess the effect of durability on the demand functions. Set $\mathrm{z}_{0}=0$ and consider a class of economies parametrized by the depreciation rate $\alpha$ and identical in all other respects. Note that the economy with two perishable commodities is obtained for $\alpha=0$. Fix Arrow-Debreu and commodity prices. Restricted to an appropriate range of the parameter $\alpha$ the demand functions are well defined, continuous with respect to $\alpha$, with limits the demand functions for the perishable commodities. If the two commodities are substitutes (complements) in the limit economy the demands for the perishable commodity in the neighboring durable economies, $\mathrm{c}^{*}$, are lower (higher) than in the limit economy. Also, if the second commodity is a normal good in the limit economy the demands $1^{*}$ in the neighboring durable economies will be higher. Hence, small amounts of durability 
may reduce or increase demand functions depending on the nature of the goods under consideration (Corollary 2 in the Appendix).

\section{Equilibrium.}

In this section we study equilibrium prices and allocations in a pure exchange economy satisfying the assumptions of section 2 . Our next theorem provides explicit solutions for equilibrium Arrow-Debreu prices $\xi$, the price of the durable good p, the rate of interest $r$ and the premium on risky securities $\mu$-r1.

Theorem 3: Consider the economy described in section 2 and suppose that assumptions 1, 2 and 4 hold. In equilibrium aggregate consumption of perishables and purchases of durable goods are, respectively, $\mathrm{c}_{\mathrm{t}}^{*}=\mathrm{e}_{\mathrm{t}}$ and $\mathrm{l}_{\mathrm{t}}^{*}=\mathrm{f}_{\mathrm{t}}$. The services provided by past purchases of the durable commodity are,

$$
\mathrm{z}_{\mathrm{t}}(\mathrm{f})=\mathrm{z}_{0} \mathrm{e}^{-\alpha \mathrm{t}}+\alpha \int_{0}^{\mathrm{t}} \mathrm{e}^{-\alpha(\mathrm{t}-\mathrm{s})} f_{\mathrm{s}} \mathrm{ds}, \mathrm{t} \in[0, \mathrm{~T}],
$$

and the status achieved is $\mathrm{s}_{\mathrm{t}} \equiv \mathrm{f}_{\mathrm{t}}$. Equilibrium Arrow-Debreu $(\xi)$ and commodity (p) prices are,

$$
\begin{gathered}
\xi_{\mathrm{t}}^{*}=\rho_{\mathrm{t}}^{-1} \mathrm{u}_{1}\left(\mathrm{e}_{\mathrm{t}}, \mathrm{s}_{\mathrm{t}}+\mathrm{z}_{\mathrm{t}}(\mathrm{f})\right) / \mathrm{u}_{1}\left(\mathrm{e}_{0}, \mathrm{~s}_{0}+\mathrm{z}_{0}\right) \\
\mathrm{p}_{\mathrm{t}}=\mathrm{u}_{1}\left(\mathrm{e}_{\mathrm{t}}, \mathrm{s}_{\mathrm{t}}+\mathrm{z}_{\mathrm{t}}(\mathrm{f})\right)^{-1}\left\{\mathrm{u}_{2}\left(\mathrm{e}_{\mathrm{t}}, \mathrm{s}_{\mathrm{t}}+\mathrm{z}_{\mathrm{t}}(\mathrm{f})\right)+\alpha \mathrm{E}_{\mathrm{t}}\left[\int_{\mathrm{t}}^{\mathrm{T}} \mathrm{e}^{-} \mathrm{f}_{\mathrm{t}}^{\left(\mathrm{\rho}_{\mathrm{u}}+\alpha\right) \mathrm{d}} \mathrm{u}_{2}\left(\mathrm{e}_{\mathrm{s}}, \mathrm{s}_{\mathrm{s}}+\mathrm{z}_{\mathrm{s}}(\mathrm{f})\right) \mathrm{ds}\right]\right\}
\end{gathered}
$$

Finally, the equilibrium rate of interest and asset premia are respectively given by,

$r_{t}^{*}=\beta_{t}-u_{1}\left(e_{t}, s_{t}+z_{t}(f)\right)^{-1}\left\{u_{11}\left(e_{t}, s_{t}+z_{t}(f)\right) e_{t} \mu_{e}(t)+u_{12}\left(e_{t}, s_{t}+z_{t}(f)\right)\left[f_{t} u_{f}(t)+\alpha\left(f_{t}-z_{t}(f)\right)\right]\right.$

$\left.+1 / 2 u_{111}\left(e_{t}, s_{t}+z_{t}(f)\right) e_{t} \sigma_{e} \sigma_{e} e_{t}+u_{112}\left(e_{t}, s_{t}+z_{t}(f)\right) e_{t} \sigma_{e} \sigma_{f} f_{t}+1 / 2 u_{122}\left(e_{t}, s_{t}+z_{t}(f)\right) f_{t} \sigma_{f} \sigma_{f}^{\prime} f_{t}\right\},(34)$

$$
\mu_{t}-r_{t} 1=-u_{1}\left(e_{t}, s_{t}+z_{t}(f)\right)^{-1}\left[u_{11}\left(e_{t}, s_{t}+z_{t}(f)\right) \sigma_{t} \sigma_{e} e_{t}+u_{12}\left(e_{t}, s_{t}+z_{t}(f)\right) \sigma_{t} \sigma_{f}^{\prime} f_{t}\right]
$$

Equilibrium allocations are supported by the no-trade strategy $\pi_{\mathrm{t}}^{*}=0$; equilibrium wealth is $\mathrm{X}_{\mathrm{t}}^{*}=0$.

Since the perishable commodity serves as the numeraire state prices are equal to the marginal utility of the perishable evaluated at the equilibrium allocation. Absent habit formation this marginal utility depends only on current aggregates and 
not on future allocations. By way of contrast the relative price of the durable commodity reflects both the symbolic value and the usage value of the durable commodity. In particular it reflects the intertemporal nonseparabilities implied by the technology for production of services.

The equilibrium rate of interest is the negative of the expected rate of growth of the state price density $\left(\mathrm{r}_{\mathrm{t}}=-\mathrm{E}_{\mathrm{t}}\left[\mathrm{d} \xi_{\mathrm{t}} / \xi_{\mathrm{t}}\right]\right)$. Asset risk premia are related to the covariation between the rate of growth of the state price density and asset rates of returns $\left(\mu_{t}-r_{t} 1=-\left(S_{t} \xi_{t}\right)^{-1} d[S, \xi]\right) .{ }^{12}$ Implications of formulas (34)-(35) pertaining to the dynamic behavior of asset risk premia and of the interest rate are pursued in section 5. To complete this section we state a representation formula for the equilibrium price of a contingent claim in this economy.

Theorem 4: Consider a contingent claim with payoff $\mathrm{B} \in \mathscr{L}^{2}(\Omega, \Im, \mathrm{P})$ at a (sure) time $\tau$, where $\mathrm{B}$ is $\Im_{\tau}$-measurable. The price $\mathrm{q}$ of the claim is given by $\mathrm{q}_{\mathrm{t}}=\mathrm{E}_{\mathrm{t}}^{*}\left[\mathrm{e}^{-\int_{\mathrm{t}}^{\tau_{\mathrm{r}}^{*}} \mathrm{~d} \mathrm{~d}} \mathrm{~B}\right]$,

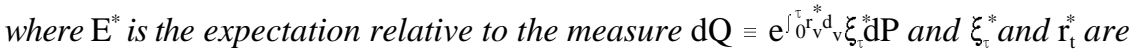
respectively given by (32) and (34).

\section{Asset risk premia and interest rate.}

The characterization of equilibrium in section 4 provides an explicit link between the endogenous prices and the interest rate on the one hand and the primitives of the economy on the other hand. In this section we examine the relationship between endogenous variables and aggregate consumption (subsection 5.1) and compare equilibria across economies with and without durability (subsections 5.2 and 5.3).

\subsection{Asset Prices, Interest Rate and Aggregate Consumption.}

First we note that relationship (34) of Theorem 3 can be written as,

12 Let $\mathrm{X}$ and $\mathrm{Y}$ denote two semimartingales. The (quadratic) covariation of $\mathrm{X}$ and $\mathrm{Y}$ is defined by, $[\mathrm{X}, \mathrm{Y}]_{\mathrm{t}} \equiv \mathrm{X}_{\mathrm{t}} \mathrm{Y}_{\mathrm{t}}-\int_{0}^{\mathrm{t}} \mathrm{X}_{\mathrm{s}-\mathrm{d}} \mathrm{dY} \mathrm{s}_{\mathrm{s}}-\int_{0}^{\mathrm{t}} \mathrm{Y}_{\mathrm{s}-\mathrm{d}} \mathrm{d} \mathrm{X}_{\mathrm{s}}$. The quadratic variation is, $[X]_{t} \equiv X_{t}^{2}-2 \int_{0}^{t} X_{s-} d X_{s}$. 


$$
r_{t}^{*}=\beta_{t}+\lambda_{1 t} \mu_{e}+\lambda_{2 t} \mu_{s}+\lambda_{3 t}\left[\mu_{z(f)} / z_{t}(f)\right]-1 / 2 \lambda_{4 t} \sigma_{e} \sigma_{e}{ }^{\prime}-\lambda_{5 t} \sigma_{e} \sigma_{f}^{\prime}-1 / 2 \lambda_{6 t} \sigma_{f} \sigma_{f}^{\prime}
$$

where the coefficients $\lambda_{\mathrm{it}}, \mathrm{i}=1, . .6$, are appropriately defined, $\mu_{\mathrm{z}(\mathrm{f})} \equiv \alpha(1-\mathrm{z})$ and $\mu_{\mathrm{s}} \equiv \mu_{\mathrm{f}}$.

Equation (36) reveals a relationship between the interest rate and the (instantaneous) moments of the growth rates of perishable consumption and of the attributes embedded in the durable. The durable goods affect the interest rate through the growth rate in status and in the flow of services that it provides. Specifically, the model predicts that the interest rate is positively related to the expected growth in status and to the growth rate in the services provided by past purchases when $\mathrm{u}_{12}<0$. Under this condition and ceteris paribus, economic periods experiencing positive growth in the flow of services are associated with a higher equilibrium rate of interest. Durability, therefore, introduces a dependence on the history of purchases, but no effect on future consumption plans. This stands in contrast with models of habit formation or models with a single durable commodity in which the interest rate also depends on possible future consumption plans (Detemple and Zapatero (1991)). Summarizing the relationship between consumption and the interest rate,

Proposition 1: The interest rate is:

(i) positively related to the expected growth rate of aggregate consumption of the perishable good. It is also negatively (positively) related to the expected growth rate in status and in the services provided by purchases of the durable if the cross partial $\mathrm{u}_{12}$ is positive (negative),

(ii) negatively (positively) related to the variation of the consumption growth rate of the perishable good if $\mathrm{u}_{111}$ is positive (negative), negatively (positively) related to the covariation between growth rates of consumption of the perishable good and of the status associated with purchases of the durable if $\mathrm{u}_{112}$ is positive (negative) and, negatively (positively) related to the quadratic variation of the growth rate in status if $\mathrm{u}_{122}$ is positive (negative). 
To understand the structure of asset risk premia, combine equations (6) and (35) as,

$$
\left(\mu_{t}^{*}-r_{t}^{*} 1\right) d t=\lambda_{1 t}\left(S_{t} e_{t}\right)^{-1} d[S, e]_{t}+\lambda_{2 t}\left(S_{t} f_{t}\right)^{-1} d[S, f]_{t} .
$$

This relationship is in the form of a two-beta CAPM where the first factor is aggregate consumption of the perishable commodity and the second factor status associated with current purchases of the durable. The weights assigned to each factor are respectively $\lambda_{1 \mathrm{t}} \equiv-\mathrm{e}_{\mathrm{t}}\left[\mathrm{u}_{11} / \mathrm{u}_{1}\right]$ the (atemporal) measure of conditional relative risk aversion with respect to the perishable commodity and $\lambda_{2 \mathrm{t}} \equiv-\mathrm{f}_{\mathrm{t}}\left[\mathrm{u}_{12} / \mathrm{u}_{1}\right]$ which is a mixture of the elasticity of substitution and of the conditional relative risk aversion with respect to the attributes of the durable commodity. ${ }^{13}$ Both coefficients are evaluated at aggregate consumption levels, $\left(\mathrm{e}_{\mathrm{t}}, \mathrm{s}_{\mathrm{t}}+\mathrm{z}_{\mathrm{t}}(\mathrm{f})\right)$. The single beta consumption CAPM of Breeden (1979) is retrieved if either (i) the utility function is additively separable, or (ii) the asset under consideration is uncorrelated with stochastic fluctuations in status, or (iii) the endowment of the durable follows a locally deterministic process, or (iv) the durable is a single attribute commodity providing services only. Also, a single beta CAPM relative to a basket of (two) goods can be constructed.

Formula (37) reveals the link between the asset market and economic forces in the goods market. Under decreasing conditional relative risk aversion, periods of high consumption of the perishable commodity are associated with lower sensitivity with respect to the first factor. Ceteris paribus the sensitivity with respect to the second factor depends on the behavior of the coefficient $\lambda_{2 t}$. Note that when $\lambda_{2 t}$ is positive (i.e. when $\mathrm{u}_{12}<0$ ) and $\left(\mathrm{f}_{\mathrm{t}} \mathrm{S}_{\mathrm{t}}\right)^{-1} \mathrm{~d}[\mathrm{~S}, \mathrm{f}]_{\mathrm{t}}$ is positive the premium induced by the status effect associated with purchases of durables is positive. Durability may increase asset risk premia even when the contribution of the second factor is negative $\left(u_{12}>0\right)$ since its attributes have an indirect effect on conditional relative risk aversion (and

13 When preferences are defined over multiple risky commodities the Kihlstrom and Mirman (1981) measure of risk aversion properly captures attitudes toward multivariate risks. By restricting preferences to (timeless) uncertain $\mathrm{x}$ certain pairs conditional risk preferences can be defined. The implied atemporal measure of conditional risk aversion is the standard Arrow-Pratt measure of risk aversion. 
hence on the sensitivity to the first factor). Thus, consideration of the status attribute of durables in a two good economy may actually help to explain the equity premium puzzle. The main properties of asset risk premia are summarized in the next proposition.

Proposition 2: Asset risk premia are positively related to the covariation between asset rates of returns and the rate of growth of aggregate perishable consumption.

They are negatively (positively) related to the covariation between the asset rates of returns and the rate of growth of status associated with aggregate purchases of the durable if the cross partial $\mathrm{u}_{12}$ is positive (negative).

\subsection{Asset Premia, Interest Rate and Durability.}

In this subsection we demonstrate that the presence of a multiattribute durable good may simultaneously increase the size of asset risk premia (for a given volatility structure) and decrease the level of the interest rate. ${ }^{14}$ The source of this result is the combination of the status attribute of the durable and the possibility of spillover effects across goods. We also derive conditions under which the same conclusions are achieved in economies with a single multiattribute durable commodity.

Consider two economies. The first one, $\mathbf{E}(\boldsymbol{\alpha}, \mathrm{e}, \mathrm{f})$, is the general economy of section 2 with both a multiattribute durable good and a perishable good and respective endowment processes e and $\mathrm{f}$. The second one, $\mathbf{E}(0, \mathrm{e}, \mathrm{f})$ is the (nested) economy with two perishable goods obtained by setting $\alpha=0$. To simplify the comparison between the two economies we assume that the inherited stock of services is null $\left(\mathrm{z}_{0}=0\right)$. In the economy $\mathbf{E}(0, \mathrm{e}, \mathrm{f})$ the second commodity only procures transitory felicity. Comparison

\footnotetext{
${ }^{14}$ It is important to note that we examine the effects of durability on the risk premium corresponding to a fixed volatility structure. This approach parrallels the procedure followed in calibration exercises which typically fix the volatilities at observed levels and attempt to match the risk premia implied by the model with their empirical values. In appendix B we provide explicit solutions for the endogenous volatilities of the values of the firms producing the endowments e and $\mathrm{f}$. These results show that the volatility of a given asset (with fixed payoff) changes as the structure of the economy changes. The impact of durability on equilibrium volatilities could, in principle, be assessed from these formulas.
} 
of $\mathbf{E}(\alpha, e, f)$ and $\mathbf{E}(0, e, f)$ is made for a given endowment process (e,f) and for a given volatility process of the asset under consideration: we are comparing an asset with a given volatility profile in an economy with a (multiattribute) durable good to an asset with the same volatility profile in an economy in which the durable has been replaced by a perishable commodity, but otherwise identical.

Before stating the main result of the section we define the measures of (atemporal) conditional risk aversion associated with the two economies,

$$
\begin{gathered}
\lambda_{1 t}(0, e, f) \equiv-e_{t} u_{11}\left(e_{t}, f_{t}\right) / u_{1}\left(e_{t}, f_{t}\right), \\
\lambda_{1 t}(\alpha, e, f) \equiv-e_{t} u_{11}\left(e_{t}, s_{t}+z_{t}(f)\right) / u_{1}\left(e_{t}, s_{t}+z_{t}(f)\right) .
\end{gathered}
$$

Similarly, other preference coefficients are indexed by the coefficient of durability and the endowment processes corresponding to the economy under consideration, $\lambda_{\mathrm{it}}(\alpha, \mathrm{e}, \mathrm{f})$ and $\lambda_{\mathrm{it}}(0, \mathrm{e}, \mathrm{f}), \mathrm{i}=1, \ldots, 6$. Sufficient conditions for increased risk premia and lower interest rate in the economy with durability relative to the same economy with two perishable commodities are,

Proposition 3: Consider the two economies $\mathbf{E}(\boldsymbol{\alpha}, \mathrm{e}, \mathrm{f})$ and $\mathbf{E}(0, \mathrm{e}, \mathrm{f})$. The risk premium corresponding to a given volatility profile is higher in the economy $\mathbf{E}(\alpha, \mathrm{e}, \mathrm{f})$ with a multiattribute durable and a perishable commodity if and only if,

$\left[\lambda_{1 \mathrm{t}}(\alpha, \mathrm{e}, \mathrm{f})-\lambda_{1 \mathrm{t}}(0, \mathrm{e}, \mathrm{f})\right]\left(\mathrm{S}_{\mathrm{t}} \mathrm{e}_{\mathrm{t}}\right)^{-1} \mathrm{~d}[\mathrm{~S}, \mathrm{e}]_{\mathrm{t}}+\left[\lambda_{2 \mathrm{t}}(\boldsymbol{\alpha}, \mathrm{e}, \mathrm{f})-\lambda_{2 \mathrm{t}}(0, \mathrm{e}, \mathrm{f})\right]\left(\mathrm{S}_{\mathrm{t}} \mathrm{f}_{\mathrm{t}}\right)^{-1} \mathrm{~d}[\mathrm{~S}, \mathrm{f}]_{\mathrm{t}}>0$.

The interest rate is lower in $\mathbf{E}(\boldsymbol{\alpha}, \mathrm{e}, \mathrm{f})$ if and only if,

$$
\begin{gathered}
{\left[\lambda_{1 \mathrm{t}}(\alpha, \mathrm{e}, \mathrm{f})-\lambda_{1 \mathrm{t}}(0, \mathrm{e}, \mathrm{f})\right] \mu_{\mathrm{e}}+\left[\lambda_{2 \mathrm{t}}(\alpha, \mathrm{e}, \mathrm{f})-\lambda_{2 \mathrm{t}}(0, \mathrm{e}, \mathrm{f})\right] \mu_{\mathrm{s}}} \\
+\lambda_{3 \mathrm{t}}(\alpha, \mathrm{e}, \mathrm{f})\left(\mu_{\mathrm{z}(\mathrm{f})} / \mathrm{z}_{\mathrm{ff}}\right)-1 / 2\left[\lambda_{4 \mathrm{t}}(\alpha, \mathrm{e}, \mathrm{f})-\lambda_{4 \mathrm{t}}(0, \mathrm{e}, \mathrm{f})\right] \mathrm{e}_{\mathrm{t}}^{-2} \mathrm{~d}[\mathrm{e}]_{\mathrm{t}} \\
-\left[\lambda_{5 \mathrm{t}}(\alpha, \mathrm{e}, \mathrm{f})-\lambda_{5 \mathrm{t}}(0, \mathrm{e}, \mathrm{f})\right]\left(\mathrm{e}_{\mathrm{t}} \mathrm{f}_{\mathrm{t}}\right)^{-1} \mathrm{~d}[\mathrm{e}, \mathrm{f}]_{\mathrm{t}}-1 / 2\left[\lambda_{6 \mathrm{t}}(\alpha, \mathrm{e}, \mathrm{f})-\lambda_{6 \mathrm{t}}(0, \mathrm{e}, \mathrm{f})\right] \mathrm{f}_{\mathrm{t}}^{-2} \mathrm{~d}[\mathrm{f}]_{\mathrm{t}}<0 .
\end{gathered}
$$

The interplay among the different factors affecting asset risk premia and the interest rate is complex. For instance, increasing conditional relative risk aversion $\lambda_{1 \mathrm{t}}(\alpha, \mathrm{e}, \mathrm{f})$ and increasing coefficient $\lambda_{2 \mathrm{t}}(\boldsymbol{\alpha}, \mathrm{e}, \mathrm{s})$ with respect to attributes are sufficient conditions for (38) to hold. The same conditions, though, have the opposite effect on condition (39). However, other components of (39) such as third order derivatives or 
growth of the attributes provided by the durable complement the risk aversion and elasticity effects and may produce a lower interest rate as well as increased asset risk premia. The Cobb-Douglas economy of section 5.3 provides an example in which this is the case under a simple condition.

The ability to obtain a reduction in the interest rate and an increase in asset risk premia with durability is tied to the structure of the utility function. Indeed, for the additive separable model $\mathrm{u}(\mathrm{c}, \mathrm{s}) \equiv \mathrm{u}(\mathrm{c})+\mathrm{v}(\mathrm{s})$ we find that $\lambda_{1 \mathrm{t}}(0, \mathrm{e}, \mathrm{f})=\lambda_{1 \mathrm{t}}(\alpha, \mathrm{e}, \mathrm{f})$ whereas $\lambda_{2 \mathrm{t}}(0, \mathrm{e}, \mathrm{f})=\lambda_{2 \mathrm{t}}(\alpha, \mathrm{e}, \mathrm{f})=\lambda_{3 \mathrm{t}}(0, \mathrm{e}, \mathrm{f})=\lambda_{3 \mathrm{t}}(\alpha, \mathrm{e}, \mathrm{f})=0$. Hence the single beta CCAPM holds and asset risk premia are immune to both attributes of durability. Inspection of (34) also reveals that the interest rate does not depend on $\alpha$ in the additively separable model. Only the price of the durable commodity (equation (33)) depends on the service technology parameter, $\boldsymbol{\alpha}$.

For purposes of comparison consider now an economy with a single durable commodity (with two attributes) and suppose that the subjective discount rate is deterministic (to simplify equilibrium formulas). The optimality condition is (setting $\mathrm{p}=1)$,

$$
\mathrm{u}_{1}\left(\mathrm{~s}_{\mathrm{t}}+\mathrm{z}_{\mathrm{t}}(\mathrm{l})\right)+\alpha \mathrm{E}_{\mathrm{t}}\left[\int_{\mathrm{t}}^{\mathrm{T}} \rho_{\mathrm{s}, \mathrm{t}} \mathrm{e}^{-\alpha(s-\mathrm{t})} \mathrm{u}_{1}\left(\mathrm{~s}_{\mathrm{s}}+\mathrm{z}_{\mathrm{s}}(1)\right) \mathrm{ds}\right] \leq \mathrm{y} \rho_{\mathrm{t}} \xi_{\mathrm{t}} ;=\text { if } \mathrm{l}_{\mathrm{t}}>0
$$

so that equilibrium Arrow-Debreu prices implied by the output process $\left\{\mathrm{f}_{\mathrm{t}}: \mathrm{t} \in[0, \mathrm{~T}]\right\}$ become,

$$
\mathrm{u}_{1}\left(\mathrm{~s}_{\mathrm{t}}+\mathrm{z}_{\mathrm{t}}(\mathrm{f})\right)+\alpha \mathrm{E}_{\mathrm{t}}\left[\int_{\mathrm{t}}^{\mathrm{T}} \rho_{\mathrm{s}, \mathrm{t}} \mathrm{e}^{-\alpha(s-\mathrm{t})} \mathrm{u}_{1}\left(\mathrm{~s}_{\mathrm{s}}+\mathrm{z}_{\mathrm{s}}(\mathrm{f})\right) \mathrm{ds}\right]=\mathrm{y}^{*} \rho_{\mathrm{t}} \xi_{\mathrm{t}} .
$$

Hence, asset risk premia satisfy the two beta CAPM,

$$
\left(\mu_{\mathrm{t}}^{*}-\mathrm{r}_{\mathrm{t}}^{*} \mathbf{1}\right) \mathrm{dt}=\phi_{1 \mathrm{t}}(\alpha, \mathrm{f})\left(\mathrm{S}_{\mathrm{t}} \mathrm{f}_{\mathrm{t}}\right)^{-1} \mathrm{~d}[\mathrm{~S}, \mathrm{f}]_{\mathrm{t}}-\alpha \mathrm{S}_{\mathrm{t}}^{-1} \mathrm{~d}\left[\mathrm{~S}, \mathrm{M}^{\mathrm{Y}}\right]_{\mathrm{t}} .
$$

where $\mathrm{M}_{\mathrm{t}}^{\mathrm{Y}} \equiv \int_{0}^{\mathrm{t}} \mathrm{Y}_{\mathrm{v}} \mathrm{dW}_{\mathrm{v}}$ and the coefficient of the consumption factor,

$$
\begin{gathered}
\phi_{1 \mathrm{t}}(\alpha, \mathrm{f}) \equiv-\left(\mathrm{y}^{*} \rho_{\mathrm{t}} \xi_{\mathrm{t}}\right)^{-1}\left\{\mathrm{u}_{11}\left(\mathrm{~s}_{\mathrm{t}}+\mathrm{z}_{\mathrm{t}}(\mathrm{f})\right) \mathrm{f}_{\mathrm{t}}\right. \\
\left.+\alpha \mathrm{E}_{\mathrm{t}}\left[\int_{\mathrm{t}}^{\mathrm{T}} \rho_{\mathrm{s}, \mathrm{t}} \mathrm{e}^{-\alpha(s-t)} \mathrm{u}_{11}\left(\mathrm{~s}_{\mathrm{s}}+\mathrm{z}_{\mathrm{s}}(\mathrm{f})\right)\left(\mathrm{f}_{\mathrm{s}}+\alpha \int_{\mathrm{t}}^{\mathrm{s}} \mathrm{e}^{-\alpha(s-u)} \mathrm{f}_{\mathrm{u}} \mathrm{du}\right) \mathrm{ds}\right]\right\},
\end{gathered}
$$

depends on contemporaneous, historical and future consumption trajectories. The second factor represents a hedging premium due to stochastic shifts in the drift and the volatility of the output process. The d-dimensional vector process $\mathrm{Y}$ is defined by, 


$$
\mathrm{Y}_{\mathrm{t}} \equiv\left(\mathrm{y}^{*} \rho_{\mathrm{t}} \xi_{\mathrm{t}}\right)^{-1} \mathrm{E}_{\mathrm{t}}\left[\int _ { \mathrm { t } } ^ { \mathrm { T } } \rho _ { \mathrm { s } , \mathrm { t } } \mathrm { e } ^ { - \alpha ( \mathrm { s } - \mathrm { t } ) } \mathrm { u } _ { 1 1 } ( \mathrm { s } _ { \mathrm { s } } + \mathrm { Z } _ { \mathrm { s } } ( \mathrm { f } ) ) \left\{\mathrm { f } _ { \mathrm { s } } \left[\int_{\mathrm{t}}^{\mathrm{s}} \mathbf{D}_{\mathrm{t}}\left(\mu_{\mathrm{f}}(\mathrm{v})-1 / 2 \sigma_{\mathrm{f}}(\mathrm{v}) \boldsymbol{\sigma}_{\mathrm{f}}(\mathrm{v})^{\prime}\right) \mathrm{dv}+\right.\right.\right.
$$
$\left.\left.\left.\int_{\mathrm{t}}^{\mathrm{s}} \mathbf{D}_{\mathrm{t}} \boldsymbol{\sigma}_{\mathrm{f}}(\mathrm{v}) \mathrm{dW} \mathrm{W}_{\mathrm{v}}\right]+\alpha \int_{\mathrm{t}}^{\mathrm{s}} \mathrm{e}^{-\alpha(\mathrm{s}-\mathrm{u})} \mathrm{f}_{\mathrm{u}}\left[\int_{\mathrm{t}}^{\mathrm{u}} \mathbf{D}_{\mathrm{t}}\left(\mu_{\mathrm{f}}(\mathrm{v})-1 / 2 \boldsymbol{\sigma}_{\mathrm{f}}(\mathrm{v}) \boldsymbol{\sigma}_{\mathrm{f}}(\mathrm{v})^{\prime}\right) \mathrm{dv}+\int_{\mathrm{t}}^{\mathrm{u}} \mathbf{D}_{\mathrm{t}} \boldsymbol{\sigma}_{\mathrm{f}}(\mathrm{v}) \mathrm{d} \mathrm{W}_{\mathrm{v}}\right] \mathrm{du}\right\} \mathrm{ds}\right]$, where $\mathbf{D}_{\mathrm{t}} \boldsymbol{\mu}_{\mathrm{f}}(\mathrm{v})$ and $\mathbf{D}_{\mathrm{t}} \boldsymbol{\sigma}_{\mathrm{f}}(\mathrm{v})$ represent the (d-dimensional) Malliavin derivatives of the coefficients $\mu_{\mathrm{f}}$ and $\sigma_{\mathrm{f}}$ (see, for instance, Detemple and Zapatero (1991, Appendix)). ${ }^{15}$

The equilibrium rate of interest on the other hand is given by,

$$
r_{t}^{*} d t=\beta_{t} d t+\phi_{2 t}(\alpha, f)\left(s_{t} \mu_{s}+\mu_{z(f)}\right)\left(s_{t}+z_{t}(f)\right)^{-1} d t-1 / 2 \phi_{3 t}(\alpha, f) f_{t}^{-2} d[f]_{t}-\alpha Z_{t} d t
$$

where

$$
\begin{gathered}
\phi_{2 t}(\alpha, f) \equiv-\left(y^{*} \rho_{t} \xi_{t}\right)^{-1}\left(s_{t}+z_{t}(f)\right) u_{11}\left(s_{t}+z_{t}(f)\right) \\
\phi_{3 t}(\alpha, f) \equiv\left(y^{*} \rho_{t} \xi_{t}\right)^{-1}\left(f_{t}\right)^{2} u_{111}\left(s_{t}+z_{t}(f)\right) \\
Z_{t} \equiv\left(y^{*} \rho_{t} \xi_{t}\right)^{-1}\left\{\left(\alpha+\beta_{t}\right) E_{t}\left[\int_{t}^{T} \rho_{s, t} e^{-\alpha(s-t)} u_{1}\left(s_{s}+z_{s}(f)\right) d s\right]-u_{1}\left(s_{t}+z_{t}(f)\right)\right\}
\end{gathered}
$$

First we note that asset risk premia and the rate of interest inherit a dependence on future consumption trajectories. This follows since the single good model fails to endogeneize the price of the durable commodity. Second, when the second commodity fails to provide services (or other types of intertemporal benefits), i.e. when $\alpha=0, \mathrm{z}_{0}=0$, we retrieve the standard, single beta CCAPM and interest rate formulas,

and,

$$
\begin{gathered}
\left(\mu_{t}^{*}-r_{t}^{*} \mathbf{1}\right) d t=\phi_{1 t}(0, f)\left(S_{t} f_{t}\right)^{-1} d[S, f]_{t} \\
r_{t}^{*} d t=\beta_{t} d t+\phi_{1 t}(0, f) \mu_{t} d t-1 / 2 \phi_{3 t}(0, f) f_{t}^{-2} d[f]_{t},
\end{gathered}
$$

where $\phi_{1 t}(0, f) \equiv-f_{t} u_{11}\left(f_{t}\right) / u_{1}\left(f_{t}\right)$ and $\phi_{3 t}(0, f) \equiv\left(f_{t}\right)^{2} u_{111}\left(f_{t}\right) / u_{1}\left(f_{t}\right)$. Hence, multiattribute durability increases asset risk premia and reduces the rate of interest if and only if the conditions,

$$
\begin{gathered}
{\left[\phi_{1 t}(\alpha, f)-\phi_{1 t}(0, f)\right]\left(S_{t} f_{t}\right)^{-1} d[S, f]_{t}-\alpha S_{t}^{-1} d\left[S, M^{Y}\right]_{t}>0,} \\
{\left[\phi_{2 t}(\alpha, f)\left(s_{t} \mu_{s}+\mu_{z(f)}\right)\left(s_{t}+Z_{t}(f)\right)^{-1}-\phi_{1 t}(0, f) \mu_{f}\right] d t-1 / 2\left[\phi_{3 t}(\alpha, f)-\phi_{3 t}(0, f)\right] f_{t}^{-2} d[f]_{t}-\alpha Z_{t} d t<0 .}
\end{gathered}
$$

15 We suppose that the processes $\mu_{\mathrm{f}}$ and $\boldsymbol{\sigma}_{\mathrm{f}}$ are sufficiently smooth for their Malliavin derivatives to exist (Ocone and Karatzas (1991)). The Malliavin derivative $\mathbf{D}_{\mathrm{t}} \mu_{\mathrm{f}}(\mathrm{s})$ captures the effect of a perturbation in the realization of the Brownian Motion $\mathrm{W}$ at time $\mathrm{t}$ on the coefficient $\mu_{\mathrm{f}}(\mathrm{s})$ at time $\mathrm{s}$. Note that for deterministic coefficients $\mathbf{D}_{\mathrm{t}} \mu_{\mathrm{f}}(\mathrm{s})=0$ since new information at date $\mathrm{t}$ (realization of $\mathrm{W}$ ) does not affect our (perfect) knowledge of $\mu_{\mathrm{f}}(\mathrm{s})$. 
are simultaneously satisfied. These conditions are the counterpart of (38)-(39) in the two good model.

To conclude the analysis in this section consider the single good (nested) model in which the durable commodity has only one attribute, services. In this case durable purchases affect only future utilities, $\mathrm{u}\left(\mathrm{s}_{\mathrm{t}}+\mathrm{z}_{\mathrm{t}}(\mathrm{f})\right)=\mathrm{u}\left(\mathrm{z}_{\mathrm{t}}(\mathrm{f})\right.$ ) (Hindy-Huang utilities). Equilibrium Arrow-Debreu prices are, ${ }^{16}$

$$
\alpha \mathrm{E}_{\mathrm{t}}\left[\int_{\mathrm{t}}^{\mathrm{T}} \rho_{\mathrm{s}, \mathrm{t}} \mathrm{e}^{-\alpha(\mathrm{s}-\mathrm{t})} \mathrm{u}_{1}\left(\mathrm{z}_{\mathrm{s}}(\mathrm{f})\right) \mathrm{ds}\right]=\mathrm{y}^{*} \rho_{\mathrm{t}} \xi_{\mathrm{t}},
$$

so that asset risk premia become,

$$
\left(\mu_{t}^{*}-r_{t}^{*} \mathbf{1}\right) d t=\psi_{1 t}(\alpha, f)\left(S_{t} f_{t}\right)^{-1} d[S, f]_{t}-\alpha S_{t}^{-1} d\left[S, M^{v}\right]_{t} .
$$

where,

$$
\begin{aligned}
& \mathrm{M}_{\mathrm{t}}^{\mathrm{v}} \equiv \int_{0}^{\mathrm{t}} \mathrm{V}_{\mathrm{v}} \mathrm{dW}_{\mathrm{v}} \\
& \left.\psi_{1 \mathrm{t}}(\alpha, \mathrm{f}) \equiv-\left(\mathrm{y}^{*} \rho_{\mathrm{t}} \xi_{\mathrm{t}}\right)^{-1} \alpha \mathrm{E}_{\mathrm{t}}\left[\int_{\mathrm{t}}^{\mathrm{T}} \rho_{\mathrm{s}, \mathrm{t}} \mathrm{e}^{-\alpha(\mathrm{s}-\mathrm{t})} \mathrm{u}_{11}\left(\mathrm{z}_{\mathrm{s}}(\mathrm{f})\right) \alpha\left(\int_{\mathrm{t}}^{\mathrm{s}} \mathrm{e}^{-\alpha(s-u)} \mathrm{f}_{\mathrm{u}} \mathrm{du}\right) \mathrm{ds}\right]\right\}, \\
& \mathrm{V}_{\mathrm{t}} \equiv\left(\mathrm{y}^{*} \rho_{\mathrm{t}} \xi_{\mathrm{t}}\right)^{-1} \mathrm{E}_{\mathrm{t}}\left[\int _ { \mathrm { t } } ^ { \mathrm { T } } \rho _ { \mathrm { s } , \mathrm { t } } \mathrm { e } ^ { - \alpha ( s - t ) } \mathrm { u } _ { 1 1 } ( \mathrm { z } _ { \mathrm { s } } ( \mathrm { f } ) ) \left(\alpha \int _ { \mathrm { t } } ^ { \mathrm { s } } \mathrm { e } ^ { - \alpha ( s - u ) } \mathrm { f } _ { \mathrm { u } } \left[\int_{\mathrm{t}}^{\mathrm{u}} \mathbf{D}_{\mathrm{t}}\left(\mu_{\mathrm{f}}(\mathrm{v})-1 / 2 \boldsymbol{\sigma}_{\mathrm{f}}(\mathrm{v}) \boldsymbol{\sigma}_{\mathrm{f}}(\mathrm{v})^{\prime}\right) \mathrm{dv}\right.\right.\right. \\
& \left.\left.\left.+\int_{\mathrm{t}}^{\mathrm{u}} \mathbf{D}_{\mathrm{t}} \boldsymbol{\sigma}_{\mathrm{f}}(\mathrm{v}) \mathrm{dW}_{\mathrm{v}}\right] \mathrm{du}\right) \mathrm{ds}\right],
\end{aligned}
$$

and the interest rate equals,

$$
r_{t}=\beta_{t}-\alpha H_{t}
$$

with, $\quad \mathrm{H}_{\mathrm{t}} \equiv\left(\alpha+\beta_{\mathrm{t}}\right) / \alpha-\left(\mathrm{y}^{*} \rho_{\mathrm{t}} \xi_{\mathrm{t}}\right)^{-1} \mathrm{u}_{1}\left(\mathrm{z}_{\mathrm{t}}(\mathrm{f})\right)$.

For this specification of preferences note that the coefficients of the CCAPM and of the interest rate process depend exclusively on the trajectories of future services, $\left\{z_{s}(f): s>t\right\}$. In particular, the interest rate does not depend directly on the moments of consumption growth. For this model it is difficult to compare the economies with and without the durable since the models are not nested. The effect of a change in the technology for production of services (parameter $\alpha$ ), however, can be assessed.

16 In production economies with endogenous consumption asset prices and the interest rate generally inherit the singular components of the optimal consumption policy (see Hindy and Huang (1993)). 


\subsection{The Cobb-Douglas Economy.}

We now provide more explicit results for the economy with Cobb-Douglas utility function, i.e. $\mathrm{u}\left(\mathrm{c}_{\mathrm{t}}, \mathrm{s}_{\mathrm{t}}+\mathrm{z}_{\mathrm{t}}\right)=\mathrm{c}_{\mathrm{t}}^{\mathrm{A}}\left(\mathrm{s}_{\mathrm{t}}+\mathrm{z}_{\mathrm{t}}\right)^{\mathrm{B}} ; \mathrm{A} \in(0,1), \mathrm{B} \in(0,1)$ and 1-A-B $>0$. For this preference specification demand functions become,

Proposition 4: Consider the Cobb-Douglas economy. Under the assumptions of Theorem 2 the demand functions are given by,

$$
\begin{gathered}
c_{t}=\left[\left(\rho_{t} \xi_{t}\right)^{-1} A^{1-B} N_{t}^{B} B^{B}\left(1 / y^{*}\right)\right]^{1 /(1-A-B)} \\
1_{t}=\left[\left(\rho_{t} \xi_{t}\right)^{-1} A^{A} N_{t}^{A-1} B^{1-A}\left(1 / y^{*}\right)\right]^{1 /(1-A-B)}-z_{t} .
\end{gathered}
$$

The associated services from past purchases of the durable are,

$$
\mathrm{z}_{\mathrm{t}}=\mathrm{z}_{0} \mathrm{e}^{-2 \alpha \mathrm{t}}+\alpha\left(\mathrm{y}^{*}\right)^{-1 /(1-\mathrm{A}-\mathrm{B})} \int_{0}^{\mathrm{t}} \mathrm{e}^{-2 \alpha(\mathrm{t}-\mathrm{s})}\left[\left(\rho_{\mathrm{s}} \xi_{\mathrm{s}}\right)^{-1} \mathrm{~A}^{\mathrm{A}} \mathrm{N}_{\mathrm{s}}^{\mathrm{A}-1} \mathrm{~B}^{1-\mathrm{A}}\right]^{1 /(1-\mathrm{A}-\mathrm{B})} \mathrm{ds}
$$

where $\mathrm{y}^{*}$ is the Lagrange multiplier solving the budget constraint (14),

$$
\left.y^{*}=x^{-(1-A-B)}\left\{E^{*}\left[\int_{0}^{T} b_{t}\left(\rho_{t} \xi_{t}\right)^{-1 /(1-A-B)} A^{A /(1-A-B)}\left(N_{t} / B\right)^{-B /(1-A-B)}(A+B)\right) d t\right]\right\}^{1-A-B} .
$$

Here $\mathrm{x} \equiv \mathrm{E}^{*}\left[\int_{0}^{\mathrm{T}} \mathrm{b}_{\mathrm{t}}\left(\mathrm{e}_{\mathrm{t}}+\mathrm{f}_{\mathrm{t}} \mathrm{p}_{\mathrm{t}}\right) \mathrm{dt}\right]+\mathrm{E}^{*}\left[\int_{0}^{\mathrm{T}} \mathrm{b}_{\mathrm{t}} \mathrm{p}_{\mathrm{t}} \mathrm{z}_{0} \mathrm{e}^{-2 \alpha \mathrm{t}} \mathrm{dt}\right]$ represents the date 0 market value of all the resources of the consumer including the value of the initial stock of the durable good; $\mathrm{N}_{\mathrm{t}} \equiv \mathrm{p}_{\mathrm{t}}-\alpha \mathrm{E}_{\mathrm{t}}^{*}\left[\int_{\mathrm{t}}^{\mathrm{T}} \mathrm{e}^{-2 \alpha(\mathrm{s}-\mathrm{t})}\left(\mathrm{b}_{\mathrm{s}} / \mathrm{b}_{\mathrm{t}}\right) \mathrm{p}_{\mathrm{s}} \mathrm{ds}\right]$ is the cost of status.

As in Theorem 2 we assume that the parameters of the economy are restricted so that purchases of the durable good are interior at all times. A necessary and sufficient condition for this is,

$$
\begin{gathered}
{\left[\left(\rho_{\mathrm{t}} \xi_{\mathrm{t}}\right)^{-1}\left(\mathrm{~N}_{\mathrm{t}}\right)^{\mathrm{A}-1}\right]^{1 /(1-\mathrm{A}-\mathrm{B})}>} \\
\mathrm{z}_{0} \mathrm{e}^{-2 \alpha \mathrm{t}}\left(\mathrm{y}^{*}\right)^{1 /(1-\mathrm{A}-\mathrm{B})}\left[\mathrm{A}^{-\mathrm{A}} \mathrm{B}^{\mathrm{A}-1}\right]^{1 /(1-\mathrm{A}-\mathrm{B})}+\alpha \int_{0}^{\mathrm{t}} \mathrm{e}^{-2 \alpha(\mathrm{t}-\mathrm{s})}\left[\left(\rho_{\mathrm{s}} \xi_{\mathrm{s}}\right)^{-1}\left(\mathrm{~N}_{\mathrm{s}}\right)^{\mathrm{A}-1}\right]^{1 /(1-\mathrm{A}-\mathrm{B})} \mathrm{ds}
\end{gathered}
$$

This condition imposes restrictions on the structure of the economy, in particular on the commodity price process.

For Cobb-Douglas utility we also remark that the cross-partial derivative $\mathrm{u}_{12}$ is positive. It follows that the demand functions are decreasing in both $\mathrm{y} \xi$ and $\mathrm{y} \gamma$. 
Comparison of equilibrium prices across economies yields in this case,

Proposition 5: Introduction of a multiattribute durable good in the Cobb-Douglas economy increases asset risk premia. The interest rate at date t also decreases (relative to the economy with perishable commodities) if and only if the rate of growth of the services provided by past durable purchases $\left(\mathrm{dz}_{\mathrm{t}}(\mathrm{f}) / \mathrm{z}_{\mathrm{t}}(\mathrm{f})\right)$ exceeds the expected rate of growth of the status attribute associated with current durable purchases $\mu_{\mathrm{f}}$.

With Cobb-Douglas utility, $\lambda_{1 \mathrm{t}}(\boldsymbol{\alpha}, \mathrm{e}, \mathrm{f})=\lambda_{1 \mathrm{t}}(0, \mathrm{e}, \mathrm{f})=1$-A and $\lambda_{2 \mathrm{t}}(\boldsymbol{\alpha}, \mathrm{e}, \mathrm{f})=$ $-\mathrm{B}\left(\mathrm{f}_{\mathrm{t}} /\left(\mathrm{s}_{\mathrm{t}}+\mathrm{z}_{\mathrm{t}}(\mathrm{f})\right)\right)>-\mathrm{B}=\lambda_{2 \mathrm{t}}(0, \mathrm{e}, \mathrm{f})$. It follows that assets which are positively correlated with aggregate purchases of the durable have higher risk premium when durability is present with a status component (see equation (38)).

At times when the rate of growth of services from past durable purchases exceeds the expected rate of growth of status production from current purchases,

$$
\alpha\left(\mathrm{f}_{\mathrm{t}}-\mathrm{z}_{\mathrm{t}}\right) / \mathrm{z}_{\mathrm{t}}>\mu_{\mathrm{f}}
$$

condition (39) is also satisfied ensuring a lower interest rate for the economy with the durable commodity.

This example shows that multiattribute durability may produce higher risk premia combined with lower rate of interest in economic periods in which conditions such as (44) hold. These implications are desirable since they may help to resolve discrepancies between theoretical models and empirical regularities. We reemphasize the fact that a key element behind these results is the possibility of spillover effects between the durable and perishable commodities (nonseparability of the utility function).

\section{An extension of the model.}

The model can be extended to more general preferences defined over attributes. Consider the following preference-attributes structure, 
Assumption 5: Preferences have the representation,

$$
\mathrm{U}(\mathrm{c}, \mathrm{s}, \mathrm{z}) \equiv \mathrm{E}\left[\int_{0}^{\mathrm{T}}\left(\rho_{\mathrm{t}}\right)^{-1} \mathrm{u}\left(\mathrm{c}_{\mathrm{t}}, \mathrm{s}_{\mathrm{t}}, \mathrm{z}_{\mathrm{t}}\right)\right] \mathrm{dt}
$$

where $\rho_{\mathrm{t}}=\exp \left[\int_{0}^{1} \beta_{\mathrm{v}} \mathrm{dv}\right], \beta$ is a bounded, $\Im_{(\cdot)}$-progressively measurable process, $\mathrm{u}(\cdot, \cdot$, is the instantaneous utility function, $\mathrm{s}_{\mathrm{t}}$ is the status level and $\mathrm{z}_{\mathrm{t}}$ represents services. The utility function, $\mathrm{u}(\cdot):,[0, \infty)^{3} \rightarrow(-\infty, \infty)$, is twice continuously differentiable, strictly increasing, strictly concave with respect to each argument and concave in $(\mathrm{c}, \mathrm{s}, \mathrm{z})$. It has the limiting values $\lim _{\mathrm{c} \backslash 0} \mathrm{u}_{1}(\mathrm{c}, \mathrm{s}, \mathrm{z})=\infty, \lim _{\mathrm{s} \downarrow} \mathrm{u}_{2}(\mathrm{c}, \mathrm{s}, \mathrm{z})=\infty, \lim _{\mathrm{z}\lrcorner 0} \mathrm{u}_{3}(\mathrm{c}, \mathrm{s}, \mathrm{z})=\infty$, $\lim _{\mathrm{c} 1 \omega} \mathrm{u}_{1}(\mathrm{c}, \mathrm{s}, \mathrm{z})=0, \lim _{\mathrm{s} 1 \omega} \mathrm{u}_{2}(\mathrm{c}, \mathrm{s}, \mathrm{z})=0, \lim _{\mathrm{z} 1 \omega} \mathrm{u}_{3}(\mathrm{c}, \mathrm{s}, \mathrm{z})=0$.

The utility functional (45) allows for imperfect substitutability between status and services. Attributes are related to purchases of the durable as follows,

Assumption 6: The technology for production of services is,

$$
\mathrm{z}_{\mathrm{t}}=\mathrm{z}_{0} \mathrm{e}^{-\alpha \mathrm{t}}+\alpha \int_{0}^{\mathrm{t}} \mathrm{e}^{-\alpha(\mathrm{t}-\mathrm{s})} 1_{\mathrm{s}} \mathrm{ds}, \mathrm{z}_{0} \geq 0 ; \mathrm{t} \in[0, \mathrm{~T}]
$$

where $\alpha$ and $\mathrm{z}_{0}$ are nonnegative constants and $\mathrm{l}_{\mathrm{s}} \geq 0$, represents purchases of the durable commodity at time $\mathrm{s}, \mathrm{s} \in[0, \mathrm{t})$. Initial services, $\mathrm{z}_{0}$, are produced from an inherited stock of the durable; $\alpha$ captures the relative weight of past durable purchases in the production of current services.

Assumption 7: Status is given by,

$$
\mathrm{s}_{\mathrm{t}}=\mathrm{g}\left(\mathrm{l}_{\mathrm{t}}, \mathrm{x}_{\mathrm{t}}\right)
$$

where $\mathrm{x}$ captures intertemporal effects in status creation. The variable $\mathrm{x}$ satisfies,

$$
\left.\mathrm{x}_{\mathrm{t}}=\mathrm{x}_{0} \mathrm{e}^{-\delta \mathrm{t}}+\delta \int_{0}^{\mathrm{t}} \mathrm{e}^{-\delta(t-s)}\right]_{\mathrm{s}} \mathrm{ds}, \mathrm{x}_{0} \geq 0 ; \mathrm{t} \in[0, \mathrm{~T}]
$$

where $\delta$ is a depreciation factor and $\mathrm{x}_{0}$ represents the contribution of the inherited stock of the durable. The status production function $\mathrm{g}(\cdot, \cdot):[0, \infty)^{2} \rightarrow(-\infty, \infty)$, is twice continuously differentiable, strictly increasing in each argument, strictly concave 
with respect to each argument and concave in $(1, \mathrm{x})$. Denoting the partial derivatives of $\mathrm{g}(1, \mathrm{x})$ by $\mathrm{g}_{\mathrm{i}}(1, \mathrm{x}), \mathrm{i}=1,2$, we assume $\lim _{100} \mathrm{~g}_{1}(1, \mathrm{x})=\infty$.

The status production function (47)-(48) is quite general. This formulation allows for persistence in the symbolic function performed by the durable. The marginal product at date $\mathrm{v}$ of a purchase of the durable at date $\mathrm{t}, \mathrm{v}>\mathrm{t}$, equals $\mathrm{g}_{2}\left(1_{v}, \mathrm{X}_{\mathrm{v}}\right) \delta \mathrm{e}^{-\delta(\mathrm{v}-\mathrm{t})}$. The strength of this effect is controlled by the weighing parameter $\delta$ and by the size of the derivative $g_{2}$. The model of sections $2-5$ with transitory and linear status effects is obtained by setting $\mathrm{g}_{1}=1$ and $\mathrm{g}_{2}=0$. The formulation (47) also enables us to model decreasing returns to scale in status.

Suppose that the other components of the economy (endowments, asset structure, etc,...) are as in section 2.

The demand functions corresponding to this preference structure are analyzed in Appendix C. In particular we show that conditions on the exogenous parameters and processes of the economy which are similar to the condition $\mathrm{N}_{\mathrm{t}}>0$ in Theorem 2 ensure that the demands are well behaved (see Theorems 9 and 10). For this model of preferences and attributes equilibrium is,

Theorem 5: Consider the economy described in section 2 with Assumptions 5, 6 and 7. Also suppose that,

$$
\lambda_{\mathrm{t}} \equiv-\mathrm{u}_{1}\left(\mathrm{e}_{\mathrm{t}}, \mathrm{s}_{\mathrm{t}}, \mathrm{z}_{\mathrm{t}}(\mathrm{f})\right)^{-1}\left[\mathrm{u}_{11}\left(\mathrm{e}_{\mathrm{t}}, \mathrm{s}_{\mathrm{t}}, \mathrm{z}_{\mathrm{t}}(\mathrm{f})\right) \mathrm{e}_{\mathrm{t}} \boldsymbol{\sigma}_{\mathrm{e}}{ }^{\prime}+\mathrm{u}_{12}\left(\mathrm{e}_{\mathrm{t}}, \mathrm{s}_{\mathrm{t}}, \mathrm{z}_{\mathrm{t}}(\mathrm{f})\right) \mathrm{g}_{1}\left(\mathrm{f}_{\mathrm{t}}, \mathrm{x}_{\mathrm{t}}\right) \mathrm{f}_{\mathrm{t}} \sigma_{\mathrm{f}}{ }^{\prime}\right],
$$

satisfies the condition,

$$
\operatorname{Eexp}\left[(1 / 2) \int_{0}^{\mathrm{T}}\left\|\lambda_{\mathrm{t}}\right\|^{2} \mathrm{dt}\right]<\infty .
$$

In equilibrium aggregate consumption of perishable and purchases of durable goods are, respectively, $\mathrm{c}_{\mathrm{t}}^{*}=\mathrm{e}_{\mathrm{t}}$ and $\mathrm{l}_{\mathrm{t}}^{*}=\mathrm{f}_{\mathrm{t}}$. The status achieved is,

$$
s_{t}=g\left(f_{t}, x_{t}(f)\right)
$$

where,

$$
x_{t}(f)=x_{0} e^{-\delta t}+\delta \int_{0}^{t} e^{-\delta(t-s)} f_{s} d s, t \in[0, T]
$$


Services provided by past purchases of the durable commodity are,

$$
\mathrm{z}_{\mathrm{t}}(\mathrm{f})=\mathrm{z}_{0} \mathrm{e}^{-\alpha \mathrm{t}}+\alpha \int_{0}^{\mathrm{t}} \mathrm{e}^{-\alpha(\mathrm{t}-\mathrm{s})} \mathrm{f}_{\mathrm{s}} \mathrm{ds}, \mathrm{t} \in[0, \mathrm{~T}],
$$

Equilibrium Arrow-Debreu ( $\xi$ ) and commodity (p) prices are equal to,

$$
\begin{gathered}
\xi_{\mathrm{t}}^{*}=\rho_{\mathrm{t}}^{-1} \mathrm{u}_{1}\left(\mathrm{e}_{\mathrm{t}}, \mathrm{s}_{\mathrm{t}}, \mathrm{z}_{\mathrm{t}}(\mathrm{f})\right) / \mathrm{u}_{1}\left(\mathrm{e}_{0}, \mathrm{~s}_{0}, \mathrm{z}_{0}\right) \\
\mathrm{p}_{\mathrm{t}}=\mathrm{u}_{1}\left(\mathrm{e}_{\mathrm{t}} \mathrm{s}_{\mathrm{t}}, \mathrm{z}_{\mathrm{t}}(\mathrm{f})\right)^{-1}\left\{\mathrm{u}_{2}\left(\mathrm{e}_{\mathrm{t}}, \mathrm{s}_{\mathrm{t}}, \mathrm{z}_{\mathrm{t}}(\mathrm{f})\right) \mathrm{g}_{1}\left(\mathrm{f}_{\mathrm{t}}, \mathrm{x}_{\mathrm{t}}(\mathrm{f})\right)+\alpha \mathrm{E}_{\mathrm{t}}\left[\int_{\mathrm{t}}^{\mathrm{T}} \rho_{\mathrm{s}, \mathrm{t}} \mathrm{e}^{-\alpha(\mathrm{s}-\mathrm{t})} \mathrm{u}_{2}\left(\mathrm{e}_{\mathrm{s}}, \mathrm{s}_{\mathrm{s}}, \mathrm{z}_{\mathrm{s}}(\mathrm{f})\right) \mathrm{g}_{2}\left(\mathrm{f}_{\mathrm{s}}, \mathrm{x}_{\mathrm{s}}(\mathrm{f})\right) \mathrm{ds}\right]\right. \\
\left.+\delta \mathrm{E}_{\mathrm{t}}\left[\int_{\mathrm{t}}^{\mathrm{T}} \rho_{\mathrm{s}, \mathrm{t}} \mathrm{e}^{-\alpha(\mathrm{s}-\mathrm{t})} \mathrm{u}_{3}\left(\mathrm{e}_{\mathrm{s}}, \mathrm{s}_{\mathrm{s}}, \mathrm{z}_{\mathrm{s}}(\mathrm{f})\right) \mathrm{ds}\right]\right\}
\end{gathered}
$$

Finally, the equilibrium rate of interest and asset premia are respectively given by,

$$
\begin{gathered}
\mathrm{r}_{\mathrm{t}}^{*}=\beta_{\mathrm{t}}-\mathrm{u}_{1}^{-1}\left\{\mathrm{u}_{11} \mathrm{e}_{\mathrm{t}} \mu_{\mathrm{e}}(\mathrm{t})+\mathrm{u}_{12}\left[\mathrm{~g}_{1} \mathrm{f}_{\mathrm{t}} \mathrm{u}_{\mathrm{f}}(\mathrm{t})+\mathrm{g}_{2} \delta\left(\mathrm{f}_{\mathrm{t}}-\mathrm{x}_{\mathrm{t}}(\mathrm{f})\right)\right]+\mathrm{u}_{13} \alpha\left(\mathrm{f}_{\mathrm{t}}-\mathrm{z}_{\mathrm{t}}(\mathrm{f})\right)\right] \\
\left.+1 / 2 \mathrm{u}_{111} \mathrm{e}_{\mathrm{t}} \sigma_{\mathrm{e}} \sigma_{\mathrm{e}} \mathrm{e}_{\mathrm{t}}+\mathrm{u}_{112} \mathrm{~g}_{1} \mathrm{e}_{\mathrm{t}} \sigma_{\mathrm{e}} \sigma_{\mathrm{f}} \mathrm{f}_{\mathrm{t}}+1 / 2 \mathrm{u}_{122}\left(\mathrm{~g}_{2}\right)^{2} \mathrm{f}_{\mathrm{t}} \sigma_{\mathrm{f}} \sigma_{\mathrm{f}} \mathrm{f}_{\mathrm{t}}\right\}, \\
\mu_{\mathrm{t}}-\mathrm{r}_{\mathrm{t}} \mathbf{1}=-\mathrm{u}_{1}^{-1}\left[\mathrm{u}_{11} \sigma_{\mathrm{t}} \mathrm{e}_{\mathrm{t}} \sigma_{\mathrm{e}}{ }^{\prime}+\mathrm{u}_{12} \mathrm{~g}_{1} \sigma_{\mathrm{t}} \mathrm{f}_{\mathrm{t}} \sigma_{\mathrm{f}}{ }^{\prime}\right],
\end{gathered}
$$

where the derivatives of the utility function appearing in (56), (57) are evaluated at $\left(\mathrm{e}_{\mathrm{t}}, \mathrm{s}_{\mathrm{t}}, \mathrm{z}_{\mathrm{t}}(\mathrm{f})\right)$ and the derivatives of the status function are evaluated at $\left(\mathrm{f}_{\mathrm{t}}, \mathrm{x}_{\mathrm{t}}(\mathrm{f})\right)$. Equilibrium allocations are supported by the no-trade strategy $\pi_{\mathrm{t}}^{*}=0$; equilibrium wealth is $\mathrm{X}_{\mathrm{t}}^{*}=0$.

Condition (50) ensures that the equivalent martingale measure is well defined in equilibrium. The relationships (54)-(57) characterize the structure of equilibrium for the general preference-attribute model of assumptions 5-7. As in section 5 comparisons of equilibria across different economies can be performed. In particular, conditions similar to (38), (39) will identify time periods in which the interest rate is reduced while asset risk premia are increased when a multiattribute durable good is available in place of a perishable commodity. 
Appendix A: proofs.

This appendix provides the proofs for the results in the body of the paper.

Theorem 6: The policy $(\mathrm{c}, \mathrm{l})$ is optimal for the static problem if and only if $(\mathrm{c}, \mathrm{l}, \mathrm{y})$ satisfies,

$$
\begin{gathered}
\mathrm{u}_{1}\left(\mathrm{c}_{\mathrm{t}}, \mathrm{l}_{\mathrm{t}}+\mathrm{z}_{\mathrm{t}}\right)=\mathrm{y} \rho_{\mathrm{t}} \xi_{\mathrm{t}}, \\
\mathrm{u}_{2}\left(\mathrm{c}_{\mathrm{t}}, \mathrm{l}_{\mathrm{t}}+\mathrm{z}_{\mathrm{s}}\right)+\alpha \mathrm{E}_{\mathrm{t}}\left[\int_{\mathrm{t}}^{\mathrm{T}} \rho_{\mathrm{s}, \mathrm{t}} \mathrm{e}^{-\alpha(\mathrm{s}-\mathrm{t})} \mathrm{u}_{2}\left(\mathrm{c}_{\mathrm{s}}, 1_{\mathrm{s}}+\mathrm{z}_{\mathrm{s}}\right) \mathrm{ds}\right] \leq \mathrm{y} \rho_{\mathrm{t}} \xi_{\mathrm{t}} \mathrm{p}_{\mathrm{t}} ;=\text { if } 1>0, \\
\mathrm{c}_{\mathrm{t}} \geq 0,1_{\mathrm{t}} \geq 0, \mathrm{t} \in[0, \mathrm{~T}] ; \mathrm{y}>0, \\
\mathrm{E}^{*}\left[\int_{0}^{\mathrm{T}} \mathrm{b}_{\mathrm{t}}\left(\mathrm{c}_{\mathrm{t}}+\mathrm{l}_{\mathrm{t}} \mathrm{p}_{\mathrm{t}}\right) \mathrm{dt}\right] \leq \mathrm{E}^{*}\left[\int_{0}^{\mathrm{T}} \mathrm{b}_{\mathrm{t}}\left(\mathrm{e}_{\mathrm{t}}+\mathrm{f}_{\mathrm{t}} \mathrm{p}_{\mathrm{t}}\right) \mathrm{dt}\right] .
\end{gathered}
$$

\section{Proof of Theorem 6:}

(i) necessity: the utility gradient implied by the preference structure (1)-(2) has components given by the left hand sides of (A.1) and (A.2) (see Detemple and Zapatero (1992) and Duffie and Skiadas (1992)). The conditions (A.1)-(A.4) are then standard Karush-Kuhn-Tucker conditions (Saddle Point Theorem).

(ii) sufficiency: consider an alternative budget feasible policy $\left(\mathrm{c}^{\mathrm{o}}, 1^{\circ}\right)$. Defining the process $h_{t}(1) \equiv l_{t}+z_{t}(1)$ we have by concavity of the utility function,

$$
\mathrm{u}\left(\mathrm{c}_{\mathrm{t}}, \mathrm{h}_{\mathrm{t}}(1)\right) \geq \mathrm{u}\left(\mathrm{c}_{\mathrm{t}}^{\mathrm{o}}, \mathrm{h}_{\mathrm{t}}\left(1^{\circ}\right)\right)+\mathrm{u}_{1}\left(\mathrm{c}_{\mathrm{t}}, \mathrm{h}_{\mathrm{t}}(1)\right)\left(\mathrm{c}_{\mathrm{t}}-\mathrm{c}_{\mathrm{t}}^{\mathrm{o}}\right)+\mathrm{u}_{2}\left(\mathrm{c}_{\mathrm{t}}, \mathrm{h}_{\mathrm{t}}(1)\right)\left(\mathrm{h}_{\mathrm{t}}(1)-\left(\mathrm{h}_{\mathrm{t}}\left(\mathrm{l}^{\circ}\right)\right) .\right.
$$

Multiplying both sides by $\rho_{\mathrm{t}}^{-1}$ and integrating over the product measure dPxdt yields,

$$
\begin{array}{r}
\mathrm{E}\left[\int_{0}^{\mathrm{T}} \rho_{\mathrm{t}}^{-1} \mathrm{u}\left(\mathrm{c}_{\mathrm{t}}, \mathrm{h}_{\mathrm{t}}(1)\right) \mathrm{dt}\right] \geq \mathrm{E} \int_{0}^{\mathrm{T}} \rho_{\mathrm{t}}^{-1}\left[\mathrm{u}\left(\mathrm{c}_{\mathrm{t}}^{\mathrm{o}} \mathrm{h}_{\mathrm{t}}\left(1^{\circ}\right)\right)+\mathrm{u}_{1}\left(\mathrm{c}_{\mathrm{t}}, \mathrm{h}_{\mathrm{t}}(1)\right)\left(\mathrm{c}_{\mathrm{t}}-\mathrm{c}_{\mathrm{t}}^{\mathrm{o}}\right)\right. \\
+\mathrm{u}_{2}\left(\mathrm{c}_{\mathrm{t}}, \mathrm{h}_{\mathrm{t}}(1)\right)\left(\mathrm{h}_{\mathrm{t}}(1)-\left(\mathrm{h}_{\mathrm{t}}\left(1^{\circ}\right)\right)\right] \mathrm{dt}
\end{array}
$$

It is enough to show that the sum of the last two terms on the right hand side of the inequality above is nonnegative. Since $\mathrm{z}_{\mathrm{t}}(1)-\mathrm{z}_{\mathrm{t}}\left(1^{0}\right)=\alpha \int_{0}^{\mathrm{t}} \mathrm{e}^{-\alpha(\mathrm{t}-\mathrm{s})}\left(1_{\mathrm{s}}-1_{\mathrm{s}}^{0}\right) \mathrm{ds}$ we have,

$$
\begin{aligned}
& E \int_{0}^{\mathrm{T}} \rho_{t}^{-1} u_{2}\left(c_{t}, h_{t}(1)\right)\left[h_{t}(l)-\left(h_{t}\left(1^{0}\right)\right] d t\right. \\
& =\mathrm{E} \int_{0}^{\mathrm{T}} \rho_{\mathrm{t}}^{-1} \mathrm{u}_{2}\left(\mathrm{c}_{\mathrm{t}}, \mathrm{h}_{\mathrm{t}}(1)\right)\left[\mathrm{l}_{\mathrm{t}}-1_{\mathrm{t}}^{\mathrm{o}}+\alpha \int_{0}^{\mathrm{t}} \mathrm{e}^{-\alpha(\mathrm{t}-\mathrm{s})}\left(1_{\mathrm{s}}-1_{\mathrm{s}}^{\mathrm{o}}\right) \mathrm{ds}\right] \mathrm{dt} \\
& =E\left[\int_{0}^{\mathrm{T}} \rho_{\mathrm{t}}^{-1} \mathrm{u}_{2}\left(\mathrm{c}_{\mathrm{t}}, \mathrm{h}_{\mathrm{t}}(1)\right)\left(\mathrm{l}_{\mathrm{t}}-1_{\mathrm{t}}^{\mathrm{o}}\right) \mathrm{dt}\right]+\mathrm{E}\left[\int_{0}^{\mathrm{T}} \int_{\mathrm{t}}^{\mathrm{T}} \rho_{\mathrm{s}}^{-1} \mathrm{u}_{2}\left(\mathrm{c}_{\mathrm{s}}, \mathrm{h}_{\mathrm{s}}(1)\right) \alpha \mathrm{e}^{-\alpha(s-t)}\left(1_{\mathrm{t}}-1_{\mathrm{t}}^{\mathrm{o}}\right) \mathrm{dsdt}\right] \\
& =E \int_{0}^{\mathrm{T}}\left(\mathrm{l}_{\mathrm{t}}-\mathrm{l}_{\mathrm{t}}^{\mathrm{o}}\right)\left[\rho_{\mathrm{t}}^{-1} \mathrm{u}_{2}\left(\mathrm{c}_{\mathrm{t}}, \mathrm{h}_{\mathrm{t}}(\mathrm{l})\right)+\alpha \int_{\mathrm{t}}^{\mathrm{T}} \rho_{\mathrm{s}}^{-1} \mathrm{u}_{2}\left(\mathrm{c}_{\mathrm{s}}, \mathrm{h}_{\mathrm{s}}(\mathrm{l})\right) \mathrm{e}^{-\alpha(\mathrm{s}-\mathrm{t})} \mathrm{ds}\right] \mathrm{dt} \\
& \geq \mathrm{E} \int_{0}^{\mathrm{T}}\left(\mathrm{l}_{\mathrm{t}}-1_{\mathrm{t}}^{\mathrm{o}}\right) \mathrm{y} \xi_{\mathrm{t}} \mathrm{p}_{\mathrm{t}} \mathrm{dt} \text {. }
\end{aligned}
$$


The inequality in the last step of (A.6) follows since (A.1)-(A.3) implies,

$$
1_{\mathrm{t}}\left[\rho_{\mathrm{t}}^{-1} \mathrm{u}_{2}\left(\mathrm{c}_{\mathrm{t}}, 1_{\mathrm{t}}+\mathrm{z}_{\mathrm{t}}\right)+\alpha \mathrm{E}_{\mathrm{t}}\left[\int_{\mathrm{t}}^{\mathrm{T}} \rho_{\mathrm{s}}^{-1} \mathrm{e}^{-\alpha(s-t)} \mathrm{u}_{2}\left(\mathrm{c}_{\mathrm{s}}, 1_{\mathrm{s}}+\mathrm{z}_{\mathrm{s}}\right) \mathrm{ds}\right]\right]=1_{\mathrm{t}} \mathrm{y} \xi_{\mathrm{t}} \mathrm{p}_{\mathrm{t}}
$$

while admissibility of $\left(\mathrm{c}^{\mathrm{o}}, \mathrm{l}^{\circ}\right)$ in combination with (A.2) implies,

$$
--_{t}^{0}\left[\rho_{t}^{-1} u_{2}\left(c_{t}, l_{t}+z_{t}\right)+\alpha E_{t}\left[\int_{t}^{T} \rho_{s}^{-1} e^{-\alpha(s-t)} u_{2}\left(c_{s}, 1_{s}+z_{s}\right) d s\right]\right] \geq-1_{t}^{0} y \xi_{t} p_{t} .
$$

Hence, substituting (A.1) and (A.6) in (A.5) yields,

$$
E\left[\int_{0}^{T} \rho_{t}^{-1} u\left(c_{t}, h_{t}(1)\right) d t\right] \geq E\left[\int_{0}^{T} \rho_{t}^{-1} u\left(c_{t}^{o}, h_{t}\left(1^{0}\right)\right) d t\right]+y E \int_{0}^{T}\left[\left(c_{t}-c_{t}^{o}\right)+\left(l_{t}-1_{t}^{0}\right) p_{t}\right] \xi_{t} d t .
$$

By the budget constraint (A.4) and the condition $y>0$ the last term is nonnegative.

Optimality of (c,l) follows.

Proof of Theorem 1: We assume that (16) has a solution. ${ }^{17}$ The demand functions stated in the theorem are then obtained by construction.

Proof of Theorem 2: The solution (25) to the recursive equation is computed using the procedure outlined in appendix $\mathrm{C}$ and passing to the Q-measure. To prove the theorem we show (i) existence of $y^{*}>0$, (ii) uniqueness of $y^{*}$ and (iii) admissibility of the policies $\left(c^{*}, l^{*}\right)$.

(i) Existence of $y^{*}$ : Since the inverse marginal utility $\mathrm{I}(., \mathrm{s}):[0, \infty) \rightarrow[0, \infty)$ satisfies $\mathrm{u}_{1}(\mathrm{I}(\mathrm{y} \rho \xi, \mathrm{s}), \mathrm{s})=\mathrm{y} \rho \xi$ we have $\mathrm{I}_{1}=\left(\mathrm{u}_{11}\right)^{-1}$ and $\mathrm{I}_{2}=-\left(\mathrm{u}_{12} / \mathrm{u}_{11}\right)$. Assumption 1 then implies that I $(\cdot$,$) is continuously differentiable and strictly decreasing in its first argument with$ limiting values $\mathrm{I}\left(0^{+}, \mathrm{s}\right)=+\infty$ and $\mathrm{I}(\infty, \mathrm{s})=0$, for all $\mathrm{s} \in \Re^{+}$. The inverse function $\mathrm{H}(\cdot, \cdot)$ : $[0, \infty) \times[0, \infty) \rightarrow[0, \infty)$ is also continuously differentiable and satisfies $\mathrm{u}_{2}(\mathrm{I}(\mathrm{y} \rho \xi, \mathrm{H}(\mathrm{y} \rho \xi, \mathrm{y} \gamma)), \mathrm{H}(\mathrm{y} \xi, \mathrm{y} \gamma))=\mathrm{y} \gamma$. It has limiting values $0 \leq \mathrm{H}\left(0^{+}, 0^{+}\right)<\infty$ and $\mathrm{H}(\infty, \infty)=0$ (assumption 1 (ii)-(iii)); also $\mathrm{I}(\infty, \mathrm{H}(\infty, \infty))=0$ (assumption 1 (iv)).

17 Conditions for existence of a solution to this nonlinear recursive equation involve functional Lipschitz and integrability conditions on the integrand which appears on the right hand side of (16) (Detemple and Zapatero (1992), Antonelli (1993)). 
Hence the map $\chi(y)$ is continuous and satisfies,

$$
\begin{gathered}
\chi(\infty) \equiv \lim _{\mathrm{y} 1 \propto \infty} \chi(\mathrm{y})=-\mathrm{E}^{*}\left[\int_{0}^{\mathrm{T}} \mathrm{b}_{\mathrm{t}} \mathrm{z}_{0} \mathrm{p}_{\mathrm{t}} \mathrm{e}^{-2 \alpha \mathrm{t}} \mathrm{dt}\right]<0 . \\
\chi\left(0^{+}\right)=\lim _{\mathrm{y} \downarrow 0} \chi(\mathrm{y})=+\infty .
\end{gathered}
$$

The existence of $\mathrm{y}^{*}>0$ such that $\chi\left(\mathrm{y}^{*}\right)=0$ follows.

(ii) Uniqueness of $\mathrm{y}^{*}$ : Note that $\chi(\mathrm{y})$ can be rewritten as follows,

$$
\begin{aligned}
& \chi(\mathrm{y}) \equiv \mathrm{E}^{*} \int_{0}^{\mathrm{T}} \mathrm{b}_{\mathrm{t}}\left[\mathrm{I}\left(\mathrm{y} \rho_{\mathrm{t}} \xi_{\mathrm{t}}, \mathrm{H}\left(\mathrm{y} \rho_{\mathrm{t}} \xi_{\mathrm{t}}, \mathrm{y} \gamma_{\mathrm{t}}\right)\right)-\mathrm{p}_{\mathrm{t}} \mathrm{z}_{0} \mathrm{e}^{-2 \alpha \mathrm{t}}+\mathrm{H}\left(\mathrm{y} \rho_{\mathrm{t}} \xi_{\mathrm{t}}, \mathrm{y} \gamma_{\mathrm{t}}\right)\right. \\
&\left.\left\{\mathrm{p}_{\mathrm{t}}-\alpha \int_{\mathrm{t}}^{\mathrm{T}} \mathrm{e}^{-2 \alpha(\mathrm{s}-\mathrm{t})}\left(\mathrm{b}_{\mathrm{s}} / \mathrm{b}_{\mathrm{t}}\right) \mathrm{p}_{\mathrm{s}} \mathrm{ds}\right\}\right] \mathrm{dt} . \\
&=\mathrm{E}^{*} \int_{0}^{\mathrm{T}} \mathrm{b}_{\mathrm{t}}\left[\mathrm{I}\left(\mathrm{y} \rho_{\mathrm{t}} \xi_{\mathrm{t}}, \mathrm{H}\left(\mathrm{y} \rho_{\mathrm{t}} \xi_{\mathrm{t}}, \mathrm{y} \gamma_{\mathrm{t}}\right)\right)-\mathrm{p}_{\mathrm{t}} \mathrm{z}_{0} \mathrm{e}^{-2 \alpha t}+\mathrm{H}\left(\mathrm{y} \rho_{\mathrm{t}} \xi_{\mathrm{t}} \mathrm{y} \gamma_{\mathrm{t}}\right) \mathrm{N}_{\mathrm{t}}\right] \mathrm{dt} .
\end{aligned}
$$

where $\mathrm{N}_{\mathrm{t}} \equiv \mathrm{p}_{\mathrm{t}}-\alpha \mathrm{E}_{\mathrm{t}}^{*}\left[\int_{\mathrm{t}}^{\mathrm{T}} \mathrm{e}^{-2 \alpha(\mathrm{s}-\mathrm{t})}\left(\mathrm{b}_{\mathrm{s}} / \mathrm{b}_{\mathrm{t}}\right) \mathrm{p}_{\mathrm{s}} \mathrm{ds}\right]$ is positive by assumption.

Using the definition of $\mathrm{H}$ and differentiating leads to,

$$
\begin{gathered}
\mathrm{u}_{21}\left(\mathrm{I}_{1}+\mathrm{I}_{2} \mathrm{H}_{1}\right)+\mathrm{u}_{22} \mathrm{H}_{1}=0 \\
\mathrm{u}_{21} \mathrm{I}_{2} \mathrm{H}_{2}+\mathrm{u}_{22} \mathrm{H}_{2}=1
\end{gathered}
$$

so that $\mathrm{H}_{1}=-\left(\mathrm{u}_{21} / \mathrm{u}_{11}\right)\left[\mathrm{u}_{22}-\left(\mathrm{u}_{21}\right)^{2} / \mathrm{u}_{11}\right]^{-1}$ (ambiguous sign depending on -sgn $\left(\mathrm{u}_{12}\right)$ ) and $\mathrm{H}_{2}=\left[\mathrm{u}_{22}-\left(\mathrm{u}_{21}\right)^{2} / \mathrm{u}_{11}\right]^{-1}<0$. Hence, $\mathrm{H}\left(\mathrm{y} \rho_{\mathrm{t}} \xi_{\mathrm{t}}, \mathrm{y} \gamma_{\mathrm{t}}\right)$ is decreasing in $\mathrm{y}$ if $\mathrm{u}_{12}>0$. Also $\partial \mathrm{I}\left(\mathrm{y} \rho_{\mathrm{t}} \xi_{\mathrm{t}}, \mathrm{H}\left(\mathrm{y} \rho_{\mathrm{t}} \xi_{\mathrm{t}}, \mathrm{y} \gamma_{\mathrm{t}}\right)\right) / \partial \mathrm{y}=\left[\mathrm{I}_{1}+\mathrm{I}_{2} \mathrm{H}_{1}\right] \rho_{\mathrm{t}} \xi_{\mathrm{t}}+\mathrm{I}_{2} \mathrm{H}_{2} \gamma_{\mathrm{t}}$ has negative sign if $\mathrm{u}_{12} \geq 0$. It follows that under the conditions of the Theorem the map $\chi(y)$ is strictly decreasing in $y$ and the fixed point $\mathrm{y}^{*}$ is unique.

(iii) Admissibility of $\left(\mathrm{c}^{*}, 1^{*}\right)$ : The processes $\mathrm{c}\left(\mathrm{y}^{*}\right)$ and $1\left(\mathrm{y}^{*}\right)$ are nonnegative and progressively measurable. The budget constraint (A.4) is satisfied by construction. This completes the proof of Theorem 2 .

Corollary 1: Suppose that the demand for the durable good is interior (1>0). Then, the demand for the perishable good is decreasing in $\mathrm{y} \xi$, decreasing (increasing) in $\mathrm{y} \gamma$ if $\mathrm{u}_{12}>0\left(\mathrm{u}_{12}<0\right)$ and independent of $\mathrm{z}$. The demand for the durable is decreasing in $\mathrm{y} \gamma$ and decreasing (increasing) in $\mathrm{y} \xi$ if $\mathrm{u}_{12}$ is positive (negative); it is also decreasing in the level of services from past purchases $\mathrm{z}$. 
Proof of Corollary 1: We have, $\partial \mathrm{c}_{\mathrm{t}}^{*} / \partial\left(\mathrm{y}^{*} \rho_{\mathrm{t}}\right)=\left(\mathrm{I}_{1}+\mathrm{I}_{2} \mathrm{H}_{1}\right) \rho_{\mathrm{t}}<0, \partial \mathrm{c}_{\mathrm{t}}^{*} / \partial\left(\mathrm{y} \gamma_{\mathrm{t}}\right)=\mathrm{I}_{2} \mathrm{H}_{2} \mathrm{y}^{*}<$ $0(>0)$ if and only if $\mathrm{I}_{2}>0(<0)$. Also, $\partial \mathrm{l}_{\mathrm{t}}^{*} / \partial\left(\mathrm{y}^{*} \rho_{\mathrm{t}}\right)=\mathrm{H}_{1} \rho_{\mathrm{t}}<0(>0)$ if and only if $\mathrm{H}_{1}<0$ $(>0)$ and $\partial \mathrm{l}_{\mathrm{t}}^{*} / \partial\left(\mathrm{y}^{*} \gamma_{\mathrm{t}}\right)=\mathrm{H}_{2}<0$

Corollary 2: Consider the economy with two perishable commodities (i.e. $\alpha=0$, $\mathrm{z}_{0}=0$ ). If the two commodities are substitutes (complements) then the demand $\mathrm{c}^{*}$ decreases (increases) when durability is introduced locally (in a neighborhood of $\alpha=0)$ in the economy. If the second commodity is a normal good local introduction of durability increases the demand $1^{*}$ for the second commodity.

Proof of Corollary 2: In a neighborhood of $\alpha=0$ we have, $\partial \gamma_{\mathrm{t}} / \partial \alpha=-\left(\rho_{\mathrm{t}} \xi_{\mathrm{t}}\right) \mathrm{E}_{\mathrm{t}}^{*}\left[\int_{\mathrm{t}}^{\mathrm{T}} \mathrm{e}^{-2 \alpha(\mathrm{s}-}\right.$ $\left.{ }^{t} b_{t, s} p_{s} d s\right]$. Substitutability (complementarity) implies $\partial c_{t}^{*} / \partial \gamma_{t}>0(<0)$ in the economy with $\alpha=0$. The result follows since demand functions are continuous in $\alpha$ over the appropriate range, in particular in neighborhoods of $\alpha=0$.

Proof of Theorem 3: At equilibrium the representative agent consumes his endowments: $c_{t}^{*}=e_{t}$ and $l_{t}^{*}=f_{t}$. The index $z(f)$ is then uniquely defined by (31). Equilibrium Arrow-Debreu prices and the price of the durable commodity are obtained by substituting allocations in the optimality conditions (11)-(12).

To compute asset risk premia apply Ito's lemma to both sides of (32). The derivative of the left hand side is,

$$
\mathrm{d} \xi_{\mathrm{t}}^{*}=-\xi_{\mathrm{t}}^{*} \mathrm{r}_{\mathrm{t}}^{*} \mathrm{dt}-\xi_{\mathrm{t}}^{*} \theta_{\mathrm{t}} \mathrm{dW}
$$

while the derivative of the right hand side equals,

$$
\begin{gathered}
\left(y^{*} \rho_{t}\right)^{-1}\left[-\beta_{t} d t+u_{11} d e_{t}+1 / 2 u_{111} e_{t} \sigma_{e} \sigma_{e}{ }^{\prime} e_{t} d t+u_{112} e_{t} \sigma_{e} \sigma_{f} f_{t} d t+1 / 2 u_{122} f_{t} \sigma_{f} \sigma_{f} f_{t} d t+\right. \\
\left.u_{12} d h(f)\right]
\end{gathered}
$$


where all derivatives are evaluated at the equilibrium allocations e and $h(f)=$ $\mathrm{f}+\mathrm{z}(\mathrm{f})$. Substituting the processes specified in assumption 4 and equating terms in $\mathrm{dt}$ on the one hand and terms in $\mathrm{dW}_{\mathrm{t}}$ on the other hand yields formulas (34) and (35). 


\section{Appendix B: the valuation of productive assets.}

This appendix complements sections $4-5$ by providing valuation formulas for the two productive technologies which generate, respectively, the flows e and $f$ of the perishable and durable goods. These prices represent the values of the firms (or of their equity under all equity financing) producing the two commodities. Particular care is taken to endogeneize the volatility coefficients of these values.

Let $\mathrm{V}_{1}$ and $\mathrm{V}_{2}$ denote the respective market values of the two firms. To simplify notation we write $\mathrm{u}_{\mathrm{i}}(\mathrm{t})$ and $\mathrm{u}_{\mathrm{ij}}(\mathrm{t}), \mathrm{i}, \mathrm{j}=1,2$, for the first and second partial derivatives evaluated of the utility function evaluated at $\left(e_{t}, s_{t}+z_{t}(f)\right)$. Our next Theorem describes the structure of the firms' values.

Theorem 7: Consider the economy described in section 2 and suppose that assumptions 1, 2 and 4 hold. The values of the firms are, respectively, given by,

$$
\begin{gathered}
\mathrm{V}_{1 \mathrm{t}}=\mathrm{E}_{\mathrm{t}}^{*}\left[\int_{\mathrm{t}}^{\mathrm{T}} \mathrm{b}_{\mathrm{t}, \mathrm{s}} \mathrm{e}_{\mathrm{s}} \mathrm{ds}\right] \\
\mathrm{V}_{2 \mathrm{t}}=\mathrm{E}_{\mathrm{t}}^{*}\left[\int_{\mathrm{t}}^{\mathrm{T}} \mathrm{b}_{\mathrm{t}, \mathrm{s}} \mathrm{p}_{\mathrm{s}} \mathrm{f}_{\mathrm{s}} \mathrm{ds} \mid \mathfrak{\Im}_{\mathrm{t}}\right],
\end{gathered}
$$

where $\mathrm{E}^{*}$ is the expectation relative to the measure $\mathrm{dQ} \equiv\left(\mathrm{b}_{\mathrm{T}}\right)^{-1} \xi_{\mathrm{T}}^{*} \mathrm{dP}$ and $\xi_{\mathrm{T}}^{*}$ and $\mathrm{r}_{\mathrm{t}}^{*}$ are respectively given by (32) and (34). The volatility coefficients associated with these values are,

$$
\begin{gathered}
\mathrm{V}_{1 \mathrm{t}} \sigma_{1 \mathrm{t}}=\mathrm{u}_{1}(\mathrm{t})^{-1}\left[\rho_{\mathrm{t}} \mathrm{E}_{\mathrm{t}}\left[\mathbf{D}_{\mathrm{t}} \mathrm{F}\right]-\mathrm{V}_{1 \mathrm{t}}\left[\mathrm{u}_{11}(\mathrm{t}) \mathrm{e}_{\mathrm{t}} \sigma_{\mathrm{e}}+\mathrm{u}_{12}(\mathrm{t}) \mathrm{f}_{\mathrm{t}} \sigma_{\mathrm{f}}\right]\right] \\
\mathrm{V}_{2 \mathrm{t}} \sigma_{2 \mathrm{t}}=\mathrm{u}_{1}(\mathrm{t})^{-1}\left[\rho_{\mathrm{t}}\left(\mathrm{E}_{\mathrm{t}}\left[\mathbf{D}_{\mathrm{t}} \mathrm{G}\right]+\mathrm{E}_{\mathrm{t}}\left[\mathbf{D}_{\mathrm{t}} \mathrm{I}\right]-\mathrm{H}_{\mathrm{t}} \mathrm{E}_{\mathrm{t}}\left[\mathbf{D}_{\mathrm{t}} \mathrm{J}\right]\right)\right. \\
\left.-\mathrm{V}_{2 \mathrm{t}}\left[\mathrm{u}_{11}(\mathrm{t}) \mathrm{e}_{\mathrm{t}} \sigma_{\mathrm{e}}+\mathrm{u}_{12}(\mathrm{t}) \mathrm{f}_{\mathrm{t}} \sigma_{\mathrm{f}}\right]\right]
\end{gathered}
$$

where,

$$
\begin{aligned}
\mathbf{D}_{\mathrm{t}} \mathrm{F}= & \int_{\mathrm{t}}^{\mathrm{T}} \rho_{\mathrm{v}}^{-1}\left[\mathrm{u}_{1}(\mathrm{v}) \mathrm{e}_{\mathrm{v}}\left(-\int_{\mathrm{t}}^{\mathrm{v}} \mathbf{D}_{\mathrm{t}} \boldsymbol{\beta}_{\mathrm{u}} \mathrm{du}\right)+\left(\mathrm{u}_{11}(\mathrm{v}) \mathrm{e}_{\mathrm{v}}+\mathrm{u}_{1}(\mathrm{v})\right) \mathbf{D}_{\mathrm{t}} \mathrm{e}_{\mathrm{v}}\right. \\
& \left.+\mathrm{u}_{12}(\mathrm{v}) \mathrm{e}_{\mathrm{v}}\left(\mathbf{D}_{\mathrm{t}} \mathrm{s}_{\mathrm{v}}+\mathbf{D}_{\mathrm{t}} \mathrm{z}_{\mathrm{v}}(\mathrm{f})\right)\right] \mathrm{dv} .
\end{aligned}
$$




$$
\begin{aligned}
& \mathbf{D}_{\mathrm{t}} \mathrm{G}=\int_{\mathrm{t}}^{\mathrm{T}} \rho_{\mathrm{v}}^{-1}\left[\mathrm{u}_{2}(\mathrm{v}) \mathrm{f}_{\mathrm{v}}\left(-\int_{\mathrm{t}}^{\mathrm{D}} \mathbf{D}_{\mathrm{t}} \boldsymbol{\beta}_{\mathrm{u}} \mathrm{du}\right)+\mathrm{u}_{21}(\mathrm{v}) \mathrm{f}_{\mathrm{v}} \mathbf{D}_{\mathrm{t}} \mathrm{e}_{\mathrm{v}}+\mathrm{u}_{22}(\mathrm{v}) \mathrm{f}_{\mathrm{v}}\left(\mathbf{D}_{\mathrm{t}} \mathrm{s}_{\mathrm{v}}+\mathbf{D}_{\mathrm{t}} \mathrm{z}_{\mathrm{v}}(\mathrm{f})\right)\right. \\
& \left.+\mathrm{u}_{2}(\mathrm{v}) \mathbf{D}_{\mathrm{t}} \mathrm{f}_{\mathrm{v}}\right] \mathrm{dv} \\
& \mathbf{D}_{\mathrm{t}} \mathrm{I}=\int_{\mathrm{t}}^{\mathrm{T}} \boldsymbol{\rho}_{\mathrm{v}}^{-1} \mathrm{e}^{-\alpha v}\left[\mathrm{u}_{2}(\mathrm{v}) \mathrm{H}_{\mathrm{v}}\left(-\int_{\mathrm{t}}^{\mathrm{v}} \mathbf{D}_{\mathrm{t}} \boldsymbol{\beta}_{\mathrm{u}} \mathrm{du}\right)+\mathrm{u}_{21}(\mathrm{v}) \mathrm{H}_{\mathrm{v}} \mathbf{D}_{\mathrm{t}} \mathrm{e}_{\mathrm{v}}+\mathrm{u}_{22}(\mathrm{v}) \mathrm{H}_{\mathrm{v}}\left(\mathbf{D}_{\mathrm{t}} \mathrm{s}_{\mathrm{v}}+\mathbf{D}_{\mathrm{t}} \mathrm{z}_{\mathrm{v}}(\mathrm{f})\right)\right. \\
& \left.+\mathrm{u}_{2}(\mathrm{v}) \mathbf{D}_{\mathrm{t}} \mathrm{H}_{\mathrm{v}}\right] \mathrm{dv} \\
& \mathrm{H}_{\mathrm{s}} \equiv \int_{\mathrm{t}}^{\mathrm{s}} \alpha \mathrm{e}^{-\alpha v} \mathrm{f}_{\mathrm{v}} \mathrm{dv}, \mathbf{D}_{\mathrm{t}} \mathrm{H}_{\mathrm{s}}=\int_{\mathrm{t}}^{\mathrm{s}} \alpha \mathrm{e}^{-\alpha v}\left(\mathbf{D}_{\mathrm{t}} \mathrm{f}_{\mathrm{v}}\right) \mathrm{dv} \\
& \mathbf{D}_{\mathrm{t}} \mathrm{J}=\int_{\mathrm{t}}^{\mathrm{T}} \boldsymbol{\rho}_{\mathrm{v}}^{-1} \mathrm{e}^{-\alpha v}\left[\mathrm{u}_{2}(\mathrm{v})\left(-\int_{\mathrm{t}}^{\mathrm{v}} \mathbf{D}_{\mathrm{t}} \boldsymbol{\beta}_{\mathrm{u}} \mathrm{du}\right)+\mathrm{u}_{21}(\mathrm{v}) \mathbf{D}_{\mathrm{t}} \mathrm{e}_{\mathrm{v}}+\mathrm{u}_{22}(\mathrm{v})\left(\mathbf{D}_{\mathrm{t}} \mathrm{s}_{\mathrm{v}}+\mathbf{D}_{\mathrm{t}} \mathrm{z}_{\mathrm{v}}(\mathrm{f})\right)\right] \mathrm{dv} \text { (B.9) } \\
& \text { and, } \\
& \begin{array}{c}
\mathbf{D}_{\mathrm{t}} \mathrm{e}_{\mathrm{v}}=\mathrm{e}_{\mathrm{v}}\left[\int_{\mathrm{t}}^{\mathrm{D}} \mathbf{D}_{\mathrm{t}}\left(\mu_{\mathrm{e}}(\mathrm{u})-1 / 2 \sigma_{\mathrm{e}}(\mathrm{u}) \sigma_{\mathrm{e}}(\mathrm{u})^{\prime}\right) \mathrm{du}+\int_{\mathrm{t}}^{\mathrm{V}} \mathbf{D}_{\mathrm{t}} \sigma_{\mathrm{e}}(\mathrm{u}) \mathrm{dW}_{\mathrm{u}}+\sigma_{\mathrm{e}}(\mathrm{t})\right] \\
\mathbf{D}_{\mathrm{t}} \mathrm{f}_{\mathrm{v}}=\mathrm{f}_{\mathrm{v}}\left[\int_{\mathrm{t}}^{\mathrm{D}} \mathbf{D}_{\mathrm{t}}\left(\mu_{\mathrm{f}}(\mathrm{u})-1 / 2 \sigma_{\mathrm{f}}(\mathrm{u}) \sigma_{\mathrm{f}}(\mathrm{u})^{\prime}\right) \mathrm{du}+\int_{\mathrm{t}}^{\mathrm{D}} \mathbf{D}_{\mathrm{t}} \sigma_{\mathrm{f}}(\mathrm{u}) \mathrm{dW}_{\mathrm{u}}+\sigma_{\mathrm{f}}(\mathrm{t})\right] \\
\mathbf{D}_{\mathrm{t}} \mathrm{z}_{\mathrm{v}}(\mathrm{f})=\alpha \int_{\mathrm{t}}^{\mathrm{v}} \mathrm{e}^{-\alpha(\mathrm{v}-\mathrm{s})} \mathbf{D}_{\mathrm{t}} \mathrm{f}_{\mathrm{s}} \mathrm{ds}
\end{array}
\end{aligned}
$$

In (B.3)-(B.12) $\mathbf{D}_{\mathrm{t}}$ represents the Malliavin derivative operator.

Formulas (B.3)-(B.4) are closed form solutions for the volatilities of the values of the firms. These volatilities depend (i) on the contemporaneous volatilities $\sigma_{e}(t)$ and $\sigma_{f}(t)$ of the endowment processes and (ii) on the sensitivities of the future coefficients of the model to perturbations in the current Brownian motion process $\mathrm{W}_{\mathrm{t}}$ (the terms involving the Malliavin derivatives in (B.10)-(B.11)).

Proof of Theorem 7: Using the definition of the equivalent martingale measure we can write,

$$
\mathrm{V}_{1 \mathrm{t}}=\mathrm{E}_{\mathrm{t}}^{*}\left[\int_{\mathrm{t}}^{\mathrm{T}} \mathrm{b}_{\mathrm{t}, \mathrm{s}} \mathrm{e}_{\mathrm{s}} \mathrm{ds}\right]=\left(\xi_{\mathrm{t}}\right)^{-1} \mathrm{E}_{\mathrm{t}}\left[\int_{\mathrm{t}}^{\mathrm{T}} \xi_{\mathrm{s}} \mathrm{e}_{\mathrm{s}} \mathrm{ds}\right]=\left(\xi_{\mathrm{t}}\right)^{-1}\left[\mathrm{E}_{\mathrm{t}}\left[\int_{0}^{\mathrm{T}} \xi_{\mathrm{s}} \mathrm{e}_{\mathrm{s}} \mathrm{ds}\right]-\int_{0}^{\mathrm{t}} \xi_{\mathrm{s}} \mathrm{e}_{\mathrm{s}} \mathrm{ds}\right] .
$$

Substituting the equilibrium state price density (32), defining $\mathrm{F} \equiv \int_{0}^{\mathrm{T}} \rho_{\mathrm{s}}^{-1} \mathrm{u}_{1}(\mathrm{~s}) \mathrm{e}_{\mathrm{s}} \mathrm{ds}$ and applying the Clark-Ocone formula yields (B.3). Similarly,

$$
\mathrm{V}_{2 \mathrm{t}}=\mathrm{E}_{\mathrm{t}}^{*}\left[\int_{\mathrm{t}}^{\mathrm{T}} \mathrm{b}_{\mathrm{t}, \mathrm{s}} \mathrm{p}_{\mathrm{s}} \mathrm{f}_{\mathrm{s}} \mathrm{ds}\right]=\left(\xi_{\mathrm{t}}\right)^{-1} \mathrm{E}_{\mathrm{t}}\left[\int_{\mathrm{t}}^{\mathrm{T}} \xi_{\mathrm{s}} \mathrm{p}_{\mathrm{s}} \mathrm{f}_{\mathrm{s}} \mathrm{ds}\right]
$$


Substituting the equilibrium values (32)-(33) leads to,

$$
\begin{gathered}
\mathrm{E}_{\mathrm{t}}\left[\int_{\mathrm{t}}^{\mathrm{T}} \xi_{\mathrm{s}} \mathrm{p}_{\mathrm{s}} \mathrm{f}_{\mathrm{s}} \mathrm{ds}\right]=\mathrm{E}_{\mathrm{t}}\left[\int_{\mathrm{t}}^{\mathrm{T}}\left[\mathrm{u}_{1}(0)^{-1} \rho_{\mathrm{s}}^{-1}\left\{\mathrm{u}_{2}(\mathrm{~s})+\alpha \mathrm{E}_{\mathrm{s}}\left[\int_{\mathrm{s}}^{\mathrm{T}} \mathrm{e}^{-\int_{\mathrm{s}}^{\mathrm{v}}\left(\beta_{\mathrm{u}}+\alpha\right) \mathrm{d}}{ }_{\mathrm{uu}}(\mathrm{v}) \mathrm{dv}\right]\right\} \mathrm{f}_{\mathrm{s}}\right] \mathrm{ds}\right] \\
=\mathrm{u}_{1}(0)^{-1} \mathrm{E}_{\mathrm{t}}\left[\int_{\mathrm{t}}^{\mathrm{T}}\left[\rho_{\mathrm{s}}^{-1} \mathrm{u}_{2}(\mathrm{~s}) \mathrm{f}_{\mathrm{s}}+\alpha \mathrm{E}_{\mathrm{s}}\left[\int_{\mathrm{s}}^{\mathrm{T}} \rho_{\mathrm{v}}^{-1} \mathrm{e}^{\alpha(s-v)} \mathrm{u}_{2}(\mathrm{v}) \mathrm{dv}\right] \mathrm{f}_{\mathrm{s}}\right] \mathrm{ds}\right] \\
=\mathrm{u}_{1}(0)^{-1} \mathrm{E}_{\mathrm{t}}\left[\int_{\mathrm{t}}^{\mathrm{T}}\left[\rho_{\mathrm{s}}^{-1} \mathrm{u}_{2}(\mathrm{~s}) \mathrm{f}_{\mathrm{s}}+\alpha \mathrm{f}_{\mathrm{s}} \int_{\mathrm{s}}^{\mathrm{T}} \rho_{\mathrm{v}}^{-1} \mathrm{e}^{\alpha(\mathrm{s} v)} \mathrm{u}_{2}(\mathrm{v}) \mathrm{dv}\right] \mathrm{ds}\right] \\
=\mathrm{u}_{1}(0)^{-1}\left\{\mathrm{E}_{\mathrm{t}}\left[\int_{\mathrm{t}}^{\mathrm{T}} \rho_{\mathrm{s}}^{-1} \mathrm{u}_{2}(\mathrm{~s}) \mathrm{f}_{\mathrm{s}} \mathrm{ds}\right]+\mathrm{E}_{\mathrm{t}}\left[\int_{\mathrm{t}}^{\mathrm{T}} \alpha \mathrm{f}_{\mathrm{s}}\left(\int_{\mathrm{s}}^{\mathrm{T}} \rho_{\mathrm{v}}^{-1} \mathrm{e}^{\alpha(\mathrm{s}-\mathrm{v})} \mathrm{u}_{2}(\mathrm{v}) \mathrm{dv}\right) \mathrm{ds}\right]\right\} \\
=\mathrm{u}_{1}(0)^{-1}\left\{\mathrm{E}_{\mathrm{t}}\left[\int_{\mathrm{t}}^{\mathrm{T}} \rho_{\mathrm{s}}^{-1} \mathrm{u}_{2}(\mathrm{~s}) \mathrm{f}_{\mathrm{s}} \mathrm{ds}\right]+\mathrm{E}_{\mathrm{t}}\left[\int_{\mathrm{t}}^{\mathrm{T}} \rho_{\mathrm{s}}^{-1} \mathrm{u}_{2}(\mathrm{~s}) \mathrm{e}^{-\alpha s}\left(\int_{\mathrm{t}}^{\mathrm{s}} \alpha \mathrm{f}_{\mathrm{v}} \mathrm{e}^{\alpha \mathrm{v}} \mathrm{dv}\right) \mathrm{ds}\right]\right\} \\
=\mathrm{u}_{1}(0)^{-1}\left\{\mathrm{E}_{\mathrm{t}}[\mathrm{G}]-\int_{0}^{\mathrm{t}} \rho_{\mathrm{s}}^{-1} \mathrm{u}_{2}(\mathrm{~s}) \mathrm{f}_{\mathrm{s}} \mathrm{ds}+\mathrm{E}_{\mathrm{t}}[\mathrm{I}]-\int_{0}^{\mathrm{t}} \rho_{\mathrm{s}}^{-1} \mathrm{u}_{2}(\mathrm{~s}) \mathrm{e}^{-\alpha s} \mathrm{H}_{\mathrm{s}} \mathrm{ds}-\mathrm{H}_{\mathrm{t}}\left[\mathrm{E}_{\mathrm{t}}[\mathrm{J}]\right.\right. \\
\left.\left.\quad-\int_{0}^{\mathrm{t}} \rho_{\mathrm{s}}^{-1} \mathrm{u}_{2}(\mathrm{~s}) \mathrm{e}^{-\alpha s} \mathrm{ds}\right]\right\},
\end{gathered}
$$

where $\mathrm{G} \equiv \int_{0}^{\mathrm{T}} \rho_{\mathrm{s}}^{-1} \mathrm{u}_{2}(\mathrm{~s}) \mathrm{f}_{\mathrm{s}} \mathrm{ds}, \mathrm{I} \equiv \int_{0}^{\mathrm{T}} \rho_{\mathrm{s}}^{-1} \mathrm{u}_{2}(\mathrm{~s}) \mathrm{e}^{-\alpha s} \mathrm{H}_{\mathrm{s}} \mathrm{ds}, \mathrm{H}_{\mathrm{s}} \equiv \int_{0}^{\mathrm{s}} \alpha \mathrm{f}_{\mathrm{v}} \mathrm{e}^{\alpha \mathrm{v}} \mathrm{dv}$ and $\mathrm{J} \equiv \int_{0}^{\mathrm{T}} \rho_{\mathrm{s}}^{-1} \mathrm{u}_{2}(\mathrm{~s}) \mathrm{e}^{-\alpha s} \mathrm{ds}$. To obtain (B.4) we apply the Clark-Ocone formula to this last expression.

When the subjective discount rate and the coefficients of the endowment processes are deterministic the volatility formulas (B.3)-(B.4) simplify substantially.

Corollary 3: In the economy of section 2 with deterministic coefficients the equilibrium volatilities of the values of the firms are,

$$
\begin{aligned}
& \mathrm{V}_{1 \mathrm{t}} \sigma_{1 \mathrm{t}}=\mathrm{u}_{1}(\mathrm{t})^{-1}\left[\rho_{\mathrm{t}} \mathrm{F}_{1}(\mathrm{t}, \mathrm{T})-\mathrm{V}_{1 \mathrm{t}} \mathrm{u}_{11}(\mathrm{t}) \mathrm{e}_{\mathrm{t}}\right] \sigma_{\mathrm{e}}+\mathrm{u}_{1}(\mathrm{t})^{-1}\left[\rho_{\mathrm{t}} \mathrm{F}_{2}(\mathrm{t}, \mathrm{T})\right. \\
& \left.\quad-\mathrm{V}_{1 \mathrm{t}} \mathrm{u}_{12}(\mathrm{t}) \mathrm{f}_{\mathrm{t}}\right] \sigma_{\mathrm{f}} \\
& \mathrm{V}_{2 \mathrm{t}} \sigma_{2 \mathrm{t}}=\mathrm{u}_{1}(\mathrm{t})^{-1}\left[\rho_{\mathrm{t}}\left(\mathrm{G}_{1}(\mathrm{t}, \mathrm{T})+\mathrm{I}_{1}(\mathrm{t}, \mathrm{T})-\mathrm{H}_{\mathrm{t}} \mathrm{J}_{1}(\mathrm{t}, \mathrm{T})\right)-\mathrm{V}_{2 \mathrm{t}} \mathrm{u}_{11}(\mathrm{t}) \mathrm{e}_{\mathrm{t}}\right] \sigma_{\mathrm{e}} \\
& \quad+\mathrm{u}_{1}(\mathrm{t})^{-1}\left[\rho_{\mathrm{t}}\left(\mathrm{G}_{2}(\mathrm{t}, \mathrm{T})+\mathrm{I}_{2}(\mathrm{t}, \mathrm{T})-\mathrm{H}_{\mathrm{t}} \mathrm{J}_{2}(\mathrm{t}, \mathrm{T})\right)-\mathrm{V}_{2 \mathrm{t}} \mathrm{u}_{12}(\mathrm{t}) \mathrm{f}_{\mathrm{t}}\right] \sigma_{\mathrm{f}},
\end{aligned}
$$

where,

$$
\begin{gathered}
\mathrm{F}_{1}(\mathrm{t}, \mathrm{T}) \equiv \mathrm{E}_{\mathrm{t}}\left[\int_{\mathrm{t}}^{\mathrm{T}} \rho_{\mathrm{v}}^{-1}\left(\mathrm{u}_{11}(\mathrm{v}) \mathrm{e}_{\mathrm{v}}+\mathrm{u}_{1}(\mathrm{v})\right) \mathrm{e}_{\mathrm{v}} \mathrm{dv}\right] \\
\mathrm{F}_{2}(\mathrm{t}, \mathrm{T}) \equiv \mathrm{E}_{\mathrm{t}}\left[\int_{\mathrm{t}}^{\mathrm{T}} \rho_{\mathrm{v}}^{-1} \mathrm{u}_{12}(\mathrm{v}) \mathrm{e}_{\mathrm{v}}\left(\mathrm{s}_{\mathrm{v}}+\mathrm{K}_{\mathrm{t}, \mathrm{v}}\right) \mathrm{dv}\right] \\
\mathrm{K}_{\mathrm{t}, \mathrm{v}} \equiv \int_{\mathrm{t}}^{\mathrm{v}} \alpha \mathrm{e}^{-\alpha(\mathrm{v}-\mathrm{u})} \mathrm{f}_{\mathrm{u}} \mathrm{du}
\end{gathered}
$$




$$
\begin{gathered}
\mathrm{G}_{1}(\mathrm{t}, \mathrm{T}) \equiv \mathrm{E}_{\mathrm{t}}\left[\int_{\mathrm{t}}^{\mathrm{T}} \rho_{\mathrm{v}}^{-1} \mathrm{u}_{21}(\mathrm{v}) \mathrm{f}_{\mathrm{v}} \mathrm{e}_{\mathrm{v}} \mathrm{dv}\right] \\
\mathrm{G}_{2}(\mathrm{t}, \mathrm{T}) \equiv \mathrm{E}_{\mathrm{t}}\left[{ }_{\mathrm{t}}^{\mathrm{T}} \rho_{\mathrm{v}}^{-1}\left[\mathrm{u}_{22}(\mathrm{v})\left(\mathrm{s}_{\mathrm{v}}+\mathrm{K}_{\mathrm{t}, \mathrm{v}}\right)+\mathrm{u}_{2}(\mathrm{v})\right] \mathrm{f}_{\mathrm{v}} \mathrm{dv}\right] \\
\mathrm{I}_{1}(\mathrm{t}, \mathrm{T}) \equiv \mathrm{E}_{\mathrm{t}}\left[\int_{\mathrm{t}}^{\mathrm{T}} \rho_{\mathrm{v}}^{-1} \mathrm{e}^{-\alpha \mathrm{v}} \mathrm{u}_{21}(\mathrm{v}) \mathrm{H}_{\mathrm{v}} \mathrm{e}_{\mathrm{v}} \mathrm{dv}\right] \\
\mathrm{I}_{2}(\mathrm{t}, \mathrm{T}) \equiv \mathrm{E}_{\mathrm{t}}\left[\int_{\mathrm{t}}^{\mathrm{T}} \rho_{\mathrm{v}}^{-1} \mathrm{e}^{-\alpha v}\left[\mathrm{u}_{22}(\mathrm{v}) \mathrm{H}_{\mathrm{v}}\left(\mathrm{s}_{\mathrm{v}}+\mathrm{K}_{\mathrm{t}, \mathrm{v}}\right)+\mathrm{u}_{2}(\mathrm{v}) \mathrm{L}_{\mathrm{t}, \mathrm{v}}\right] \mathrm{dv}\right] \\
\mathrm{L}_{\mathrm{t}, \mathrm{v}}=\int_{\mathrm{t}}^{\mathrm{v}} \alpha \mathrm{e}^{-\alpha s} \mathrm{f}_{\mathrm{s}} \mathrm{ds} \\
\mathrm{J}_{1}(\mathrm{t}, \mathrm{T}) \equiv \mathrm{E}_{\mathrm{t}}\left[\int_{\mathrm{t}}^{\mathrm{T}} \rho_{\mathrm{v}}^{-1} \mathrm{e}^{-\alpha \mathrm{v}} \mathrm{u}_{21}(\mathrm{v}) \mathrm{e}_{\mathrm{v}} \mathrm{dv}\right] \\
\text { and, } \quad \mathrm{J}_{2}(\mathrm{t}, \mathrm{T}) \equiv \mathrm{E}_{\mathrm{t}}\left[\int_{\mathrm{t}}^{\mathrm{T}} \rho_{\mathrm{v}}^{-1} \mathrm{e}^{-\alpha v} \mathrm{u}_{22}(\mathrm{v})\left(\mathrm{s}_{\mathrm{v}}+\mathrm{K}_{\mathrm{t}, \mathrm{v}}\right) \mathrm{dv}\right]
\end{gathered}
$$

When the opportunity set is deterministic the volatilities of the values of the firms can be expressed solely in terms of the contemporaneous volatilities of the endowments processes. Formulas (B.13)-(B.24) can be further simplified by considering parametric forms of utility functions. The results of Theorem 7 and Corollary 3 can also be used to complement section 5.2 and compare the equilibrium volatilities of the firm values across economies with and without durability.

Proof of Corollary 3: In the economy with deterministic coefficients we have $\mathbf{D}_{\mathrm{t}} \mathrm{e}_{\mathrm{v}}=\mathrm{e}_{\mathrm{v}} \sigma_{\mathrm{e}}(\mathrm{t}), \mathbf{D}_{\mathrm{t}} \mathrm{f}_{\mathrm{v}}=\mathrm{f}_{\mathrm{v}} \sigma_{\mathrm{f}}(\mathrm{t})$ and $\mathbf{D}_{\mathrm{t}} \mathrm{z}_{\mathrm{v}}(\mathrm{f})=\alpha\left(\int_{\mathrm{t}}^{\mathrm{v}} \mathrm{e}^{-\alpha(\mathrm{v}-\mathrm{s})} \mathrm{f}_{\mathrm{s}} \mathrm{ds}\right) \sigma_{\mathrm{f}}(\mathrm{t}) \equiv \mathrm{K}_{\mathrm{t}, \mathrm{v}} \sigma_{\mathrm{f}}(\mathrm{t})$. Substituting in the relevant expressions and collecting terms leads to (B.13) and (B.14). 


\section{Appendix C: demand functions for general preferences over attributes.}

In this appendix we provide some insights about the optimal consumption policies for the general model of durability of section 6 . For the sake of clarity we focus on the case $\mathrm{g}(1, \mathrm{x})=\mathrm{g}(\mathrm{l})$ in which status depreciates infinitely quickly; the general case of persistence in status can be handled along the same lines with appropriate adjustments. Essentially we show that a construction similar to that of section 3 , albeit somewhat more complex, leads to the optimal policies.

Our first Theorem provides a characterization of the optimal policies,

Theorem 8: Consider the economy of section 6 and suppose that assumptions 5, 6 and 7 hold with $\mathrm{g}(1, \mathrm{x}) \equiv \mathrm{g}(\mathrm{l})$. The policy $(\mathrm{c}, \mathrm{l})$ is optimal for the static problem if and only if $(\mathrm{c}, 1, \mathrm{y})$ satisfies,

$$
\begin{gathered}
\mathrm{u}_{1}\left(\mathrm{c}_{\mathrm{t}} \mathrm{g}\left(\mathrm{l}_{\mathrm{t}}\right), \mathrm{z}_{\mathrm{t}}\right)=\mathrm{y} \rho_{\mathrm{t}} \xi_{\mathrm{t}}, \mathrm{t} \in[0, \mathrm{~T}], \\
\mathrm{g}^{\prime}\left(\mathrm{l}_{\mathrm{t}}\right) \mathrm{u}_{2}\left(\mathrm{c}_{\mathrm{t}}, \mathrm{g}\left(\mathrm{l}_{\mathrm{t}}\right), \mathrm{z}_{\mathrm{t}}\right)+\alpha \mathrm{E}_{\mathrm{t}}\left[\int_{\mathrm{t}}^{\mathrm{T}} \rho_{\mathrm{s}, \mathrm{t}} \mathrm{e}^{-\alpha(s-\mathrm{s})} \mathrm{u}_{3}\left(\mathrm{c}_{\mathrm{s}}, \mathrm{g}\left(\mathrm{l}_{\mathrm{s}}\right), \mathrm{z}_{\mathrm{s}}\right) \mathrm{ds}\right]=\mathrm{y} \rho_{\mathrm{t}} \xi_{\mathrm{t}} \mathrm{p}_{\mathrm{t}}, \mathrm{t} \in[0, \mathrm{~T}], \\
\mathrm{c}_{\mathrm{t}} \geq 0, \mathrm{l}_{\mathrm{t}} \geq 0, \mathrm{t} \in[0, \mathrm{~T}] ; \mathrm{y}>0, \\
\mathrm{E}^{*}\left[\int_{0}^{\mathrm{T}} \mathrm{b}_{\mathrm{t}}\left(\mathrm{c}_{\mathrm{t}}+\mathrm{l}_{\mathrm{t}} \mathrm{p}_{\mathrm{t}}\right) \mathrm{dt}\right] \leq \mathrm{E}^{*}\left[\int_{0}^{\mathrm{T}} \mathrm{b}_{\mathrm{t}}\left(\mathrm{e}_{\mathrm{t}}+\mathrm{f}_{\mathrm{t}} \mathrm{p}_{\mathrm{t}}\right) \mathrm{dt}\right] .
\end{gathered}
$$

Proof of Theorem 8:

(i) necessity: the utility gradient implied by the preference structure (45)-(47) has components given by the left hand sides of (C.1) and (C.2). The conditions (C.1)-(C.4) are standard Kuhn-Tucker conditions. Note that (C.2) holds as an equality since the function $\mathrm{W}(\mathrm{c}, \mathrm{l}, \mathrm{z}) \equiv \mathrm{g}^{\prime}(\mathrm{l}) \mathrm{u}_{2}(\mathrm{c}, \mathrm{g}(\mathrm{l}), \mathrm{z})$ is continuous, strictly decreasing with respect to 1 and has the limiting values $\lim _{11 \infty} \mathrm{W}(\mathrm{c}, 1, \mathrm{z})=0$ and $\lim _{1\lrcorner 0} \mathrm{~W}(\mathrm{c}, 1, \mathrm{z})=\infty$.

(ii) sufficiency: consider an alternative budget feasible policy $\left(\mathrm{c}^{\mathrm{o}}, 1^{\circ}\right)$. Concavity of the utility function and of the status production function imply, 


$$
\begin{gathered}
\mathrm{u}\left(\mathrm{c}_{\mathrm{t}}, \mathrm{g}\left(\mathrm{l}_{\mathrm{t}}\right), \mathrm{z}_{\mathrm{t}}\right) \geq \mathrm{u}\left(\mathrm{c}_{\mathrm{t}}^{\mathrm{o}} \mathrm{g}\left(\mathrm{l}_{\mathrm{t}}^{\mathrm{o}}\right), \mathrm{z}_{\mathrm{t}}^{\mathrm{o}}\right)+\mathrm{u}_{1}\left(\mathrm{c}_{\mathrm{t}}, \mathrm{g}\left(\mathrm{l}_{\mathrm{t}}\right), \mathrm{z}_{\mathrm{t}}\right)\left(\mathrm{c}_{\mathrm{t}}-\mathrm{c}_{\mathrm{t}}^{\mathrm{o}}\right)+\mathrm{u}_{2}\left(\mathrm{c}_{\mathrm{t}}, \mathrm{g}\left(\mathrm{l}_{\mathrm{t}}\right), \mathrm{z}_{\mathrm{t}}\right) \mathrm{g}^{\prime}\left(\mathrm{l}_{\mathrm{t}}\right)\left(\mathrm{l}_{\mathrm{t}}-\mathrm{l}_{\mathrm{t}}^{\mathrm{o}}\right) \\
+\mathrm{u}_{3}\left(\mathrm{c}_{\mathrm{t}}, \mathrm{g}\left(1_{\mathrm{t}}\right), \mathrm{z}_{\mathrm{t}}\right)\left(\mathrm{z}_{\mathrm{t}}-\mathrm{z}_{\mathrm{t}}^{\mathrm{o}}\right) .
\end{gathered}
$$

Multiplying both sides by $\rho_{\mathrm{t}}^{-1}$ and integrating over the product measure $\mathrm{dPxdt}$ yields,

$$
\begin{gathered}
\mathrm{E}\left[\int_{0}^{\mathrm{T}} \rho_{\mathrm{t}}^{-1} \mathrm{u}\left(\mathrm{c}_{\mathrm{t}}, \mathrm{g}\left(\mathrm{l}_{\mathrm{t}}\right), \mathrm{z}_{\mathrm{t}}\right) \mathrm{dt}\right] \geq \mathrm{E} \int_{0}^{\mathrm{T}} \rho_{\mathrm{t}}^{-1}\left[\mathrm{u}\left(\mathrm{c}_{\mathrm{t}}^{\mathrm{o}}, \mathrm{g}\left(\mathrm{l}_{\mathrm{t}}^{\mathrm{o}}\right), \mathrm{z}_{\mathrm{t}}^{\mathrm{o}}\right)+\mathrm{u}_{1}\left(\mathrm{c}_{\mathrm{t}}, \mathrm{g}\left(\mathrm{l}_{\mathrm{t}}\right), \mathrm{z}_{\mathrm{t}}\right)\left(\mathrm{c}_{\mathrm{t}}-\mathrm{c}_{\mathrm{t}}^{\mathrm{o}}\right)\right. \\
\left.+\mathrm{u}_{2}\left(\mathrm{c}_{\mathrm{t}}, \mathrm{g}\left(\mathrm{l}_{\mathrm{t}}\right), \mathrm{z}_{\mathrm{t}}\right) \mathrm{g}^{\prime}\left(\mathrm{l}_{\mathrm{t}}\right)\left(\mathrm{l}_{\mathrm{t}}-\mathrm{l}_{\mathrm{t}}^{\mathrm{o}}\right)+\mathrm{u}_{3}\left(\mathrm{c}_{\mathrm{t}}, \mathrm{g}\left(\mathrm{l}_{\mathrm{t}}\right), \mathrm{z}_{\mathrm{t}}\right)\left(\mathrm{z}_{\mathrm{t}}-\mathrm{z}_{\mathrm{t}}^{\mathrm{o}}\right)\right] \mathrm{dt}
\end{gathered}
$$

Consider the last two terms on the right hand side of the inequality above. Using $\mathrm{z}_{\mathrm{t}}-\mathrm{z}_{\mathrm{t}}^{\mathrm{o}}=\alpha \int_{0}^{\mathrm{t}} \mathrm{e}^{-\alpha(\mathrm{t}-\mathrm{s})}\left(1_{\mathrm{s}}-1_{\mathrm{s}}^{\mathrm{o}}\right) \mathrm{ds}$ and proceeding as in the proof of Theorem 6 leads to,

$$
\begin{gathered}
\mathrm{E} \int_{0}^{\mathrm{T}} \rho_{\mathrm{t}}^{-1}\left[\mathrm{u}_{2}\left(\mathrm{c}_{\mathrm{t}}, \mathrm{g}\left(\mathrm{l}_{\mathrm{t}}\right), \mathrm{z}_{\mathrm{t}}\right) \mathrm{g}^{\prime}\left(1_{\mathrm{t}}\right)\left(\mathrm{l}_{\mathrm{t}}-1_{\mathrm{t}}^{\mathrm{o}}\right)+\mathrm{u}_{3}\left(\mathrm{c}_{\mathrm{t}}, \mathrm{g}\left(\mathrm{l}_{\mathrm{t}}\right), \mathrm{z}_{\mathrm{t}}\right)\left(\mathrm{z}_{\mathrm{t}}-\mathrm{z}_{\mathrm{t}}^{\mathrm{o}}\right)\right] \mathrm{dt} \geq \\
\mathrm{E}\left[\int_{0}^{\mathrm{T}}\left(\mathrm{l}_{\mathrm{t}}-\mathrm{l}_{\mathrm{t}}^{\mathrm{o}}\right) \mathrm{y} \xi_{\mathrm{t}} \mathrm{p}_{\mathrm{t}} \mathrm{dt}\right] .
\end{gathered}
$$

Substituting (C.1) and (C.6) in (C.5) now yields,

$$
\begin{gathered}
\mathrm{E}\left[\int_{0}^{\mathrm{T}} \rho_{\mathrm{t}}^{-1} \mathrm{u}\left(\mathrm{c}_{\mathrm{t}}, \mathrm{g}\left(\mathrm{l}_{\mathrm{t}}\right), \mathrm{z}_{\mathrm{t}}\right) \mathrm{dt}\right] \geq \mathrm{E}\left[\int_{0}^{\mathrm{T}} \rho_{\mathrm{t}}^{-1} \mathrm{u}\left(\mathrm{c}_{\mathrm{t}}^{\mathrm{o}}, \mathrm{g}\left(\mathrm{l}_{\mathrm{t}}^{\mathrm{o}}\right), \mathrm{z}_{\mathrm{t}}^{\mathrm{o}}\right) \mathrm{dt}\right] \\
+\mathrm{yE} \int_{0}^{\mathrm{T}}\left[\left(\mathrm{c}_{\mathrm{t}}-\mathrm{c}_{\mathrm{t}}^{\mathrm{o}}\right)+\left(\mathrm{l}_{\mathrm{t}}-\mathrm{l}_{\mathrm{t}}^{\mathrm{o}}\right) \mathrm{p}_{\mathrm{t}}\right] \xi_{\mathrm{t}} \mathrm{tt} .
\end{gathered}
$$

The budget constraint (C.4) and the condition $y>0$ imply that the last term is nonnegative. Optimality of $(\mathrm{c}, 1)$ follows.

To construct the optimal policies we proceed as follows.

Define the map I: $\Re^{+} \mathrm{X} \Re^{+} \mathrm{X} \Re^{+} \rightarrow \Re^{+}$as the solution to the equation,

$$
\mathrm{u}_{1}(\mathrm{I}(\mathrm{y}, \mathrm{g}, \mathrm{z}), \mathrm{g}, \mathrm{z})=\mathrm{y}
$$

where $y>0$. Note that I exists, is unique and has the limiting values $\lim _{\mathrm{y} \mid \infty \infty} \mathrm{I}(\mathrm{y}, \mathrm{g}, \mathrm{z})=0$ and $\lim _{\mathrm{y}\lrcorner 0} \mathrm{I}(\mathrm{y}, \mathrm{g}, \mathrm{z})=\infty$. The strict concavity of the utility function also implies that $\mathrm{I}_{1}>0$.

Define now the map V: $\Re^{+} \mathrm{X} \Re \Re^{+} \mathrm{X} \Re^{+} \rightarrow \Re^{+}$as, 


$$
\mathrm{V}(\mathrm{l}, \mathrm{y}, \mathrm{z}) \equiv \mathrm{g}^{\prime}(\mathrm{l}) \mathrm{u}_{2}(\mathrm{I}(\mathrm{y}, \mathrm{g}(\mathrm{l}), \mathrm{z}), \mathrm{g}, \mathrm{z}(\mathrm{l}))
$$

It is easy to verify that $\mathrm{V}$ is strictly decreasing in its first argument and has the limiting values $\lim _{1\lrcorner 0} \mathrm{~V}(1, \mathrm{y}, \mathrm{z})=\infty$ and $\lim _{11 \infty} \mathrm{V}(1, \mathrm{y}, \mathrm{z})=0$. For $\gamma>0$ let $\mathrm{H}$ : $\mathfrak{R}^{+} \mathrm{X} \mathfrak{R}^{+} \mathrm{X} \mathfrak{R}^{+} \rightarrow \mathfrak{R}^{+}$denote the solution to,

$$
\mathrm{V}(\mathrm{H}(\gamma, \mathrm{y}, \mathrm{z}), \mathrm{y}, \mathrm{z})=\gamma .
$$

The function $\mathrm{H}$ exists and is unique. It is also strictly decreasing in its first argument with $\lim _{\gamma / 0} \mathrm{H}(\gamma, \mathrm{y}, \mathrm{z})=\infty$ and $\lim _{\gamma \mid \infty} \mathrm{H}(\gamma, \mathrm{y}, \mathrm{z})=0$.

Equation (C.1) now yields, $c_{t}=I\left(y \rho_{t} \xi_{t}, g\left(l_{t}\right), z_{t}\right)$. Substituting in (C.2) and defining the process,

$$
\gamma_{\mathrm{t}}=\mathrm{V}\left(1_{\mathrm{t}}, \mathrm{y} \rho_{\mathrm{t}} \xi_{\mathrm{t}}, \mathrm{z}_{\mathrm{t}}\right)
$$

produces the following simultaneous system of equations for the processes $\gamma$ and $\mathrm{z}$,

$$
\begin{aligned}
& \gamma_{\mathrm{t}}=\mathrm{yp}_{\mathrm{t}} \rho_{\mathrm{t}} \xi_{\mathrm{t}}-\alpha \mathrm{E}_{\mathrm{t}}\left[\int_{\mathrm{t}}^{\mathrm{T}} \rho_{\mathrm{s}, \mathrm{t}} \mathrm{e}^{-\alpha(\mathrm{s}-\mathrm{t})} \mathrm{f}\left(\gamma_{\mathrm{s}}, \mathrm{y} \rho_{\mathrm{s}} \xi_{\mathrm{s}}, \mathrm{z}_{\mathrm{s}}\right) \mathrm{ds}\right] ; \mathrm{t} \in[0, \mathrm{~T}] \\
& \mathrm{z}_{\mathrm{t}}=\mathrm{z}_{0} \mathrm{e}^{-\alpha \mathrm{t}}+\alpha \int_{0}^{\mathrm{t}} \mathrm{e}^{-\alpha(\mathrm{t}-\mathrm{s})} \mathrm{H}\left(\gamma_{\mathrm{s}}, \mathrm{y} \rho_{\mathrm{s}} \xi_{\mathrm{s}}, \mathrm{z}_{\mathrm{s}}\right) \mathrm{ds}, \mathrm{z}_{0} \geq 0 ; \mathrm{t} \in[0, \mathrm{~T}]
\end{aligned}
$$

where

$$
\mathrm{f}\left(\gamma_{\mathrm{s}}, \mathrm{y} \rho_{\mathrm{s}} \xi_{\mathrm{s}}, \mathrm{z}_{\mathrm{s}}\right) \equiv \mathrm{u}_{3}\left(\mathrm{I}\left(\mathrm{y} \rho_{\mathrm{s}} \xi_{\mathrm{s}}, \mathrm{g}\left(\mathrm{H}\left(\gamma_{\mathrm{s}}, \mathrm{y} \rho_{\mathrm{s}} \xi_{\mathrm{s}}, \mathrm{z}_{\mathrm{s}}\right)\right), \mathrm{z}_{\mathrm{s}}\right), \mathrm{g}\left(\mathrm{H}\left(\gamma_{\mathrm{s}}, \mathrm{y} \rho_{\mathrm{s}} \xi_{\mathrm{s}}, \mathrm{z}_{\mathrm{s}}\right)\right), \mathrm{z}_{\mathrm{s}}\right) .
$$

The system (C.7)-(C.8) is a system of forward-backward integral equations similar to the ones that are studied in Detemple and Zapatero (1992) and Antonelli (1993). A unique solution to this system exists provided that the functionals $\mathrm{f}$ and $\mathrm{H}$ satisfy appropriate Lipschitz, Growth and integrability conditions. To proceed with the construction we assume the existence of a solution $\gamma(\mathrm{y})$ which is a process taking values in $\mathfrak{R}^{+}$. Our candidate policies for consumption and durable purchases become,

$$
\mathrm{c}_{\mathrm{t}}(\mathrm{y})=\mathrm{I}\left(\mathrm{y} \rho_{\mathrm{t}} \xi_{\mathrm{t}} \mathrm{g}\left(\mathrm{H}\left(\gamma_{\mathrm{t}}(\mathrm{y}), \mathrm{y} \rho_{\mathrm{t}} \xi_{\mathrm{t}}, \mathrm{z}_{\mathrm{t}}(\mathrm{y})\right)\right), \mathrm{z}_{\mathrm{t}}(\mathrm{y})\right) \equiv \mathrm{J}\left(\gamma_{\mathrm{t}}(\mathrm{y}), \mathrm{y} \rho_{\mathrm{t}} \xi_{\mathrm{t}}, \mathrm{z}_{\mathrm{t}}(\mathrm{y})\right),(\mathrm{C} .9)
$$




$$
1_{t}(y)=H\left(\gamma_{t}(y), y \rho_{t} \xi_{t}, z_{t}(y)\right)
$$

Now define the map,

$$
\chi(y) \equiv \mathrm{E}^{*} \int_{0}^{\mathrm{T}} \mathrm{b}_{\mathrm{t}}\left[\mathrm{J}\left(\gamma_{\mathrm{t}}(\mathrm{y}), \mathrm{y} \rho_{\mathrm{t}} \xi_{\mathrm{t}}, \mathrm{z}_{\mathrm{t}}(\mathrm{y})\right)+\mathrm{p}_{\mathrm{t}} \mathrm{H}\left(\gamma_{\mathrm{t}}(\mathrm{y}), \mathrm{y} \rho_{\mathrm{t}} \xi_{\mathrm{t}}, \mathrm{z}_{\mathrm{t}}(\mathrm{y})\right)\right] \mathrm{dt}, \quad(\mathrm{C} .11)
$$

and consider the equation (in y),

$$
\chi(y)=E^{*}\left[\int_{0}^{T} b_{t}\left(e_{t}+f_{t} p_{t}\right) d t\right] .
$$

Suppose that (C.12) admits a solution $\mathrm{y}^{*}$. Substituting into equations (C.9) and (C.10) yields the optimal strategies for consumption and durable purchases.

The analog of Theorem 1 for the general model of Appendix $\mathrm{C}$ is,

Theorem 9: Consider the economy of section 6 and Appendix C. Suppose that assumptions 5, 6 and 7 hold with $\mathrm{g}(1, \mathrm{x}) \equiv \mathrm{g}(\mathrm{l})$. Also assume that the system of equations (C.7), (C.8) and (C.12) admits a solution, $\left(\mathrm{y}^{*}, \gamma^{*}, \mathrm{z}^{*}\right)$ with $\gamma^{*}>0 . .^{18}$ Then optimal policies $\left(\mathrm{c}^{*}, 1^{*}, \pi^{*}\right)$ are,

$$
\begin{gathered}
c_{t}^{*}=c_{t}\left(y^{*}\right)=J\left(\gamma_{t}^{*}, y^{*} \rho_{t} \xi_{t}, z_{t}^{*}\right) \\
1_{t}^{*}=1_{t}\left(y^{*}\right)=H\left(\gamma_{t}^{*}, y^{*} \rho_{t} \xi_{t}, z_{t}^{*}\right) \\
\pi_{t}^{*}=\left(b_{t}\right)^{-1}\left(\sigma_{t}^{\prime}\right)^{-1} \phi_{t},
\end{gathered}
$$

where $\phi=\left\{\phi_{\mathrm{t}} ; \mathrm{t} \in[0, \mathrm{~T}]\right\}$ is the d-dimensional, square integrable, adapted process that uniquely represents the martingale, $\mathrm{E}_{\mathrm{t}}^{*}\left[\int_{0}^{\mathrm{T}} \mathrm{b}_{\mathrm{t}}\left(\mathrm{c}_{\mathrm{t}}^{*}-\mathrm{e}_{\mathrm{t}}+\mathrm{p}_{\mathrm{t}}\left(\mathrm{l}_{\mathrm{t}}^{*}-\mathrm{f}_{\mathrm{t}}\right)\right) \mathrm{dt}\right]-$ $\mathrm{E}^{*}\left[\int_{0}^{\mathrm{T}} \mathrm{b}_{\mathrm{t}}\left(\mathrm{c}_{\mathrm{t}}^{*}-\mathrm{e}_{\mathrm{t}}+\mathrm{p}_{\mathrm{t}}\left(\mathrm{l}_{\mathrm{t}}^{*}-\mathrm{f}_{\mathrm{t}}\right)\right) \mathrm{dt}\right]$. Optimal wealth is $\mathrm{X}_{\mathrm{t}}^{*}=\left(\mathrm{b}_{\mathrm{t}}\right)^{-1}\left[\int_{0}^{\mathrm{t}} \mathrm{b}_{\mathrm{s}}\left(\mathrm{e}_{\mathrm{s}}^{*}+\mathrm{p}_{\mathrm{s}} \mathrm{f}_{\mathrm{s}}^{*}\right) \mathrm{ds}\right.$ $\left.\int_{0}^{t} b_{s}\left(c_{s}^{*}+p_{s} l_{s}^{*}\right) d s+\int_{0}^{t} \phi_{s} d \tilde{W}_{s}\right]$.

18 Note that we only need the existence of a solution to (C.7)-(C.8) at the point $\mathrm{y}^{*}$. Hence requiring the existence of a solution to (C.7), (C.8) and (C.12) is weaker than treating (C.7)-(C.8) in isolation. 
Remark 1: Suppose that the conditions of Theorem 9 are satisfied. Define the process,

$$
\mathrm{N}_{\mathrm{t}} \equiv \mathrm{p}_{\mathrm{t}}-\left(\mathrm{y}^{*} \rho_{\mathrm{t}} \xi_{\mathrm{t}}\right)^{-1} \alpha \mathrm{E}_{\mathrm{t}}\left[\int_{\mathrm{t}}^{\mathrm{T}} \rho_{\mathrm{s}, \mathrm{t}} \mathrm{e}^{-\alpha(\mathrm{s}-\mathrm{t})} \mathrm{f}\left(\gamma_{\mathrm{s}}^{*}, \mathrm{y}^{*} \rho_{\mathrm{s}} \xi_{\mathrm{s}}, \mathrm{z}_{\mathrm{s}}^{*}\right) \mathrm{ds}\right]
$$

for $\mathrm{t} \in[0, \mathrm{~T}]$ and note that $\mathrm{N}>0$ under the assumptions of the Theorem. As for Theorem 2, N represents the marginal cost of the status attribute embedded in durables and we can write, $\gamma_{\mathrm{t}}^{*} \equiv \gamma_{\mathrm{t}}\left(\mathrm{y}^{*}\right)=\mathrm{y}^{*} \rho_{\mathrm{t}} \xi_{\mathrm{t}} \mathrm{N}_{\mathrm{t}}$. The difference with the results contained in Theorem 2 is that in the economy with nonlinear production function for status, $\mathrm{N}$ cannot be stated in terms of exogenous processes only: as (C.16) clearly reveals it depends on the endogenous processes $\mathrm{y}^{*}, \gamma^{*}$ and $\mathrm{z}^{*}$. Due to the nonlinear form of this model of durability a simple closed form solution does not exist, at least not in the generality of the model analyzed. The absence of a closed form solution also implies that it is not as straightforward to exhibit simple conditions on the exogenous parameters and processes (as condition (24) in Theorem 2) under which the solution $\gamma^{*}$ is strictly positive.

To complete the analysis we provide a set of sufficient conditions under which the solution $\gamma(\mathrm{y})$ to (C.7)-(C.8), if it exists, is strictly positive.

Define the process $\mathrm{k}_{\mathrm{t}} \equiv \rho_{\mathrm{t}} \xi_{\mathrm{t}} \mathrm{p}_{\mathrm{t}}$ and for $\mathrm{y}>0$ consider the equation,

$$
\mathrm{dz} z_{\mathrm{t}}^{\mathrm{o}}=\alpha\left[\mathrm{H}\left(\mathrm{yk}_{\mathrm{t}}, \mathrm{y} \rho_{\mathrm{t}} \xi_{\mathrm{t}}, \mathrm{z}_{\mathrm{t}}^{\mathrm{o}}\right)-\mathrm{z}_{\mathrm{t}}^{\mathrm{o}}\right] \mathrm{dt}, \mathrm{z}_{0}>0 ; \mathrm{t} \in[0, \mathrm{~T}]
$$

If we assume that the function $\mathrm{H}$ satisfies Lipschitz and Growth conditions with respect to $\mathrm{z}$ for $\mathrm{z} \geq \mathrm{z}_{0} \mathrm{e}^{-\alpha \mathrm{T}}$, then (C.17) has a unique solution, $\mathrm{z}^{\mathrm{o}}(\mathrm{y})$. Also, for $\mathrm{y}>0$ define the process,

$$
\mathrm{L}_{\mathrm{t}}(\mathrm{y}) \equiv \mathrm{yk}_{\mathrm{t}}-\alpha \mathrm{E}_{\mathrm{t}}\left[\int_{\mathrm{t}}^{\mathrm{T}} \rho_{\mathrm{s}, \mathrm{t}} \mathrm{e}^{-\alpha(\mathrm{s}-\mathrm{t})} \mathrm{f}\left(\mathrm{yk}_{\mathrm{s}}, \mathrm{y} \rho_{\mathrm{s}} \xi_{\mathrm{s}}, \mathrm{z}_{\mathrm{s}}^{\mathrm{o}}\right) \mathrm{ds}\right], \mathrm{t} \in[0, \mathrm{~T}] .
$$

With this notation we have, 
Theorem 10: Consider the economy of section 6 and Appendix $C$, and suppose that assumptions 5, 6 and 7 hold with $\mathrm{g}(1, \mathrm{x}) \equiv \mathrm{g}(1)$. Suppose that the conditions,

$\mathrm{f}(\gamma, \mathrm{y}, \mathrm{z})$ is nondecreasing in its first argument,

there exists $\mathrm{y}_{\mathrm{o}}>0$ such that $\mathrm{L}_{\mathrm{t}}(\mathrm{y})>0$ for $\mathrm{y}>\mathrm{y}_{\mathrm{o}}$ and $\lim _{\mathrm{y} \mid \propto ⿻} \mathrm{~L}_{\mathrm{t}}(\mathrm{y})=\infty$,

hold, where $\mathrm{L}_{\mathrm{t}}(\mathrm{y})$ is defined in equation (C.18). Then,

$$
\begin{gathered}
\mathrm{yk}_{\mathrm{t}} \geq \gamma_{\mathrm{t}}(\mathrm{y}) \geq \mathrm{L}_{\mathrm{t}}(\mathrm{y})>0 \text { for all } \mathrm{y}>\mathrm{y}_{\mathrm{o}} \\
\text { and } \lim _{\mathrm{y} \mid \propto} \gamma_{\mathrm{t}}(\mathrm{y})=\infty .
\end{gathered}
$$

Assumption (C.20), in particular the condition $\mathrm{L}_{\mathrm{t}}(\mathrm{y})>0$, plays a role similar to the condition $\mathrm{N}_{\mathrm{t}}>0$ in Theorem 2 . It ensures that the demand functions are well-behaved and do not explode. In the general model this "no singularity" condition has a more complex structure since it involves the nonlinear function $f$ and the multiplier $y$. As in the linear model of section 3 it represents a restriction on the set of "admissible" exogenous processes of the economy.

Proof of Theorem 10: Let $\mathrm{y}>0$ be given. Since $\mathrm{f}>0$ by assumption 5 any solution to (C.7)-(C.8) must satisfy,

$$
\gamma_{\mathrm{t}}(\mathrm{y}) \leq \mathrm{yk}_{\mathrm{t}}
$$

Since $\mathrm{H}$ is decreasing in its first argument it follows that,

$$
\mathrm{H}\left(\gamma_{\mathrm{t}}(\mathrm{y}), \mathrm{y} \rho_{\mathrm{t}} \xi_{\mathrm{t}}, \mathrm{z}_{\mathrm{t}}\right) \geq \mathrm{H}\left(\mathrm{yk}, \mathrm{y} \rho_{\mathrm{t}} \xi_{\mathrm{t}}, \mathrm{z}_{\mathrm{t}}\right)
$$

By the comparison Theorem for solutions of stochastic differential equations (Karatzas and Shreve (1988, p. 293)), we then have,

$$
\mathrm{z}_{\mathrm{t}}(\mathrm{y}) \geq \mathrm{z}_{\mathrm{t}}^{\mathrm{o}}(\mathrm{y})
$$


where $\mathrm{z}^{\mathrm{o}}(\mathrm{y})$ solves (C.17). Using first the fact that the function $\mathrm{f}$ is decreasing in its last argument and condition (C.19) of the Theorem we obtain,

$$
-f\left(\gamma_{t}(y), y \rho_{t} \xi_{t}, z_{t}\right) \geq-f\left(\gamma_{t}(y), y \rho_{t} \xi_{t}, z_{t}^{o}(y)\right) \geq-f\left(y k_{t}, y \rho_{t} \xi_{t}, z_{t}^{o}(y)\right)
$$

Substituting this inequality in the right hand side of the recursive equation (C.7) and recalling the definition of the process $\mathrm{L}_{t}(\mathrm{y})$ in (C.18) yields the lower bound,

$$
\gamma_{\mathrm{t}}(\mathrm{y}) \geq \mathrm{L}_{\mathrm{t}}(\mathrm{y})
$$

which is positive by (C.20) for $\mathrm{y}>\mathrm{y}_{\mathrm{o}}$. Also, using (C.20) $\lim _{\mathrm{y} 1 \infty} \gamma_{\mathrm{t}}(\mathrm{y}) \geq \lim _{\mathrm{y} 1 \infty} \mathrm{L}_{\mathrm{t}}(\mathrm{y})=\infty$.

Remark 2: To obtain the existence of the multiplier $\mathrm{y}^{*}$ satisfying equation (C.12) it suffices to assume that the range of the map $\mathrm{J}\left(\gamma_{\mathrm{t}}(\mathrm{y}), \mathrm{y} \rho_{\mathrm{t}} \xi_{\mathrm{t}}, \mathrm{z}_{\mathrm{t}}(\mathrm{y})\right)+$ $\mathrm{p}_{\mathrm{t}} \mathrm{H}\left(\gamma_{\mathrm{t}}(\mathrm{y}), \mathrm{y} \rho_{\mathrm{t}} \xi_{\mathrm{t}}, \mathrm{z}_{\mathrm{t}}(\mathrm{y})\right)$ is $(0, \infty)$. This ensures the existence of $\mathrm{y}^{*}$ for all $\mathrm{x} \in(0, \infty)$. However, if we consider a given level of initial wealth $\mathrm{x}>0$ we only need the weaker condition that $\mathrm{x}$ belongs to the range of $\chi(\mathrm{y})$. Note also that the condition (C.20) of Theorem 10 is too strong: the condition $\mathrm{L}_{\mathrm{t}}(\mathrm{y})>0$ need only hold at the point $\mathrm{y}^{*}$.

To conclude we exhibit an example which satisfies several of the conditions of Theorem 10.

Example 1: Consider the economy with preferences,

$$
\mathrm{u}(\mathrm{c}, 1, \mathrm{z}) \equiv \log (\mathrm{c})+\log (\mathrm{g}(\mathrm{l}))+\mathrm{v}(\mathrm{z})
$$

where the function $\mathrm{v}$ is strictly increasing and concave with $\lim _{\mathrm{z} \mid \infty} \mathrm{v}^{\prime}(\mathrm{z})=0$ and $\lim _{\mathrm{z} \backslash 0} \mathrm{~V}^{\prime}(\mathrm{z})=\infty$. Also suppose that the status production function is, 


$$
\mathrm{g}(1) \equiv(1 / \eta) \mathbf{l}^{\eta}, \eta \in(0,1) \text {. }
$$

For this economy the recursive system (C.7)-(C.8) becomes,

$$
\begin{gathered}
\gamma_{\mathrm{t}}=\mathrm{yp}_{\mathrm{t}} \rho_{\mathrm{t}} \xi_{\mathrm{t}}-\alpha \mathrm{E}_{\mathrm{t}}\left[\int_{\mathrm{t}}^{\mathrm{T}} \rho_{\mathrm{s}, \mathrm{t}} \mathrm{e}^{-\alpha(\mathrm{s}-\mathrm{t})} \mathrm{v}^{\prime}\left(\mathrm{z}_{\mathrm{s}}\right) \mathrm{ds}\right] ; \mathrm{t} \in[0, \mathrm{~T}], \\
\mathrm{z}_{\mathrm{t}}=\mathrm{z}_{0} \mathrm{e}^{-\alpha \mathrm{t}}+\alpha \int_{0}^{\mathrm{t}} \mathrm{e}^{-\alpha(\mathrm{t}-\mathrm{s})}\left(\eta / \gamma_{\mathrm{s}}\right) \mathrm{ds}, \mathrm{t} \in[0, \mathrm{~T}],
\end{gathered}
$$

where the function $\mathrm{H}(\gamma, \mathrm{y}, \mathrm{z})=\eta / \gamma$ is independent of $\mathrm{z}$ and therefore automatically satisfies Lipschitz and Growth conditions with respect to z. Since $f(\gamma, y, z)=v^{\prime}(z)$, condition (C.19) holds. It is easy to verify that $\gamma_{\mathrm{t}}(\mathrm{y}) \geq \mathrm{L}_{\mathrm{t}}(\mathrm{y})$ with $\mathrm{L}_{\mathrm{t}}(\mathrm{y})$ given by,

$$
\mathrm{L}_{\mathrm{t}}(\mathrm{y}) \equiv \mathrm{yk}_{\mathrm{t}}-\alpha \mathrm{E}_{\mathrm{t}}\left[\int_{\mathrm{t}}^{\mathrm{T}} \rho_{\mathrm{s}, \mathrm{t}} \mathrm{e}^{-\alpha(\mathrm{s}-\mathrm{t})} \mathrm{v}^{\prime}\left(\mathrm{z}_{0} \mathrm{e}^{-\alpha \mathrm{s}}+\alpha \int_{0}^{\mathrm{s}} \mathrm{e}^{-\alpha(\mathrm{s}-\mathrm{v})}\left(\eta / \mathrm{yk}_{\mathrm{v}}\right) \mathrm{dv}\right) \mathrm{ds}\right] .
$$

The condition $\mathrm{L}_{\mathrm{t}}(\mathrm{y})>0$ for $\mathrm{y}>\mathrm{y}_{\mathrm{o}}$ in (C.20) is then a restriction on the set of processes $\left(\mathrm{k}_{\mathrm{t}}, \rho_{\mathrm{t}}\right)$, utility functions $\mathrm{v}$ and parameters $\left(\alpha, \mathrm{z}_{0}, \eta\right)$ characterizing the economy. Straightforward computations show that the limit condition in (C.20) holds. For this example we also have $\mathrm{J}\left(\gamma_{\mathrm{t}}(\mathrm{y}), \mathrm{y} \rho_{\mathrm{t}} \xi_{\mathrm{t}}, \mathrm{z}_{\mathrm{t}}(\mathrm{y})\right)+$ $\mathrm{p}_{\mathrm{t}} \mathrm{H}\left(\gamma_{\mathrm{t}}(\mathrm{y}), \mathrm{y} \rho_{\mathrm{t}} \xi_{\mathrm{t}}, \mathrm{z}_{\mathrm{t}}(\mathrm{y})\right)=\left(\mathrm{y} \rho_{\mathrm{t}} \xi_{\mathrm{t}}\right)^{-1}+\mathrm{p}_{\mathrm{t}} \eta\left(\gamma_{\mathrm{t}}(\mathrm{y})\right)^{-1}$. Since the process $\gamma_{\mathrm{t}}(\mathrm{y})$ is continuous with respect to $\mathrm{y}$ with $\lim _{\mathrm{y} \mid \infty} \gamma_{\mathrm{t}}(\mathrm{y})=\infty$ and since $\gamma_{\mathrm{t}}(\mathrm{y})$ can get arbitrarily close to zero for y sufficiently low equation (C.12) has a solution $y^{*}$. 


\section{Appendix D: linear recursive integral equations: a solution procedure.}

This appendix outlines a simple methodology to solve a class of recursive integral equations with linear or functional linear integrand and semimartingale driving term. Linear equations of this type appear in asset pricing models with habit forming utilities (Detemple and Zapatero (1991, 1992)). Nonlinear backward and backward-forward integral equations also arise in models with recursive preferences (Duffie and Epstein (1992), Duffie and Lions (1993), Duffie and Skiadas (1992), Duffie, Geoffard and Skiadas (1992)). Questions of existence and uniqueness of solutions to equations in this class have been extensively studied in the recent literature (see, for instance, Pardoux and Peng (1990) and Antonelli (1993)).

The setting is a complete probability space $(\Omega, \Im, P)$ where $\Omega$ is the set of states of nature, $\Im$ is a $\sigma$-algebra and $\mathrm{P}$ is a probability measure defined on $(\Omega, \Im)$. The time interval is finite $[0, T]$. The filtration $\mathfrak{\Im}_{(\cdot)}$ satisfies the "usual conditions" (right continuity and P-completeness) and $\Im_{\mathrm{T}}=\Im$ .

Consider the linear recursive integral equation,

$$
\psi_{\mathrm{t}}=\mathrm{X}_{\mathrm{t}}+\mathrm{E}_{\mathrm{t}}\left[\int_{\mathrm{t}}^{\mathrm{T}} \mathrm{b}_{\mathrm{t}, \mathrm{s}} \delta_{\mathrm{s}} \psi_{\mathrm{s}} \mathrm{ds}\right], \psi_{\mathrm{T}}=\mathrm{X}_{\mathrm{T}},
$$

where $X \equiv\left\{X_{t} ; t \in[0, T]\right\}$ is a semimartingale adapted to the filtration and $\delta \equiv\left\{\delta_{t} ; t \in[0, T]\right\}$ is a predictable and bounded process. We recall that the double index process $\mathrm{b}$ is $\mathrm{b}_{\mathrm{ts}} \equiv \mathrm{b}_{\mathrm{s}} / \mathrm{b}_{\mathrm{t}}$ where $\mathrm{b}_{\mathrm{t}} \equiv \exp \left[-\int_{0}^{\mathrm{t}} \mathrm{r}_{\mathrm{v}} \mathrm{dv}\right]$ and $r \equiv\{r ; t \in[0, T]\}$ is predictable and bounded. The integrand in (D.1) is linear in the contemporaneous value of the unknown process $\psi$. We seek to find an adapted solution of (D.1).

The solution procedure involves three steps. First, an assumption on the representability of a selected random variable B enables us to convert the backward integral equation into a linear forward equation. In a second step we solve the forward version as a function of the process in the representation of 
B. In the last step we use the boundary condition at time $\mathrm{T}$ and apply conditional expectations to obtain an expression for $\psi_{\mathrm{t}}$ which involves the projection of functionals of the exogenous processes $\mathrm{r}, \mathrm{X}$ and $\delta$ on the contemporaneous information set $\mathfrak{\Im}_{\mathrm{t}}$. This solution procedure is constructive and removes the need to formulate "guesses".

Defining the random variable $\mathrm{B} \equiv \int_{0}^{\mathrm{T}} \mathrm{b}_{\mathrm{s}} \boldsymbol{\delta}_{\mathrm{s}} \boldsymbol{\psi}_{\mathrm{s}} \mathrm{ds}$ we can write (D.1) as,

$$
\psi_{\mathrm{t}}=\mathrm{X}_{\mathrm{t}}+\left(\mathrm{b}_{\mathrm{t}}\right)^{-1}\left\{\mathrm{E}_{\mathrm{t}}[\mathrm{B}]-\int_{0}^{\mathrm{t}} \mathrm{b}_{\mathrm{s}} \delta_{\mathrm{s}} \psi_{\mathrm{s}} \mathrm{ds}\right\}
$$

subject to the boundary condition $\Psi_{\mathrm{T}}=\mathrm{X}_{\mathrm{T}}$. Suppose that $\mathrm{B}$ admits the representation,

$$
\mathrm{E}_{\mathrm{t}}[\mathrm{B}]=\mathrm{EB}+\int_{0}^{\mathrm{t}} \phi_{\mathrm{s}} \mathrm{dM}, \mathrm{t} \in[0, \mathrm{~T}],
$$

for some $\mathrm{k}$-dimensional martingale $\mathrm{M} \equiv\left\{\mathrm{M}_{\mathrm{t}} ; \mathrm{t} \in[0, \mathrm{~T}]\right\}$ adapted to the filtration and some predictable, square-integrable process $\phi: \mathrm{E}\left[\int_{0}^{\mathrm{T}} \phi_{\mathrm{s}}^{2} \mathrm{~d}[\mathrm{M}]_{\mathrm{s}}\right]<\infty$. Then, an application of Ito's lemma produces,

$$
\mathrm{d} \psi_{\mathrm{t}}=\mathrm{d} X_{\mathrm{t}}+\mathrm{r}_{\mathrm{t}}\left(\mathrm{b}_{\mathrm{t}}\right)^{-1}\left\{\mathrm{E}_{\mathrm{t}}[\mathrm{B}]-\int_{0}^{\mathrm{t}} \mathrm{b}_{\mathrm{s}} \delta_{\mathrm{s}} \Psi_{\mathrm{s}} \mathrm{ds}\right\} \mathrm{dt}+\left(\mathrm{b}_{\mathrm{t}}\right)^{-1} \phi_{\mathrm{t}} \mathrm{dM} \mathrm{M}_{\mathrm{t}}-\delta_{\mathrm{t}} \psi_{\mathrm{t}} \mathrm{dt} .(\mathrm{D} .4)
$$

Using the fact that $\left(\mathrm{b}_{\mathrm{t}}\right)^{-1}\left\{\mathrm{E}_{\mathrm{t}}[\mathrm{B}]-\int_{0}^{\mathrm{t}} \mathrm{b}_{\mathrm{s}} \boldsymbol{\delta}_{\mathrm{s}} \boldsymbol{\psi}_{\mathrm{s}} \mathrm{ds}\right\}=\boldsymbol{\psi}_{\mathrm{t}}-\mathrm{X}_{\mathrm{t}}($ from (C.2)) and collecting terms yields,

$$
d \psi_{t}=d X_{t}+\left[\left(r_{t}-\delta_{t}\right) \Psi_{t}-r_{t} X_{t}\right] d t+\left(b_{t}\right)^{-1} \phi_{t} d M_{t}, \Psi_{T}=X_{T},
$$

or, in integral form, ${ }^{19}$

${ }^{19}$ A related class of backward stochastic differential equations (SDE) characterizes the adjoint processes $(\mathrm{p}, \phi)$ arising in applications of the stochastic maximum principle in settings with Brownian uncertainty structure (Brock and Magill (1979), Cadenillas (1992), Cadenillas and Karatzas (1993)). A typical equation takes the form $\mathrm{dp}_{\mathrm{t}}=$ $\left[\mathrm{A}_{\mathrm{t}}+\mathrm{B}_{\mathrm{t}} \mathrm{p}_{\mathrm{t}}+\mathrm{C}_{\mathrm{t}} \phi_{\mathrm{t}}\right] \mathrm{dt}+\phi_{\mathrm{t}} \mathrm{dW}_{\mathrm{t}}, \mathrm{p}_{\mathrm{T}}=\mathrm{D}_{\mathrm{T}}$, for appropriate processes $\mathrm{A}, \mathrm{B}, \mathrm{C}, \mathrm{D}$ and where $\mathrm{W}$ is a Brownian Motion; the objective is to find an adapted pair $(p, \phi)$ which solves this equation. Since $\phi$ impacts the drift of the backward SDE the procedure outlined in (D.2)-(D.10) does not work. Cadenillas (1992) finds a parammetric family of solutions to the SDE and uses the free parameters to fit the boundary condition and 


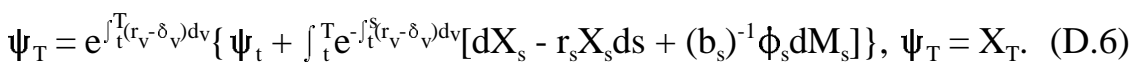

Substituting the boundary condition $\Psi_{\mathrm{T}}=\mathrm{X}_{\mathrm{T}}$ on the left hand side of (C.6) and rearranging yields,

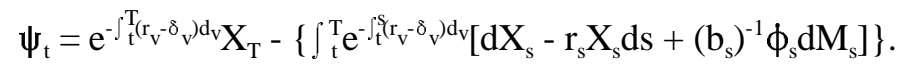

But by Ito's lemma,

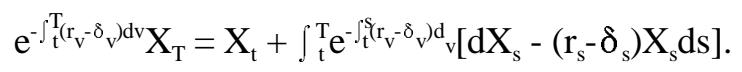

Substitution in (D.7) produces,

$$
\psi_{\mathrm{t}}=\mathrm{X}_{\mathrm{t}}+\left\{\int_{\mathrm{t}}^{\mathrm{T}}\left[\mathrm{e}^{-\int_{\mathrm{t}}^{\mathrm{S}}\left(\mathrm{r}_{\mathrm{v}}-\delta_{\mathrm{v}}\right) \mathrm{dv}} \delta_{\mathrm{s}} \mathrm{X}_{\mathrm{s}} \mathrm{ds}-\left(\mathrm{b}_{\mathrm{s}}\right)^{-1} \phi_{\mathrm{s}} \mathrm{dM} \mathrm{M}_{\mathrm{s}}\right]\right\}
$$

Since we assumed that $\phi \in \mathscr{L}^{2}[\mathrm{M}]$ is predictable and since $\mathrm{r}$ is bounded and predictable we have

$E\left[\int_{t}^{T}\left(b_{s}\right)^{-1} \phi_{s} d M_{s}\right]=0$. Taking conditional expectations on each side of (D.9) then yields,

$$
\psi_{\mathrm{t}}=\mathrm{X}_{\mathrm{t}}+\mathrm{E}_{\mathrm{t}}\left[\int_{\mathrm{t}}^{\mathrm{T}} \mathrm{e}^{-\int \mathrm{t}_{\mathrm{t}}^{\mathrm{S}}\left(\mathrm{r}_{\mathrm{v}}-\delta_{\mathrm{v}}\right) \mathrm{dv}} \boldsymbol{\delta}_{\mathrm{s}} \mathrm{X}_{\mathrm{s}} \mathrm{ds}\right]
$$

To complete the proof it suffices to ensure that the random variable $\mathrm{B} \equiv \int_{0}^{\mathrm{T}} \mathrm{b}_{\mathrm{s}} \delta_{\mathrm{s}} \psi_{\mathrm{s}} \mathrm{ds}$ has the properties assumed at the outset. Substituting (D.10) into the definition of $\mathrm{B}$ leads to a condition involving only the exogenous processes $\mathrm{X}, \mathrm{r}$ and $\delta$. Hence, we have established the following result,

Theorem 11: Consider the recursive integral equation with linear integrand (D.1) and suppose that,

$$
B \equiv \int_{0}^{T} b_{s} \delta_{s}\left[X_{s}+E_{s}\left[\int_{s}^{T} e^{-\int_{s}^{u}\left(r_{v}-\delta_{v}\right) d v} \delta_{u} X_{u} d u\right]\right] d s,
$$

meet the adaptedness condition. 
admits the representation,

$$
\mathrm{E}_{\mathrm{t}}[\mathrm{B}]=\mathrm{EB}+\int_{0}^{\mathrm{t}} \phi_{\mathrm{s}} \mathrm{dM}, \mathrm{t} \in[0, \mathrm{~T}],
$$

for $\mathrm{M} \equiv\left\{\mathrm{M}_{\mathrm{t}} ; \mathrm{t} \in[0, \mathrm{~T}]\right\}$ a $k$-dimensional martingale adapted to the filtration and some predictable, square-integrable process $\phi$. Then, the solution to the recursive integral equation (D.1) is given by

$$
\psi_{\mathrm{t}}=\mathrm{X}_{\mathrm{t}}+\mathrm{E}_{\mathrm{t}}\left[\int_{\mathrm{t}}^{\mathrm{T}} \mathrm{e}^{\left.-\int_{\mathrm{t}}^{\mathrm{S}} \mathrm{r}_{\mathrm{v}}-\delta_{\mathrm{v}}\right) \mathrm{dv}} \delta_{\mathrm{s}} \mathrm{X}_{\mathrm{s}} \mathrm{ds}\right] .
$$

If the representation (D.12) is unique the solution (D.13) is unique as well.

Remark 3: Note that the process $\phi$ which is used in the derivation of the solution can be expressed in terms of the exogeneous processes $\mathrm{X}, \mathrm{r}$ and $\delta$ only. Indeed, $\phi$ is the predictable process in the representation of the random variable $B$ defined in (D.11).

Remark 4: Conditional expectations can be applied directly to both sides of (D.7) to obtain the equivalent representation

$$
\psi_{\mathrm{t}}=\mathrm{E}_{\mathrm{t}}\left[\mathrm{e}^{-\int_{\mathrm{t}}^{\mathrm{T}}\left(\mathrm{r}_{\mathrm{v}}-\delta_{\mathrm{v}}\right) \mathrm{dv}} \mathrm{X}_{\mathrm{T}}-\int_{\mathrm{t}}^{\mathrm{T}} \mathrm{e}^{\left.-\mathrm{ft}_{\mathrm{t}}^{\mathrm{S}} \mathrm{r}_{\mathrm{v}}-\delta_{\mathrm{v}}\right) \mathrm{d}} \mathrm{d}\left[\mathrm{d} \mathrm{X}_{\mathrm{s}}-\mathrm{r}_{\mathrm{s}} \mathrm{X}_{\mathrm{s}} \mathrm{ds}\right]\right] .
$$

Example 2 (Brownian Filtration): Suppose that a d-dimensional Brownian Motion process $\mathrm{W}$ is defined on $(\Omega, \Im, P)$ and that the flow of information is given by the natural filtration $\mathfrak{\Im}_{(\cdot)}$, i.e. the P-augmentation of the Brownian

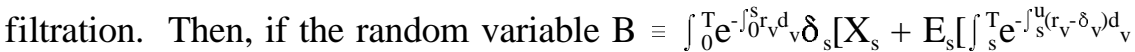
$\left.\left.\delta_{\mathrm{u}} \mathrm{X}_{\mathrm{u}} \mathrm{du}\right]\right] \mathrm{ds} \in \mathscr{L}^{2}(\Omega, \Im, P)$ the martingale representation Theorem (Karatzas and Shreve (1988)) ensures that there exists a unique progressively measurable and square integrable process $\phi$ such that $\mathrm{E}_{\mathrm{t}}[\mathrm{B}]=\mathrm{EB}+\int_{0}^{\mathrm{t}} \phi_{\mathrm{s}} \mathrm{dW}, \mathrm{t} \in[0, \mathrm{~T}]$. In this setting condition (D.12) is satisfied and the solution to the recursive equation is unique and given by (D.13). 
Example 3: Consider a complete filtered probability space $\left(\Omega, \mathfrak{\Im}_{,}, \mathfrak{\Im}_{(\cdot)}, \mathrm{P}\right)$ where the filtration $\mathfrak{\Im}_{(\cdot)}$ satisfies the usual conditions. Let $\mathbf{M}^{2}$ denote the space of square-integrable martingales endowed with the usual $\mathscr{L}^{2}$-norm and inner product. Consider the set $\mathbf{A}=\left\{\mathrm{M}_{1}, \ldots, \mathrm{M}_{\mathrm{k}}\right\}$ of square integrable martingales with $k$ elements and suppose that $\mathrm{M}_{\mathrm{i}}, \mathrm{M}_{\mathrm{j}}$ are strongly orthogonal for $\mathrm{i} \neq \mathbf{j}{ }^{20}$ Suppose also that for any $\mathbf{N} \in \mathbf{M}^{2}$ which is strongly orthogonal to all elements of $\mathbf{A}$ we have $\mathbf{N}=0$. Under these conditions any square integrable martingale has the predictable representation property (Protter (1990), Corollary 3, p.151). Hence if B defined in (D.11) belongs to $\mathscr{L}^{2}(\Omega, \mathfrak{\Im}, \mathrm{P})$ the representation property (D.12) holds.

We consider now two variations of the basic linear model (D.1). Both of these variations can be solved by finding an appropriate transformation mapping the equation into a version of (D.1).

Consider the following equations,

$$
\gamma_{t}=Y_{t}+\delta_{t} E_{t}\left[\int_{t}^{T} b_{t, s} \gamma_{s} d s\right], \gamma_{T}=Y_{T}
$$

and

$$
\psi_{\mathrm{t}}=\mathrm{X}_{\mathrm{t}}+\mathrm{E}_{\mathrm{t}}\left[\int_{\mathrm{t}}^{\mathrm{T}} \mathrm{b}_{\mathrm{t}, \mathrm{s}}\left(\boldsymbol{\delta}_{\mathrm{s}} \boldsymbol{\psi}_{\mathrm{s}}+\int_{\mathrm{t}}^{\mathrm{s}} \boldsymbol{\beta}_{\mathrm{v}} \boldsymbol{\psi}_{\mathrm{v}} \mathrm{dv}\right) \mathrm{ds}\right], \boldsymbol{\psi}_{\mathrm{T}}=\mathrm{X}_{\mathrm{T}}
$$

where $\mathrm{Y} \equiv\left\{\mathrm{Y}_{\mathrm{t}} ; \mathrm{t} \in[0, \mathrm{~T}]\right\}$ is an adapted semimartingale, $\delta \equiv\left\{\delta_{\mathrm{t}} ; \mathrm{t} \in[0, \mathrm{~T}]\right\}$ and $\mathrm{r} \equiv\left\{\mathrm{r}_{\mathrm{t}} ; \mathrm{t} \in[0, \mathrm{~T}]\right\}$ are predictable, bounded processes of the filtration and $\beta \equiv\left\{\beta_{\mathrm{t}} ; \mathrm{t} \in[0, \mathrm{~T}]\right\}$ is a predictable process. Also suppose that $\delta$ is a strictly positive process: $\delta>0$.

\footnotetext{
${ }^{20} \mathrm{M}$ and $\mathrm{N}$ are strongly orthogonal if the product $\mathrm{MN}$ is a (uniformly integrable) martingale.
} 
Corollary 4: Suppose that the random variable,

$$
\mathrm{B} \equiv \int_{0}^{\mathrm{T}} \mathrm{b}_{\mathrm{s}} \boldsymbol{\delta}_{\mathrm{s}}\left[\left(\mathrm{Y}_{\mathrm{s}} / \boldsymbol{\delta}_{\mathrm{s}}\right)+\mathrm{E}_{\mathrm{s}}\left[\int_{\mathrm{s}}^{\mathrm{T}} \mathrm{e}^{-\int_{\mathrm{s}}^{\mathrm{u}}\left(\mathrm{r}_{\mathrm{v}}-\delta_{\mathrm{v}}\right) \mathrm{dv}} \mathrm{Y}_{\mathrm{u}} \mathrm{du}\right]\right] \mathrm{ds},
$$

admits the representation, $\mathrm{E}_{\mathrm{t}}[\mathrm{B}]=\mathrm{EB}+\int_{0}^{\mathrm{t}} \phi_{\mathrm{s}} \mathrm{d} \mathrm{M}_{\mathrm{s}}, \mathrm{t} \in[0, \mathrm{~T}]$, for some $k$ dimensional martingale adapted to the filtration $\mathrm{M} \equiv\left\{\mathrm{M}_{\mathrm{t}} ; \mathrm{t} \in[0, \mathrm{~T}]\right\}$ and some predictable, square-integrable process $\phi$. Then, the solution to equation (D.14) is given by,

$$
\gamma_{t}=Y_{t}+\delta_{t} E_{t}\left[\int_{t}^{T} e^{\left.-\int t_{t}^{S} r_{v}-\delta_{v}\right) d v} Y_{s} d s\right]
$$

Proof of Corollary 4: Upon dividing both sides of (D.14) by $\delta_{t}$ and defining the new processes,

$$
\psi_{\mathrm{t}} \equiv \gamma_{\mathrm{t}} / \delta_{\mathrm{t}}, \mathrm{X}_{\mathrm{t}} \equiv \mathrm{Y}_{\mathrm{t}} / \delta_{\mathrm{t}}
$$

leads to the equation, $\psi_{\mathrm{t}}=\mathrm{X}_{\mathrm{t}}+\mathrm{E}_{\mathrm{t}}\left[\int_{\mathrm{t}}^{\mathrm{T}} \mathrm{b}_{\mathrm{t}, \mathrm{s}} \delta_{\mathrm{s}} \psi_{\mathrm{s}} \mathrm{ds}\right], \psi_{\mathrm{T}}=\mathrm{X}_{\mathrm{T}}$, which has the same form as (D.1). Applying Theorem 10 and performing the inverse transformation yields (D.17).

Corollary 5: Define the process $\rho \equiv\left\{\rho_{\mathrm{t}} ; \mathrm{t} \in[0, \mathrm{~T}]\right\}$ by $\rho_{\mathrm{t}} \equiv \mathrm{E}_{\mathrm{t}}\left[\int_{\mathrm{t}}^{\mathrm{T}} \mathrm{b}_{\mathrm{t}, \mathrm{d}} \mathrm{ds}\right]$ and suppose that,

$$
\begin{aligned}
& \mathrm{B}=\int_{0}^{\mathrm{T}} \mathrm{b}_{\mathrm{s}}\left(\boldsymbol{\delta}_{\mathrm{s}}+\boldsymbol{\beta}_{\mathrm{s}} \rho_{\mathrm{s}}\right) \\
& \left.\left[X_{s}+E_{s}\left[\int_{s}^{T} e^{-\int s_{s}^{u}\left(r_{v}-\delta\right.} \delta_{v}^{-\beta} \rho_{v} \rho_{v}\right) d v\left(\delta_{u}+\beta_{u} \rho_{u}\right) X_{u} d u\right]\right] d s,
\end{aligned}
$$

has the representation, $\mathrm{E}_{\mathrm{t}}[\mathrm{B}]=\mathrm{EB}+\int_{0}^{\mathrm{t}} \phi_{\mathrm{s}} \mathrm{dM}_{\mathrm{s}}, \mathrm{t} \in[0, \mathrm{~T}]$, for some $k$ dimensional martingale $\mathrm{M} \equiv\left\{\mathrm{M}_{\mathrm{t}} ; \mathrm{t} \in[0, \mathrm{~T}]\right\}$ adapted to the filtration and some predictable, square-integrable process $\phi$. Then, the solution to equation (D.15) is given by,

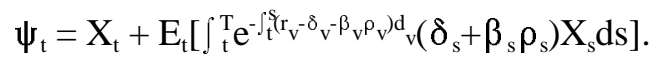


Proof of Corollary 5: Using the integration by parts formula yields,

$$
\begin{gathered}
\mathrm{E}_{\mathrm{t}}\left[\int_{\mathrm{t}}^{\mathrm{T}} \mathrm{b}_{\mathrm{t}, \mathrm{s}}\left(\int_{\mathrm{t}}^{\mathrm{s}} \boldsymbol{\beta}_{\mathrm{v}} \boldsymbol{\psi}_{\mathrm{v}} \mathrm{dv}\right) \mathrm{ds}\right]=\mathrm{E}_{\mathrm{t}}\left[\int_{\mathrm{t}}^{\mathrm{T}} \mathrm{b}_{\mathrm{t}, \mathrm{s}} \boldsymbol{\beta}_{\mathrm{s}} \boldsymbol{\psi}_{\mathrm{s}}\left(\int_{\mathrm{s}}^{\mathrm{T}} \mathrm{b}_{\mathrm{s}, \mathrm{v}} \mathrm{dv}\right) \mathrm{ds}\right] \\
=\mathrm{E}_{\mathrm{t}}\left[\int_{\mathrm{t}}^{\mathrm{T}} \mathrm{b}_{\mathrm{t}, \mathrm{s}} \boldsymbol{\beta}_{\mathrm{s}} \boldsymbol{\psi}_{\mathrm{s}} \mathrm{E}_{\mathrm{s}}\left[\int_{\mathrm{s}}^{\mathrm{T}} \mathrm{b}_{\mathrm{s}, \mathrm{v}} \mathrm{dv}\right] \mathrm{ds}\right],
\end{gathered}
$$

where the second equality follows from the law of iterated expectations and the $\mathfrak{I}_{\mathrm{s}}$-measurability of $\mathrm{b}_{\mathrm{t}, \mathrm{s}} \beta_{\mathrm{s}} \boldsymbol{\psi}_{\mathrm{s}}$. The resulting recursive equation is again of the form (D.1) with $\delta_{\mathrm{s}}$ replaced by $\delta_{\mathrm{s}}+\beta_{\mathrm{s}} \rho_{\mathrm{s}}$. The Corollary follows. 


\section{REFERENCES}

Abel, A. B., 1990, Asset Prices Under Habit Formation and Catching Up with the Joneses, American Economic Review 80, 38-42.

Antonelli, F., 1993, Backward-Forward Stochastic Differential Equations, Annals of Applied Probability 3, 777-193.

Baudrillard, J., 1981, For A Critique of the Political Economy of the Sign (Telos Press, St Louis).

Breeden, D. T., 1979, An Intertemporal Asset Pricing Model with Stochastic Consumption and Investment Opportunities, Journal of Financial Economics 7, 265-296.

Brock, W. and M. J. P. Magill, 1979, Dynamics under Uncertainty, Econometrica 47, 843-868.

Caballero, R., 1990a, Expenditure on Durable Goods: A Case for Slow Adjustment, Quarterly Journal of Economics 105, 727-744.

Caballero, R., 1990b, Durable Goods: An Explanation for Slow Adjustment, Working Paper, Columbia University.

Cadenillas, A., 1992, Contributions to the Stochastic Version of Pontryagin's Maximum Principle, Ph. D. Thesis, Columbia University.

Cadenillas, A. and I. Karatzas, 1993, The Stochastic Maximum Principle for Linear Convex Optimal Control with Random Coefficients, mimeo, Columbia University.

Clark, J. M. C., 1970, The Representation of Functionals of Brownian Motion as Stochastic Integrals, Annals of Mathematical Statistics 41, 1282-1295.

Constantinides, G. M., 1990, Habit Formation: A Resolution of the Equity Premium Puzzle, Journal of Political Economy 98, 519-543.

Cox, J. C. and C. Huang, 1989, Optimal Consumption and Portfolio Policies when Asset Prices Follow a Diffusion Process, Journal of Economic Theory 49, 33-83. 
Cox, J. C. and C. Huang, 1991, A Variational Problem Arising in Financial Economics, Journal of Mathematical Economics 20, 465-487.

Cox, J. C.,Ingersoll, J.E. and S. A. Ross, 1985, An Intertemporal General Equilibrium Model of Asset Prices, Econometrica 53, 363-384.

Detemple, J. B. and F. Zapatero, 1991, Asset Prices in an Exchange Economy with Habit Formation, Econometrica 59, 1633-1657.

Detemple, J. B. and F. Zapatero, 1992, Optimal Consumption-Portfolio Policies with Habit Formation, Mathematical Finance 4, 35-58.

Duffie,D. and L. G. Epstein, 1992, Stochastic Differential Utility, Econometrica 60, 353-394.

Duffie, D. and P. L. Lions, 1992, PDE Solutions of Stochastic Differential Utility, Journal of Mathematical Economics 21, 577-606.

Duffie, D., P.-Y. Geoffard and C. Skiadas, 1992, Efficient and Equilibrium Allocations with Stochastic Differential Utility, mimeo, Stanford University.

Duffie,D. and C. Skiadas, 1992, Continuous Time Security Pricing: A Utility Gradient Approach, Working Paper, Northwestern University.

Duffie, D. and W. Zame, 1989, The Consumption-Based Capital Asset Pricing Model, Econometrica 57, 1279-1297.

Dunn, K. B. and K. J. Singleton, 1986, Modelling the Term Structure of Interest Rates Under Non-Separable Utility and Durability of Goods, Journal of Financial Economics 17, 27-55.

Eichenbaum, M. and Hansen, L. P., 1990, Estimating Models With Intertemporal Substitution Using Aggregate Time Series Data, Journal of Business and Economic Statistics 8, 53-69.

Eichenbaum, M., L. P. Hansen and S. F. Richard, 1987, Aggregation, Durable Goods and Nonseparable Preferences in an Equilibrium Asset Pricing Model, Working Paper, Carnegie Mellon University. 
Epstein, L. G. and S. Zin, 1989, Substitution, Risk Aversion and Temporal Behavior of Consumption and Asset Returns: a Theoretical Framework, Econometrica 57, 937-969.

Farmer, R., 1990, Rince Preferences, Quarterly Journal of Economics 105, 4360.

Ferson, W. E. and G. M. Constantinides, 1991, Habit Persistence and Durability in Aggregate Consumption: Empirical Tests, Journal of Financial Economics 29, 199-240.

Grossman, S. J. and G. Laroque, 1990, Asset Pricing and Optimal Portfolio Choice in the Presence of Illiquid Durable Consumption Goods, Econometrica $58,25-51$.

Grossman, S. J. and R. J. Shiller, 1981, The Determinants of the Variability of Stock Market prices, American Economic Review 71, 222-227.

Heaton, J., 1993, An Empirical Investigation of Asset Pricing With Temporally Dependent Preference Specifications, Econometrica 61, 353-385.

Hindy, A. and C. Huang, 1992, On Intertemporal Preferences with a Continuous Time Dimension II: The Case of Uncertainty, Econometrica 60, 781-801.

Hindy, A. and C. Huang, 1993, Optimal Consumption and Portfolio Rules with Durability and Local Substitution, Econometrica 61, 85-121.

Karatzas, I., Lehoczky, J. P. and S. E. Shreve, 1987, Optimal Consumption and Portfolio Decisions for a 'Small Investor' on a Finite Horizon, SIAM Journal of Control and Optimization 25, 1557-1586.

Karatzas, I., and S. E. Shreve, 1988, Brownian Motion and Stochastic Calculus (Springer Verlag, New York).

Kihlstrom R. E. and L. J. Mirman, 1974, Risk Aversion with Many Commodities, Journal of Economic Theory 8, 361-388.

Lancaster, K., 1991, Modern Consumer Theory (Edward Edgar Publishing Limited, England). 
Lucas, R. E., 1978, Asset Prices in an Exchange Economy, Econometrica 46, 1429-1445.

Mankiw, N. G., 1985, Consumer Durables and the Real Interest Rate, The Review of Economics and Statistics 67, 353-362.

Mehra, R. and E. C. Prescott, 1985, The Equity Premium: A Puzzle, Journal of Monetary Economics 15, 145-161.

Merton, R. C., 1973, An Intertemporal Capital Asset Pricing Model, Econometrica 41, 867-887.

Ocone, D. and I. Karatzas, 1991, A Generalized Clark Representation Formula, with Applications to Optimal Portfolios, Stochastics and Stochastics Reports 34, 187-220.

Pardoux, E. and S. G. Peng, 1990, Adapted Solutions of a Backward Stochastic Differential Equation, Systems and Control Letters 14, 55-61.

Protter, P., 1990, Stochastic Integration and Differential Equations (SpringerVerlag, New York).

Ryder, H. E. and Heal, G. M., 1973, Optimal Growth with Intertemporally Dependent Preferences, Review of Economic Studies 40, 1-31.

Sundaresan, S. M., 1989, Intertemporally Dependent Preferences and the Volatility of Consumption and Wealth, The Review of Financial Studies 2, 7389.

Weil, P., 1990, Nonexpected Utility in Macroeconomics, Quarterly Journal of Economics 105, 29-42.

Weil, P., 1989, The Equity Premium Puzzle and the Risk-Free Rate Puzzle, Journal of Monetary Economics 24, 401-421. 


\section{Liste des publications au CIRANO}

\section{Cahiers CIRANO / CIRANO Papers (ISSN 1198-8169)}

94c-1 Faire ou faire faire : La perspective de l'économie des organisations / par Michel Patry

94c-2 Commercial Bankruptcy and Financial Reorganization in Canada / par Jocelyn Martel

94c-3 L'importance relative des gouvernements : causes, conséquences, et organisations alternatives / par Claude Montmarquette

95c-1 La réglementation incitative / par Marcel Boyer

95c-2 Anomalies de marché et sélection des titres au Canada / par Richard Guay, Jean-François L'Her et Jean-Marc Suret

\section{Série Scientifique / Scientific Series (ISSN 1198-8177)}

95s-32 Market Time and Asset Price Movements Theory and Estimation / par Eric Ghysels, Christian Gouriéroux et Joanna Jasiak

95s-33 Real Investment Decisions Under Information Constraints / par Gérard Gaudet, Pierre Lasserre et Ngo Van Long

95s-34 Signaling in Financial Reorganization: Theory and Evidence from Canada / parJocelyn Martel

95s-35 Capacity Commitment Versus Flexibility: The Technological Choice Nexus in a Strategic Context / Marcel Boyer et Michel Moreaux

95s-36 Some Results on the Markov Equilibria of a class of Homogeneous Differential Games / Ngo Van Long et Koji Shimomura

95s-37 Dynamic Incentive Contracts with Uncorrelated Private Information and History Dependent Outcomes / Gérard Gaudet, Pierre Lasserre et Ngo Van Long

95s-38 Costs and Benefits of Preventing Worplace Accidents: The Case of Participatory Ergonomics / Paul Lanoie et Sophie Tavenas

95s-39 On the Dynamic Specification of International Asset Pricing Models / Maral kichian, René Garcia et Eric Ghysels

95s-40 Vertical Integration, Foreclosure and Profits in the Presence of Double Marginalisation / Gérard Gaudet et Ngo Van Long

95s-41 Testing the Option Value Theory of Irreversible Investment / Tarek M. Harchaoui et Pierre Lasserre

95s-42 Trading Patterns, Time Deformation and Stochastic Volatility in Foreign Exchange Markets / Eric Ghysels, Christian Gouriéroux et Joanna Jasiak

95s-43 Empirical Martingale Simulation for Asset Prices / Jin-Chuan Duan et Jean-Guy Simonato

95s-44 Estimating and Testing Exponential-Affine Term Structure Models by Kalman Filter / JinChuan Duan et Jean-Guy Simonato

95s-45 Costs and Benefits of Preventing Workplace Accidents : Going from a Mechanical to a Manual Handling System / Paul Lanoie et Louis Trottier

95s-46 Cohort Effects and Returns to Seniority in France / David N. Margolis

95s-47 Asset and Commodity Prices with Multiattribute Durable Goods / Jérôme Detemple et Christos I. Giannikos 